\title{
Chemical Constituents of the Rhizomes of Bletilla formosana and Their Potential Anti-inflammatory Activity
}

\author{
Che-Wei Lin, ${ }^{\dagger}$ Tsong-Long Hwang, ${ }^{\ddagger,,,}{ }^{\perp}$ Fu-An Chen, $\|$ \\ Chia-Hsin Huang, ${ }^{\nabla}$ Hsin-Yi Hung, ${ }^{*} \mathrm{O}$ Tian-Shung $\mathrm{Wu}^{*}, \|, \mathrm{O}$ \\ ${ }^{\dagger}$ Department of Chemistry and National Cheng Kung University, Tainan 70101, \\ Taiwan \\ ${ }^{\ddagger}$ Graduate Institute of Natural Products, Chang Gung University, Taoyuan 33302, \\ Taiwan \\ ${ }^{\S}$ Research Center for Industry of Human Ecology and Graduate Institute of Health \\ Industry Technology, Chang Gung University of Science and Technology, Taoyuan \\ 333, Taiwan \\ ${ }^{\perp}$ Department of Anesthesiology, Chang Gung Memorial Hospital, Taoyuan 333, \\ Taiwan \\ "Department of Pharmacy and Graduate Institute of Pharmaceutical Technology, \\ Tajen University, Pingtung 90741, Taiwan \\ ${ }^{\nabla}$ Department of Biological Science and Technology, Chung Hwa University of \\ Medical Technology, Tainan 71703, Taiwan \\ ${ }^{\circ}$ School of Pharmacy, National Cheng Kung University, Tainan 70101, Taiwan \\ * Corresponding author. Tel.: 886-6-2757575 ext 65333. Fax: 886-6-2740552. \\ E-mail address: tswu@mail.ncku.edu.tw (T. S. Wu) and Tel: 886-6-2353535 \\ ext.6803 Fax: 886-6-2373149. E-mail address: z10308005@email.ncku.edu.tw \\ (H.-Y. H.)
}




\section{List of Content}

S1. ${ }^{1} \mathrm{H}$ NMR (400 MHz, Acetone- $d_{6}$ ) spectrum of the new compound 1.

S2. ${ }^{13} \mathrm{C}$ NMR (100 MHz, Acetone- $\left.d_{6}\right)$ spectrum of the new compound 1

S3. COSY spectrum of the new compound $\mathbf{1}$

S4. NOESY spectrum of the new compound 1

S5. HSQC spectrum of the new compound 1

S6. HMBC spectrum of the new compound 1

S7. UV spectrum of the new compound 1

S8. IR spectrum of the new compound 1

S9. HRESIMS spectrum of the new compound $\mathbf{1}$

S10. ${ }^{1} \mathrm{H}$ NMR (400 MHz, Acetone- $d_{6}$ ) spectrum of the new compound 2

S11. ${ }^{13} \mathrm{C}$ NMR (100 MHz, Acetone- $d_{6}$ ) spectrum of the new compound 2.

S12. COSY spectrum of the new compound 2

S13. NOESY spectrum of the new compound 2

S14. HSQC spectrum of the new compound 2

$\mathrm{S} 15 . \mathrm{HMBC}$ spectrum of the new compound 2

S16. UV spectrum of the new compound 2

S17. IR spectrum of the new compound 2

S18. HRESIMS spectrum of the new compound 2

S19. ${ }^{1} \mathrm{H}$ NMR $\left(700 \mathrm{MHz}\right.$, Acetone- $\left.d_{6}\right)$ spectrum of the new compound $\mathbf{3}$

S20. ${ }^{13} \mathrm{C}$ NMR $\left(175 \mathrm{MHz}\right.$, Acetone- $\left.d_{6}\right)$ spectrum of the new compound 3

S21. COSY spectrum of the new compound 3

$\mathrm{S} 22$. NOESY spectrum of the new compound $\mathbf{3}$

S23. HSQC spectrum of the new compound $\mathbf{3}$

S24. HMBC spectrum of the new compound 3

$\mathrm{S} 25$. UV spectrum of the new compound 3

S26. IR spectrum of the new compound 3

S27. HRESIMS spectrum of the new compound 3

S28. ECD spectrum of the new compound 3

S29. ${ }^{1} \mathrm{H}$ NMR ( $400 \mathrm{MHz}$, Acetone- $d_{6}$ ) spectrum of the new compound 4

S30. ${ }^{13} \mathrm{C}$ NMR (100 MHz, Acetone- $d_{6}$ ) spectrum of the new compound 4

S31. COSY spectrum of the new compound 4

S32. NOESY spectrum of the new compound 4

S33. HSQC spectrum of the new compound 4

S34. HMBC spectrum of the new compound 4

S35. UV spectrum of the new compound 4

S36. IR spectrum of the new compound 4

S37. HRESIMS spectrum of the new compound 4 
S38. ECD spectrum of the new compound 4

S39. ${ }^{1} \mathrm{H}$ NMR ( $400 \mathrm{MHz}$, Acetone- $d_{6}$ ) spectrum of the new compound 5

S40. ${ }^{13} \mathrm{C}$ NMR (100 MHz, Acetone- $d_{6}$ ) spectrum of the new compound 5

S41. COSY spectrum of the new compound $\mathbf{5}$

S42. NOESY spectrum of the new compound $\mathbf{5}$

S43. HSQC spectrum of the new compound 5

S44. HMBC spectrum of the new compound 5

S45. UV spectrum of the new compound $\mathbf{5}$

S46. IR spectrum of the new compound $\mathbf{5}$

S47. HRESIMS spectrum of the new compound $\mathbf{5}$

S48. ECD spectrum of the new compound $\mathbf{5}$

S49. ${ }^{1} \mathrm{H}$ NMR (400 MHz, Acetone- $d_{6}$ ) spectrum of the new compound 6

S50. ${ }^{13} \mathrm{C}$ NMR $\left(100 \mathrm{MHz}\right.$, Acetone- $\left.d_{6}\right)$ spectrum of the new compound 6

S51. COSY spectrum of the new compound 6

S52. NOESY spectrum of the new compound 6

S53. HSQC spectrum of the new compound 6

S54. HMBC spectrum of the new compound 6

S55. UV spectrum of the new compound 6

S56. IR spectrum of the new compound 6

S57. HRESIMS spectrum of the new compound 6

S58. ECD spectrum of the new compound 6

S59. ${ }^{1} \mathrm{H}$ NMR $\left(700 \mathrm{MHz}\right.$, Acetone- $\left.d_{6}\right)$ spectrum of the new compound 7

S60. ${ }^{13} \mathrm{C}$ NMR (175 MHz, Acetone- $d_{6}$ ) spectrum of the new compound 7

S61. COSY spectrum of the new compound 7

S62. NOESY spectrum of the new compound 7

S63. HSQC spectrum of the new compound 7

S64. HMBC spectrum of the new compound 7

S65. UV spectrum of the new compound 7

S66. IR spectrum of the new compound 7

S67. HRESIMS spectrum of the new compound 7

S68. ECD spectrum of the new compound 7

S69. ${ }^{1} \mathrm{H}$ NMR (400 MHz, Acetone- $d_{6}$ ) spectrum of the new compound 8

S70. ${ }^{13} \mathrm{C}$ NMR (100 MHz, Acetone- $d_{6}$ ) spectrum of the new compound 8

S71. COSY spectrum of the new compound $\mathbf{8}$

S72. NOESY spectrum of the new compound $\mathbf{8}$

S73. HSQC spectrum of the new compound $\mathbf{8}$

S74. HMBC spectrum of the new compound 8

S75. UV spectrum of the new compound 8 
S76. IR spectrum of the new compound $\mathbf{8}$

S77. HRESIMS spectrum of the new compound $\mathbf{8}$

S78. ECD spectrum of the new compound $\mathbf{8}$

S79. ${ }^{1} \mathrm{H}$ NMR (300 MHz, $\left.\mathrm{CDCl}_{3}\right)$ spectrum of the new compound 9

$\mathrm{S} 80 .{ }^{13} \mathrm{C}$ NMR $\left(300 \mathrm{MHz}, \mathrm{CDCl}_{3}\right)$ spectrum of the new compound 9

S81. COSY spectrum of the new compound 9

S82. NOESY spectrum of the new compound 9

S83. HSQC spectrum of the new compound 9

S84. HMBC spectrum of the new compound 9

S85. UV spectrum of the new compound 9

S86. IR spectrum of the new compound 9

S87. HRESIMS spectrum of the new compound 9

S88. ECD spectrum of the new compound 9

S89. ${ }^{1} \mathrm{H}$ NMR (400 MHz, $\mathrm{CD}_{3} \mathrm{OD}$ ) spectrum of the new compound $\mathbf{1 0}$

S90. ${ }^{13} \mathrm{C}$ NMR (100 MHz, $\left.\mathrm{CD}_{3} \mathrm{OD}\right)$ spectrum of the new compound $\mathbf{1 0}$

S91. COSY spectrum of the new compound $\mathbf{1 0}$

S92. NOESY spectrum of the new compound $\mathbf{1 0}$

S93. HSQC spectrum of the new compound $\mathbf{1 0}$

S94. HMBC spectrum of the new compound $\mathbf{1 0}$

S95. UV spectrum of the new compound 9

S96. IR spectrum of the new compound 9

S97. HRESIMS spectrum of the new compound 9

S98. Optical rotation data of the new compound 3-9

S99. HPLC of D-glucose $o$-toylthiocarbamate derivative

S100. HPLC of L-glucose $o$-toylthiocarbamate derivative

S101. HPLC of glycoside (10) $o$-toylthiocarbamate derivative 
S $1{ }^{1} \mathrm{H}$ NMR (400 MHz, Acetone- $d_{6}$ ) spectrum of the new compound 1

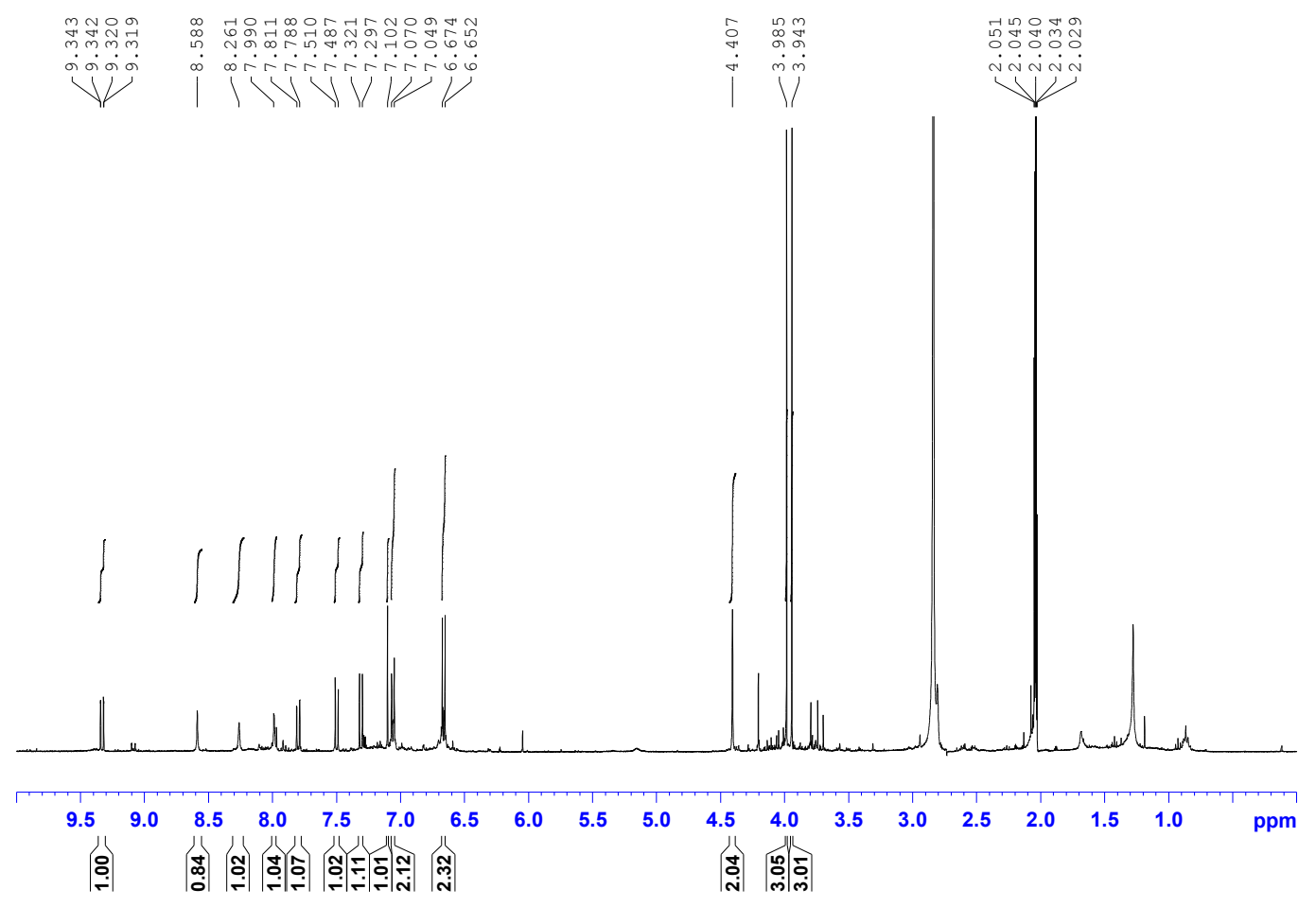


S $2{ }^{13} \mathrm{C}$ NMR $\left(100 \mathrm{MHz}\right.$, Acetone- $\left.d_{6}\right)$ spectrum of the new compound $\mathbf{1}$

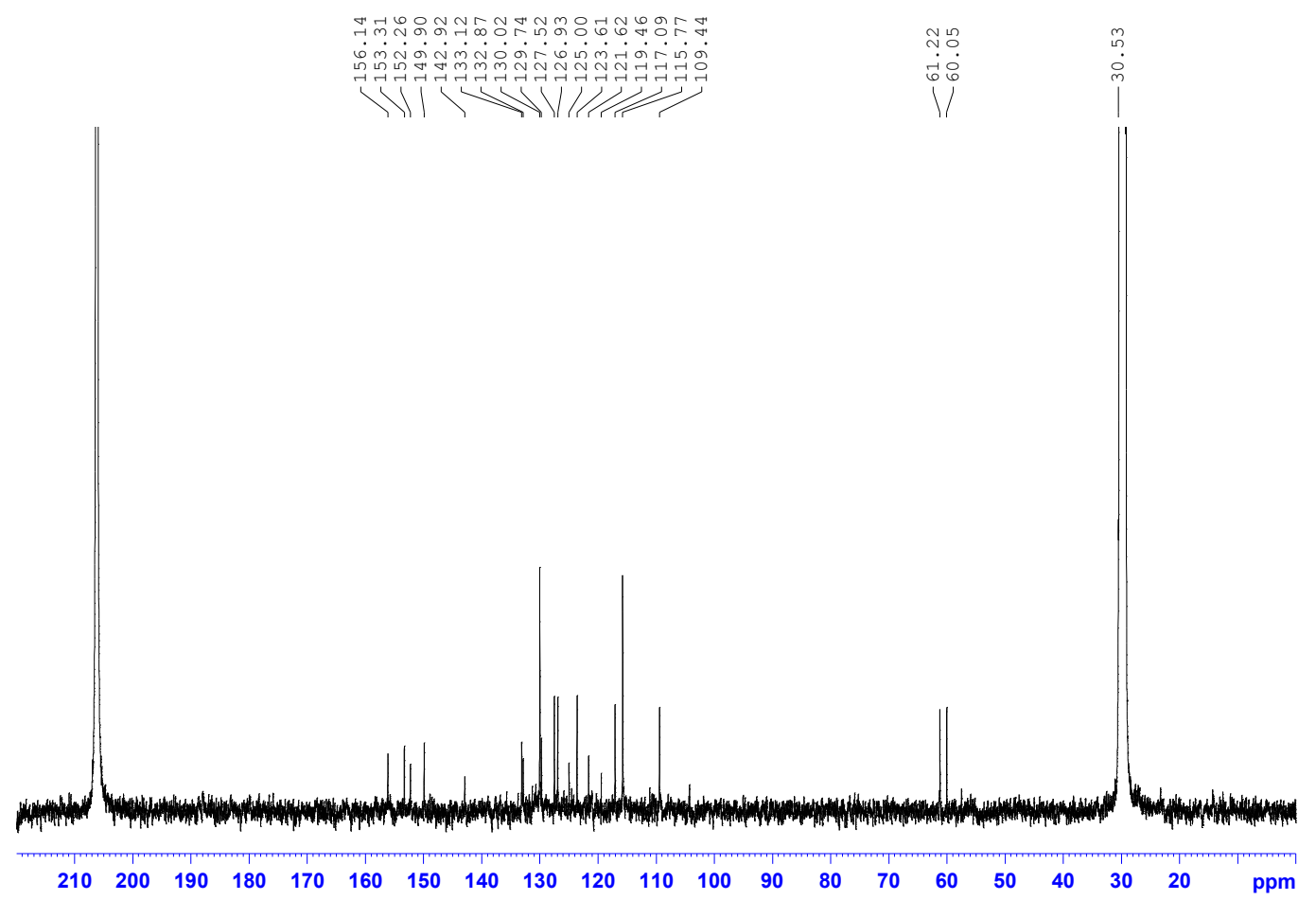


S 3 COSY spectrum of the new compound 1

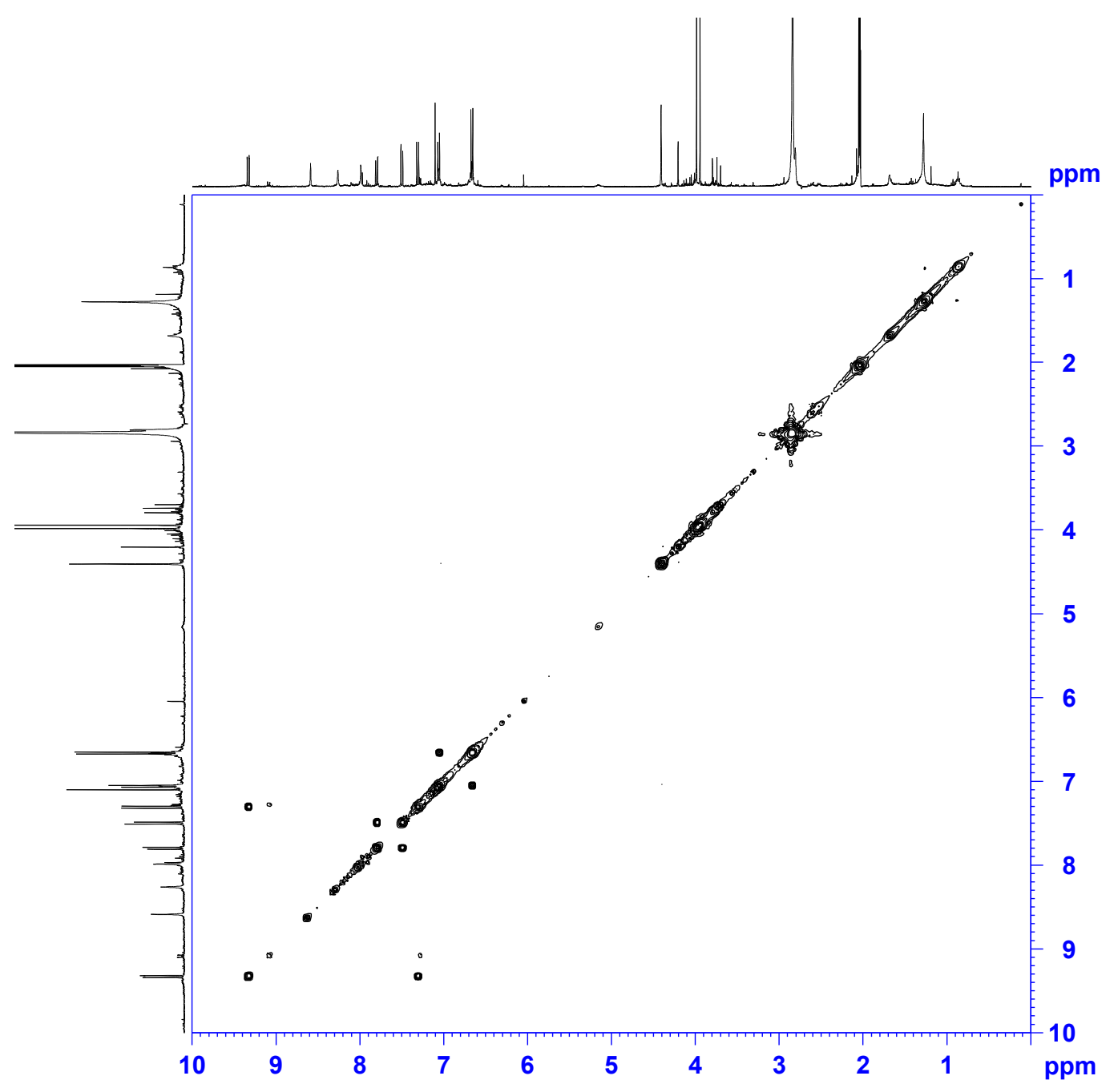


S 4 NOESY spectrum of the new compound 1

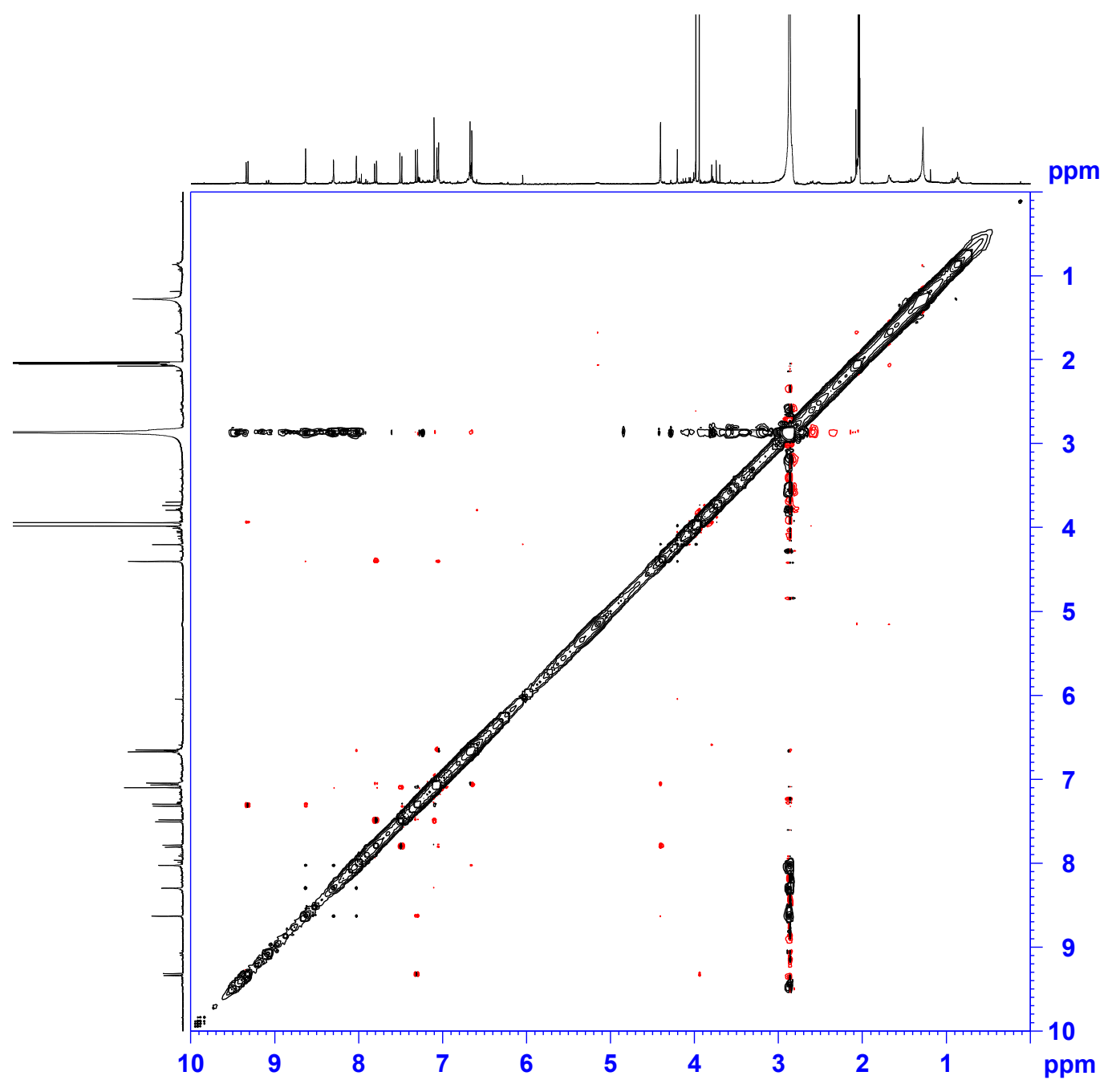


S 5 HSQC spectrum of the new compound 1

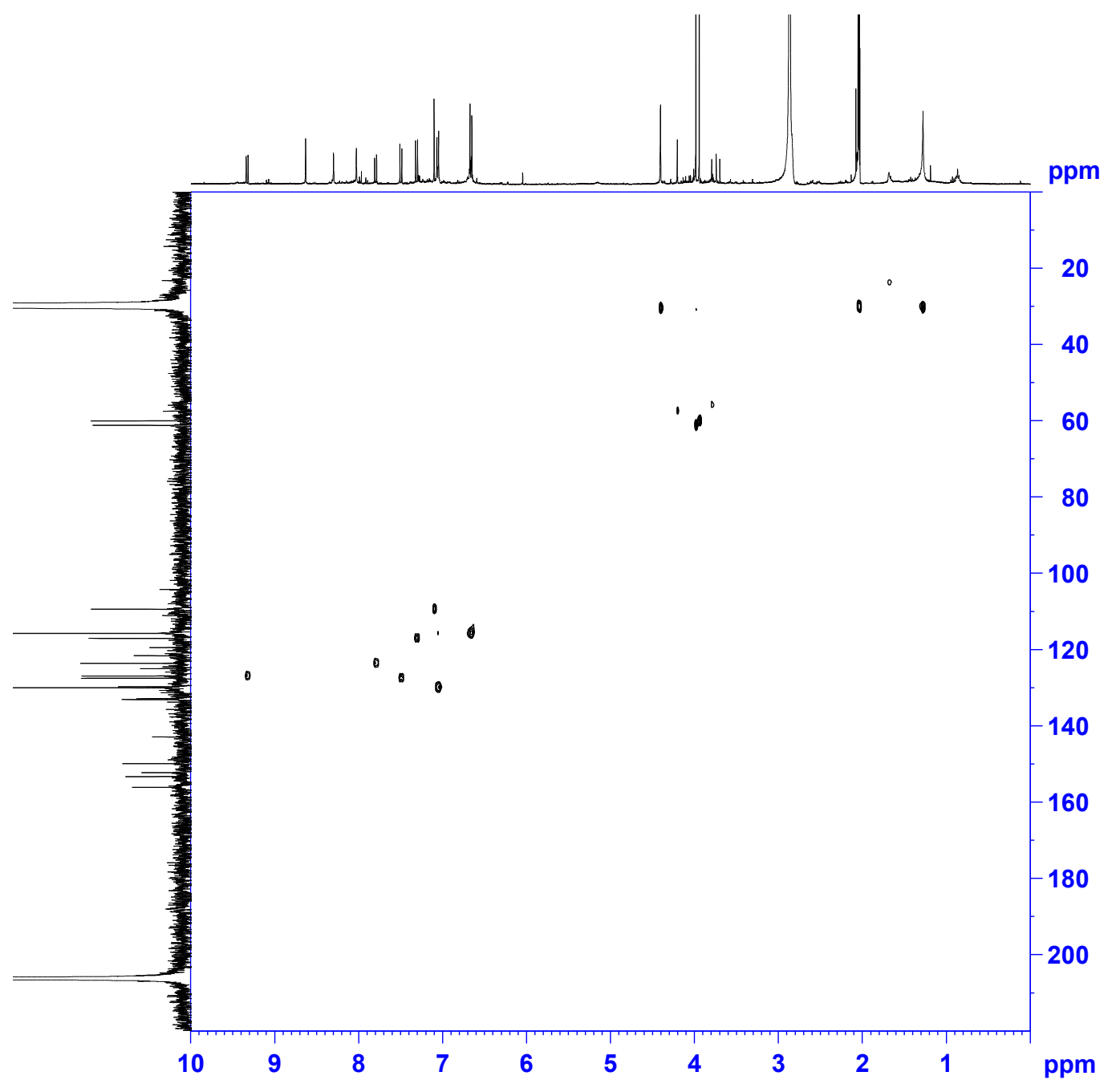


S 6 HMBC spectrum of the new compound 1

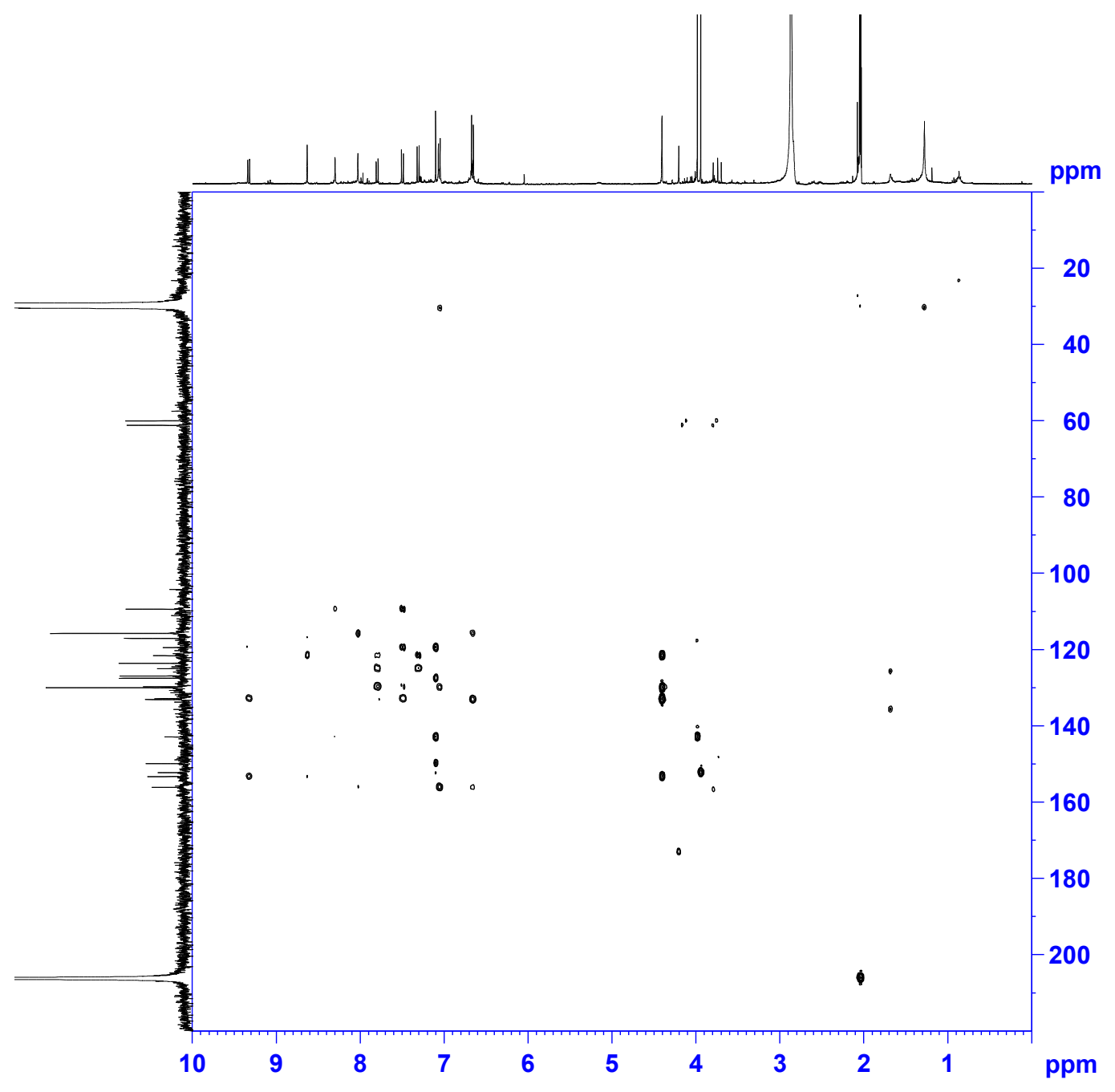


S 7 UV spectrum of the new compound 1

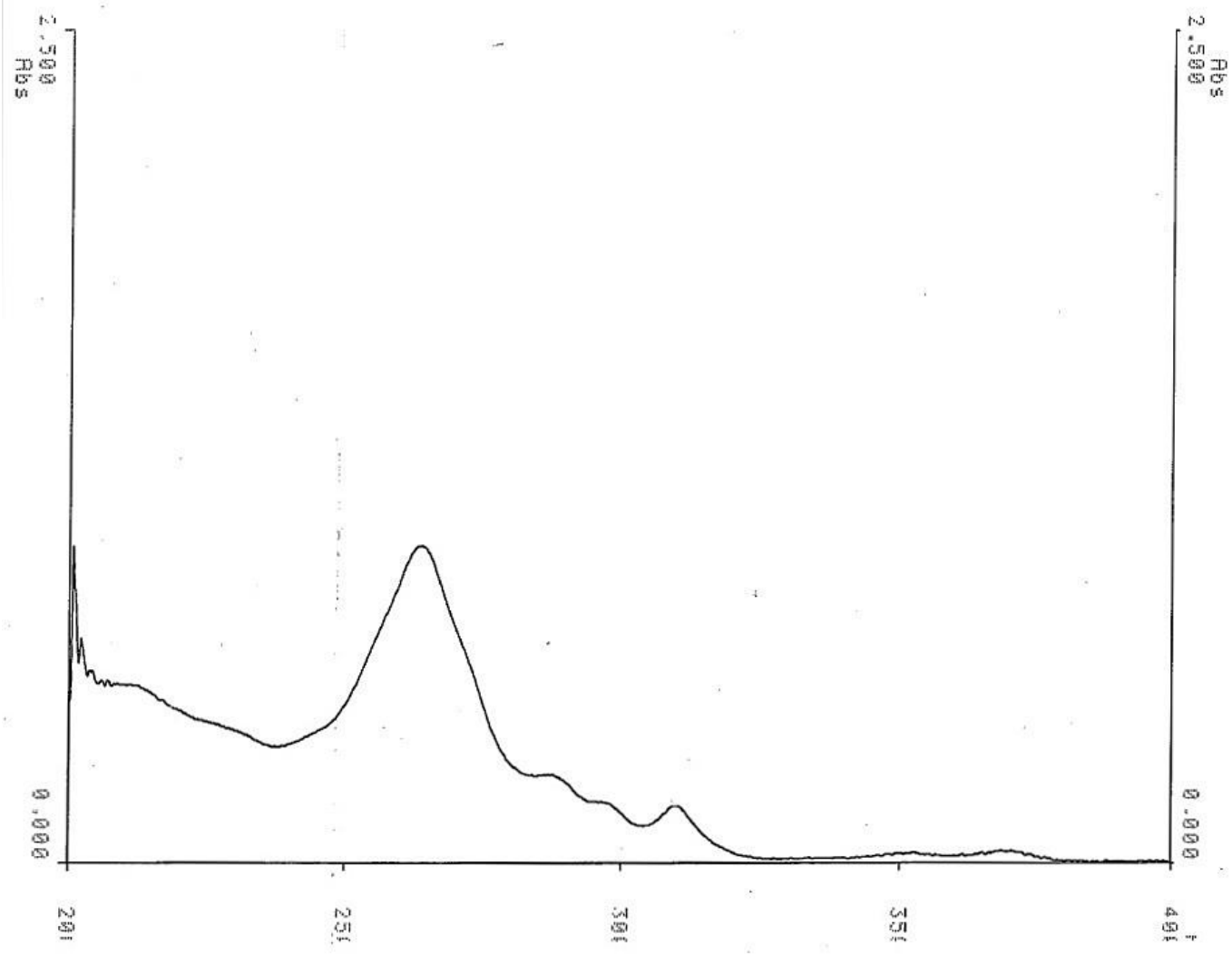


S 8 IR spectrum of the new compound 1

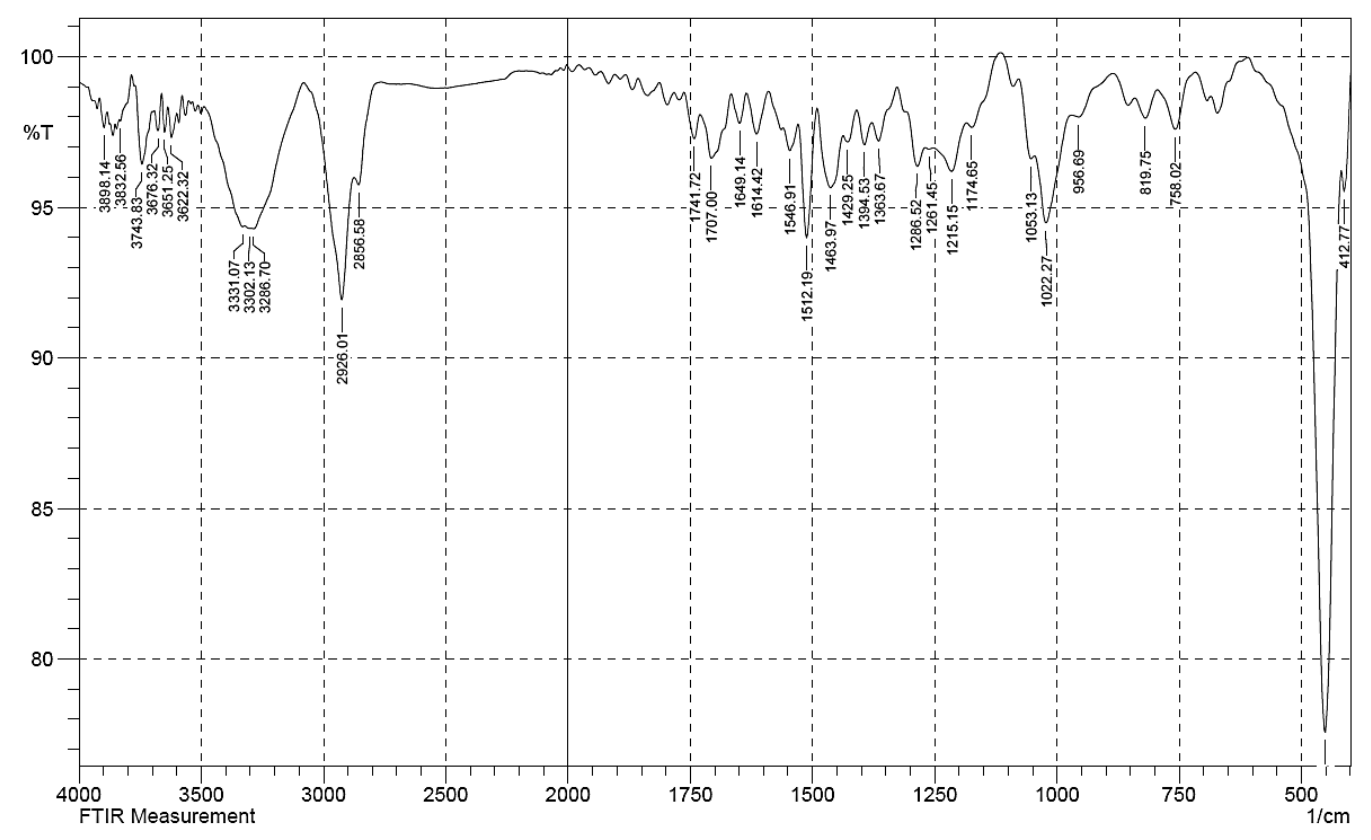


S 9 HRESIMS spectrum of the new compound 1

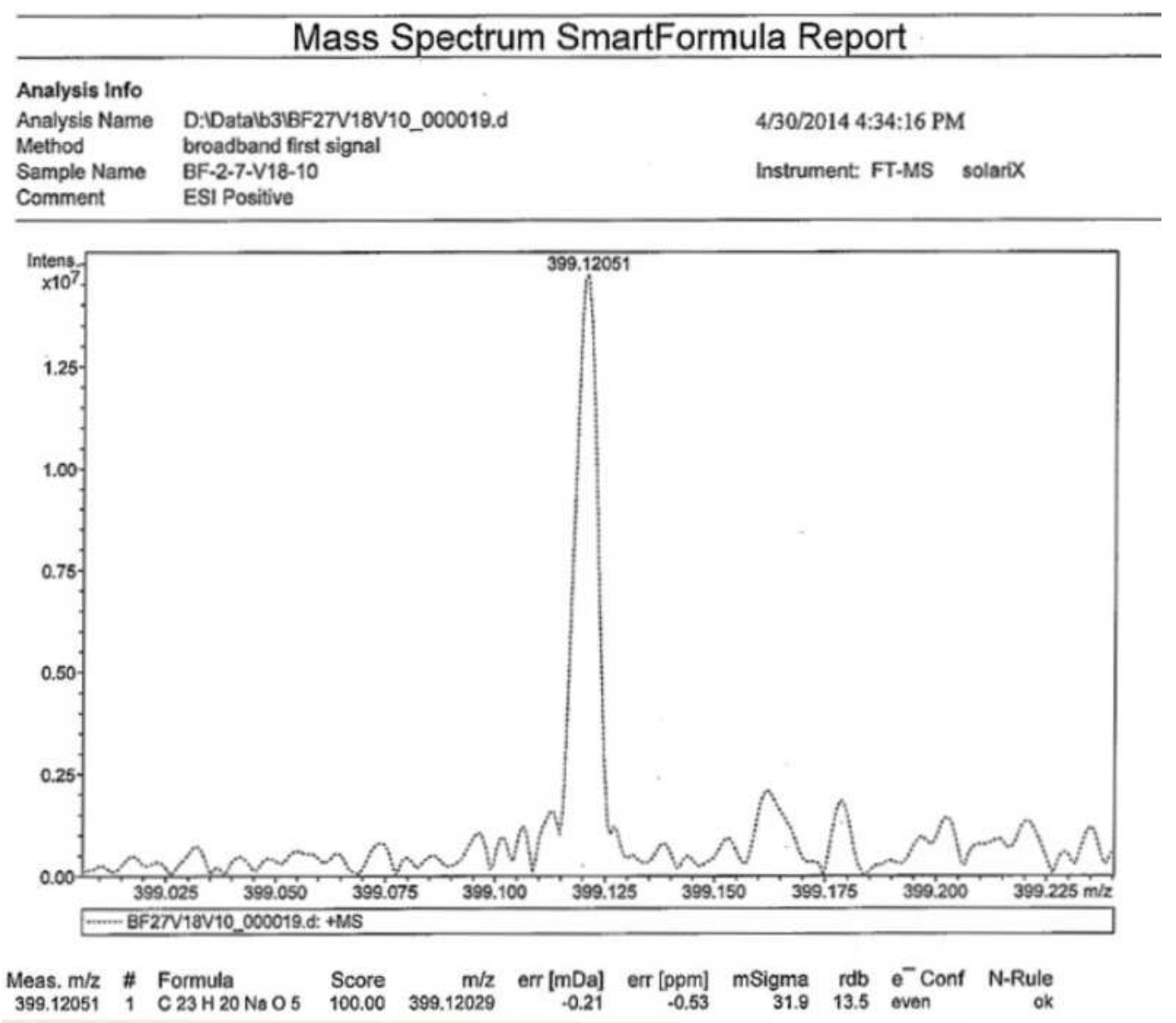


S $10{ }^{1} \mathrm{H}$ NMR (400 MHz, Acetone- $d_{6}$ ) spectrum of the new compound 2

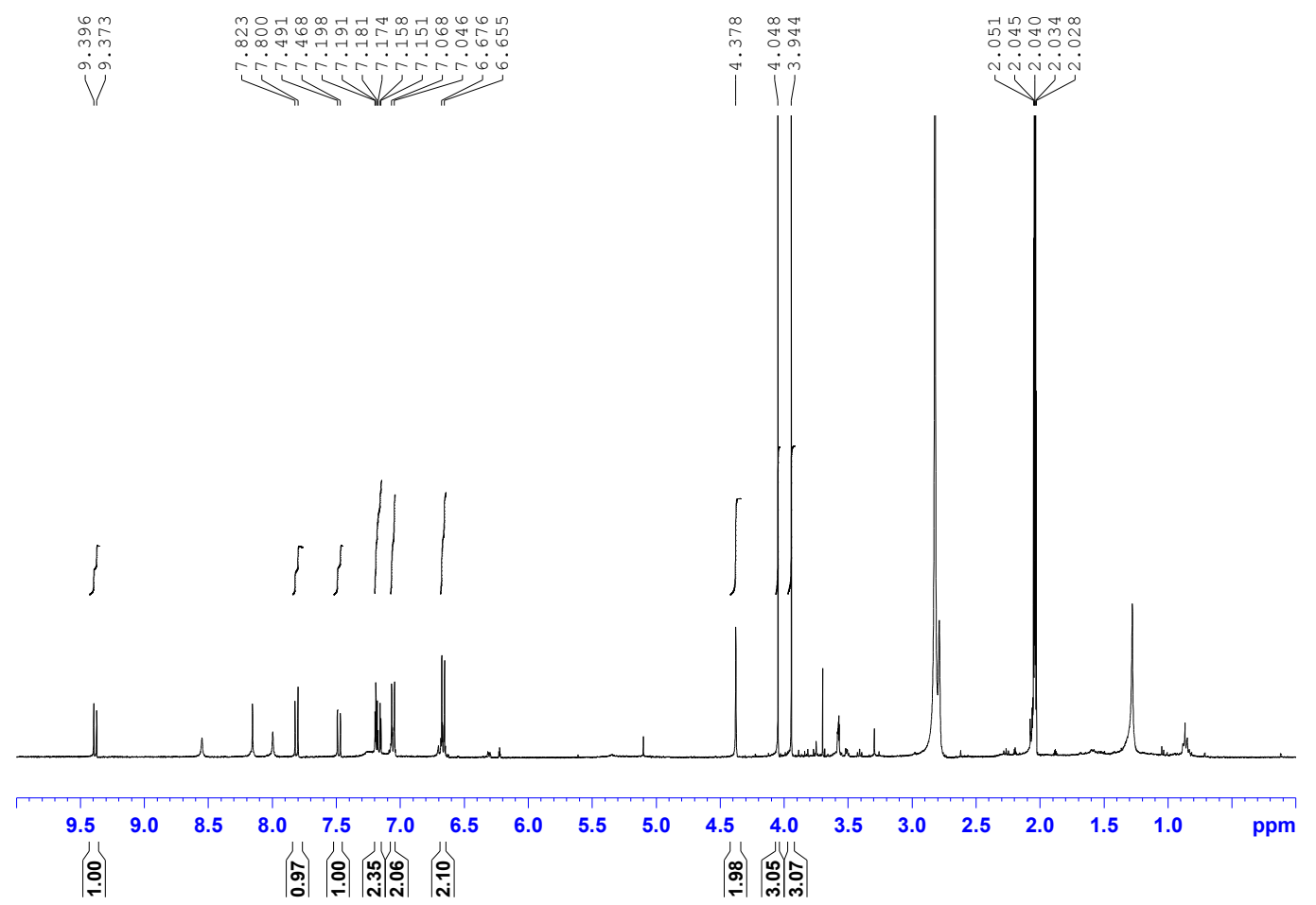


S $11{ }^{13} \mathrm{C}$ NMR (100 MHz, Acetone- $d_{6}$ ) spectrum of the new compound 2

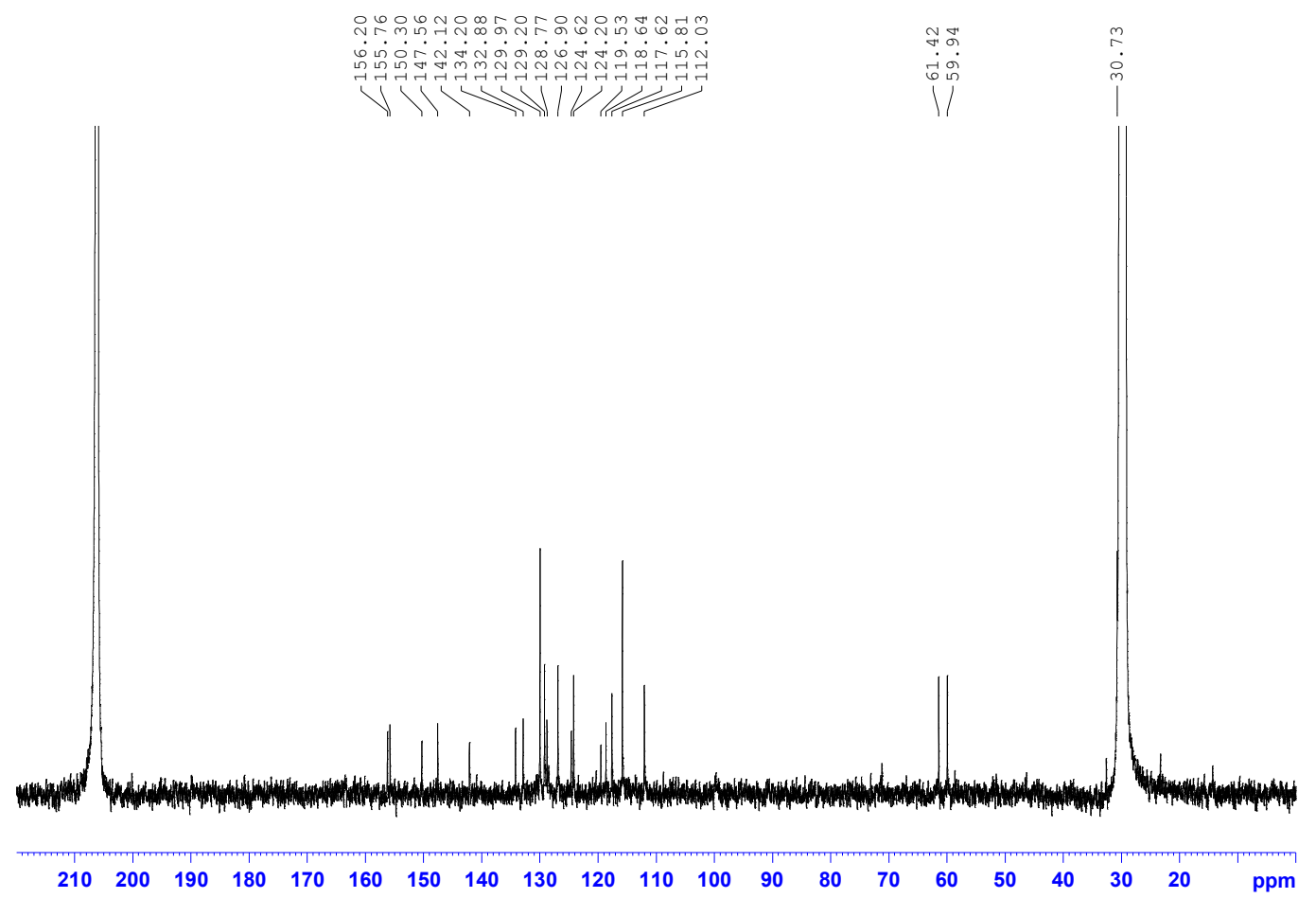


S 12 COSY spectrum of the new compound 2

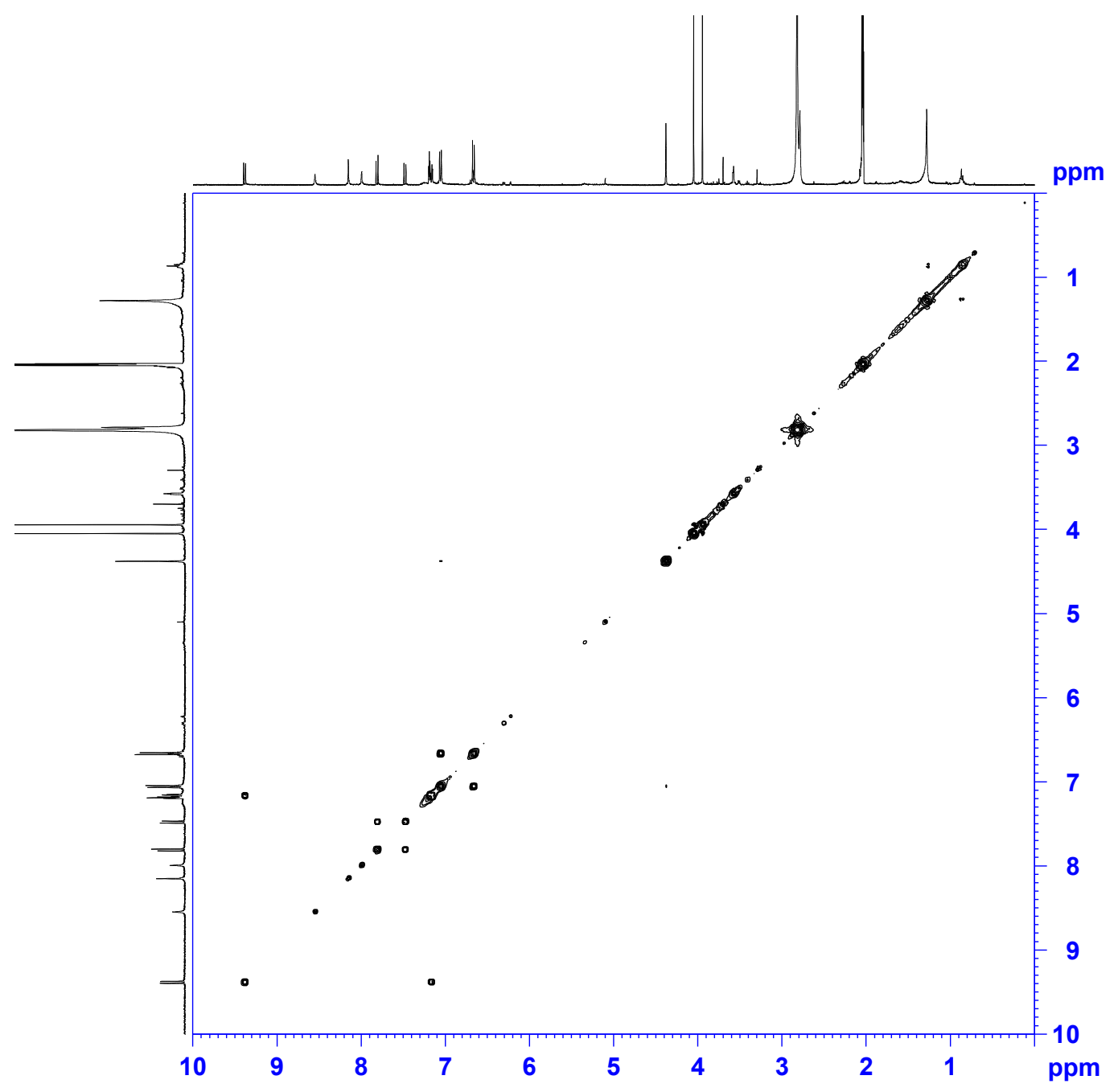


S 13 NOESY spectrum of the new compound 2

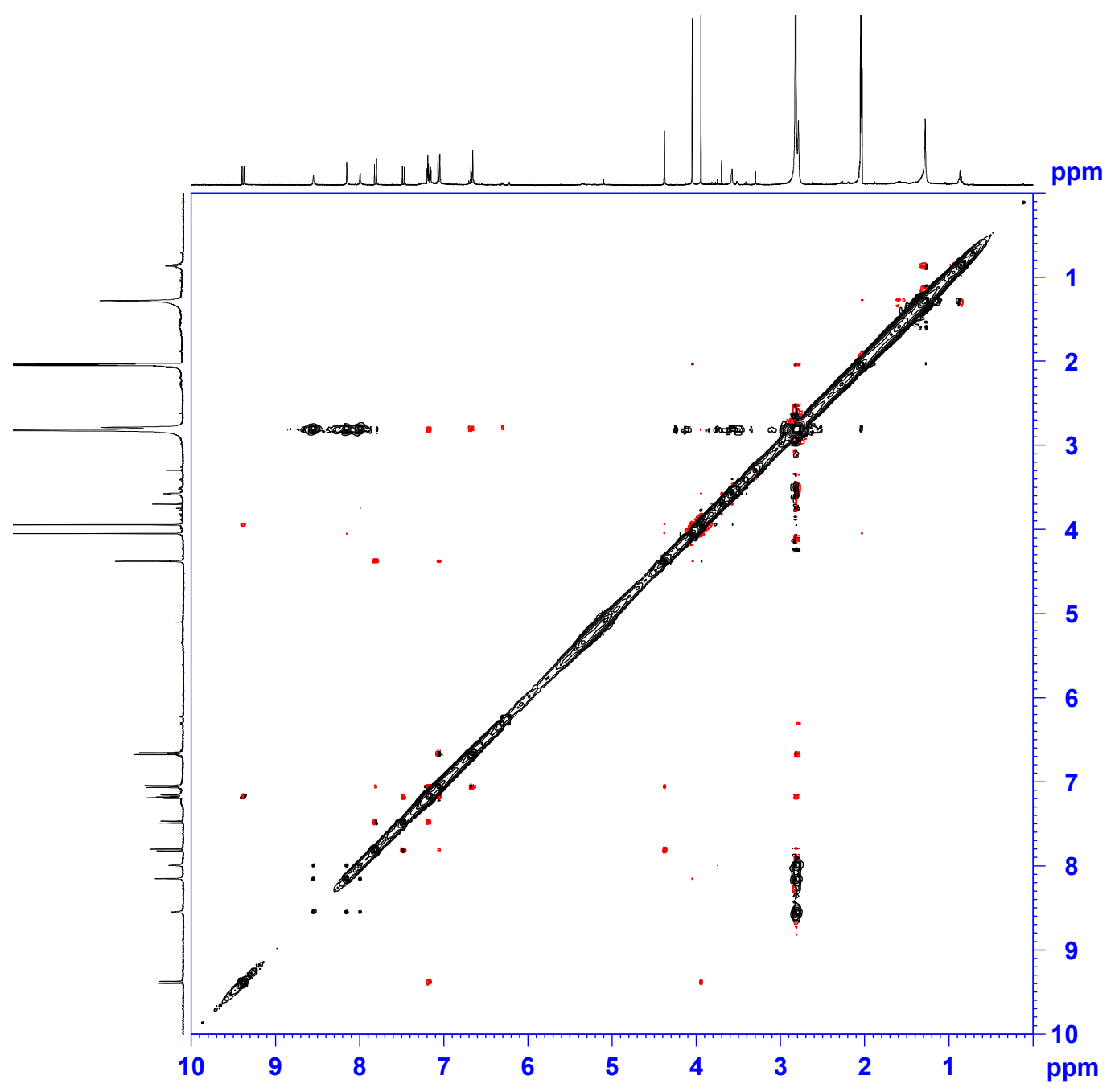


S 14 HSQC spectrum of the new compound 2

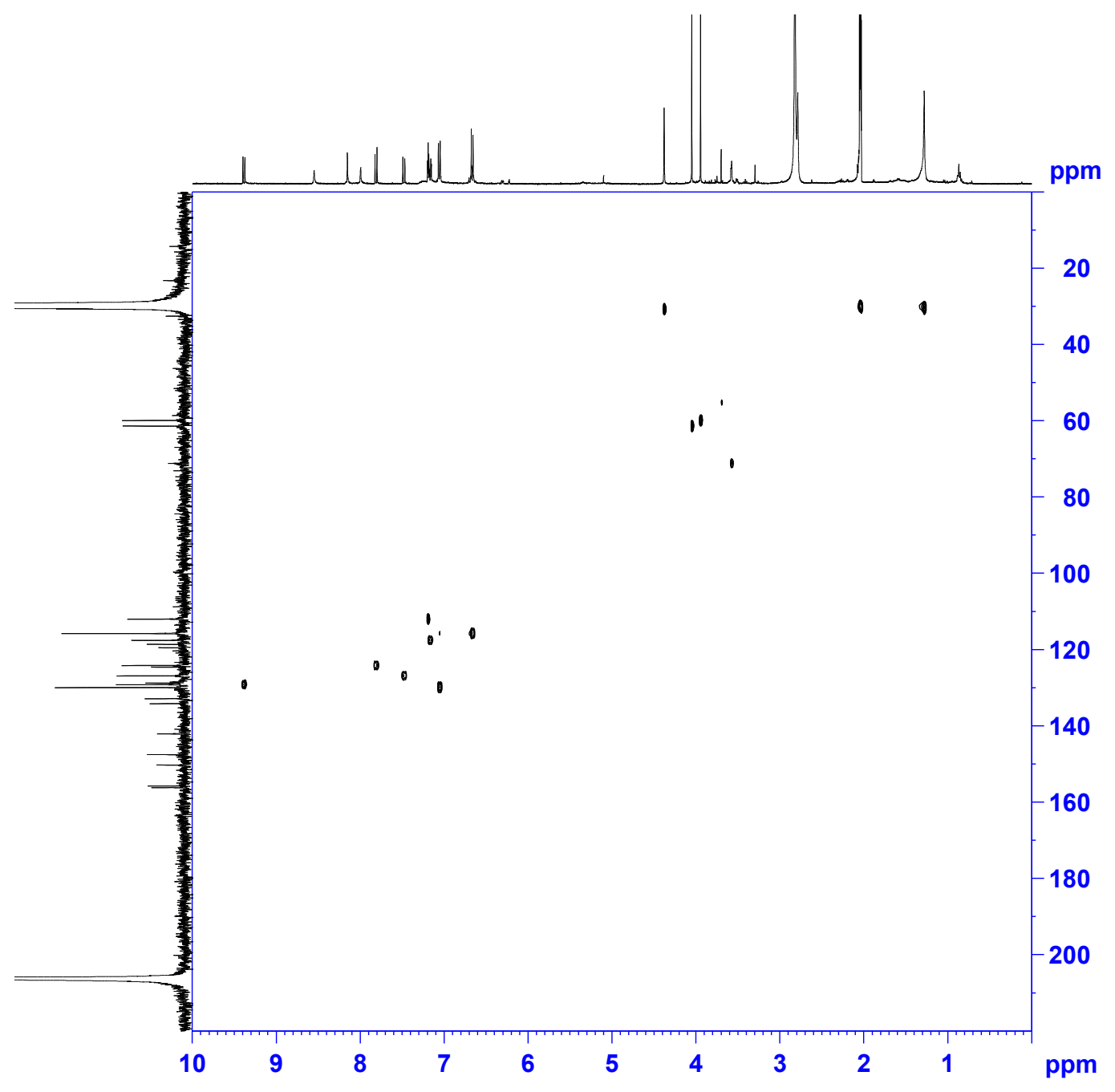


S 15 HMBC spectrum of the new compound 2

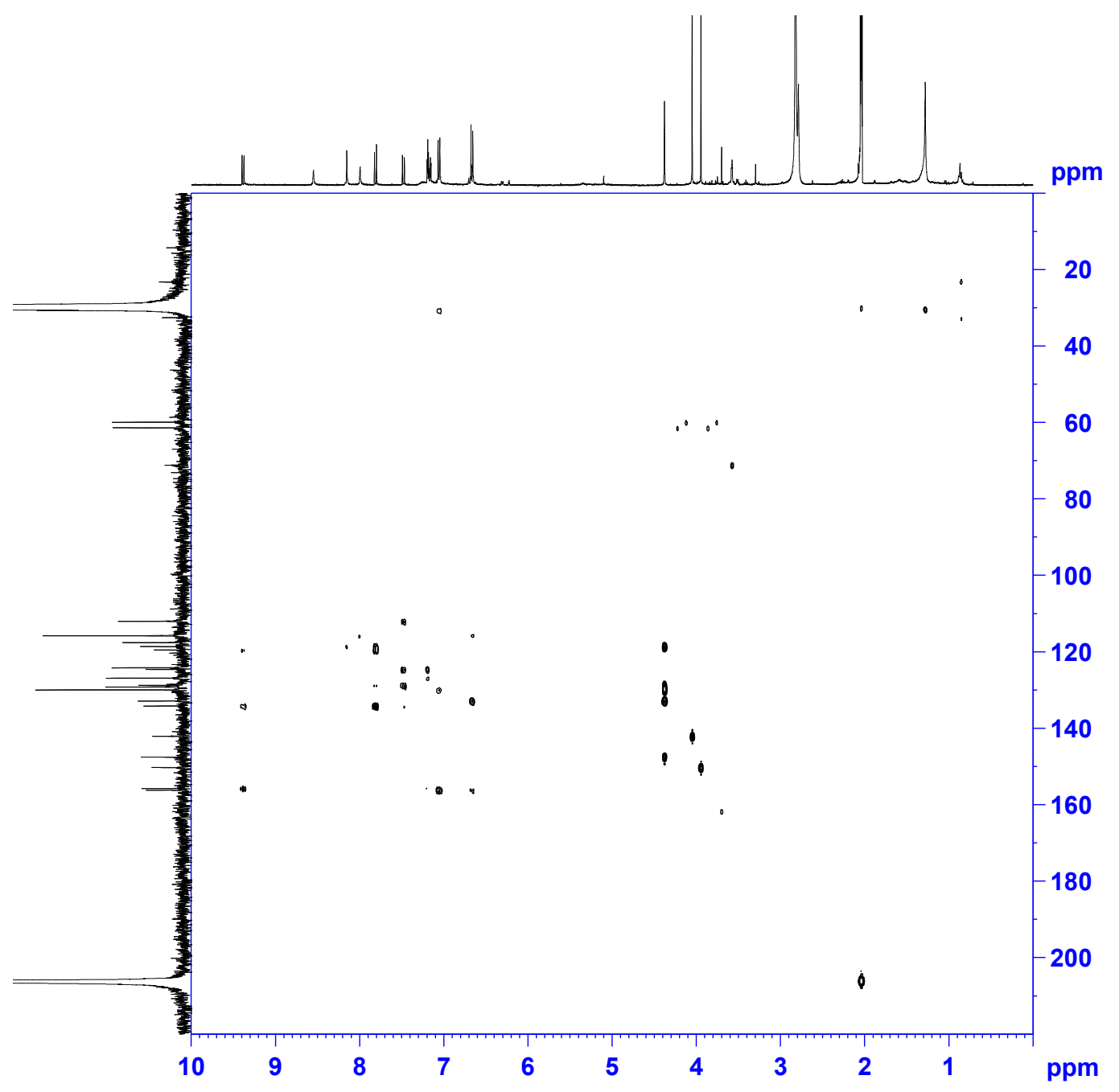


S 16 UV spectrum of the new compound 2

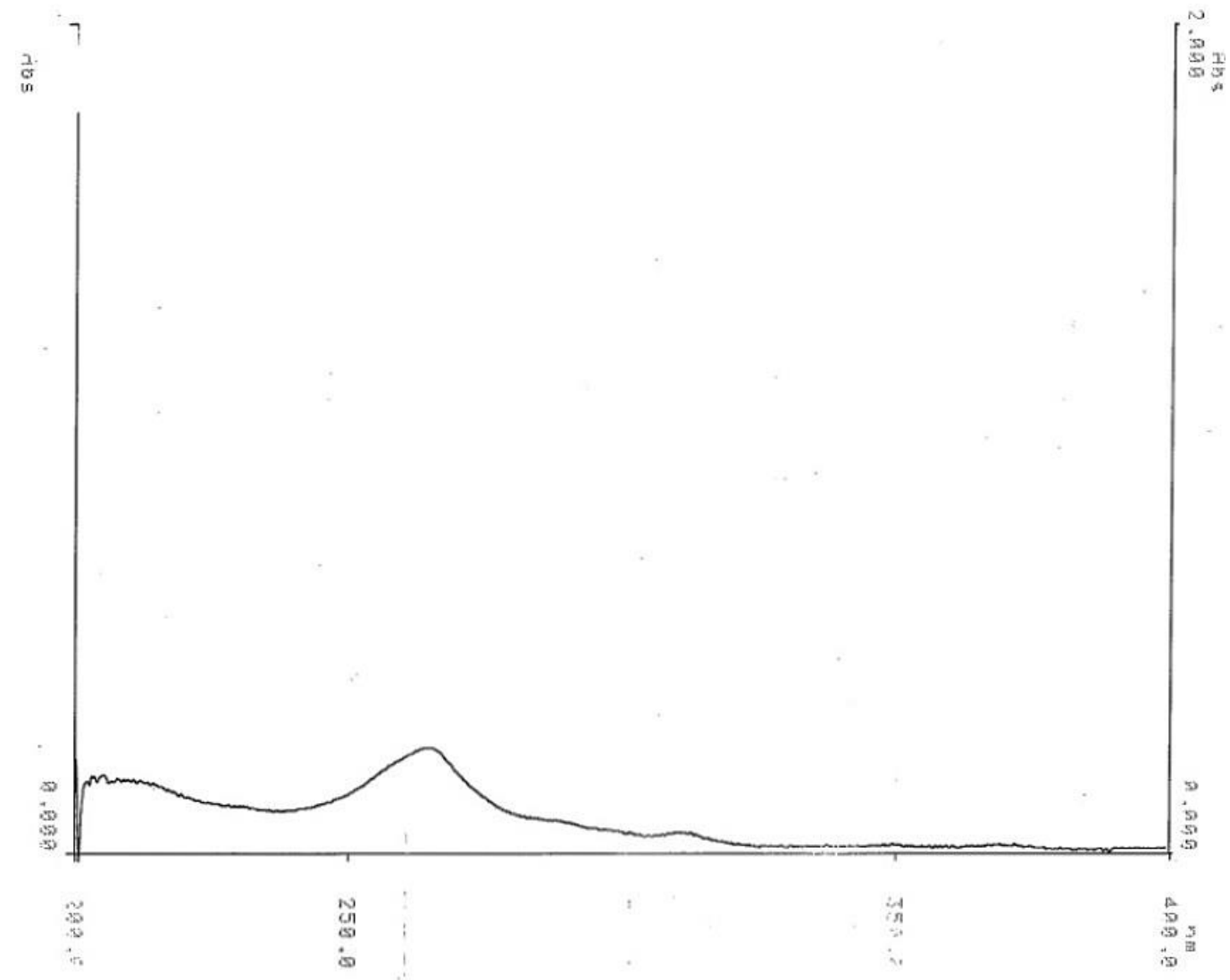


S 17 IR spectrum of the new compound 2

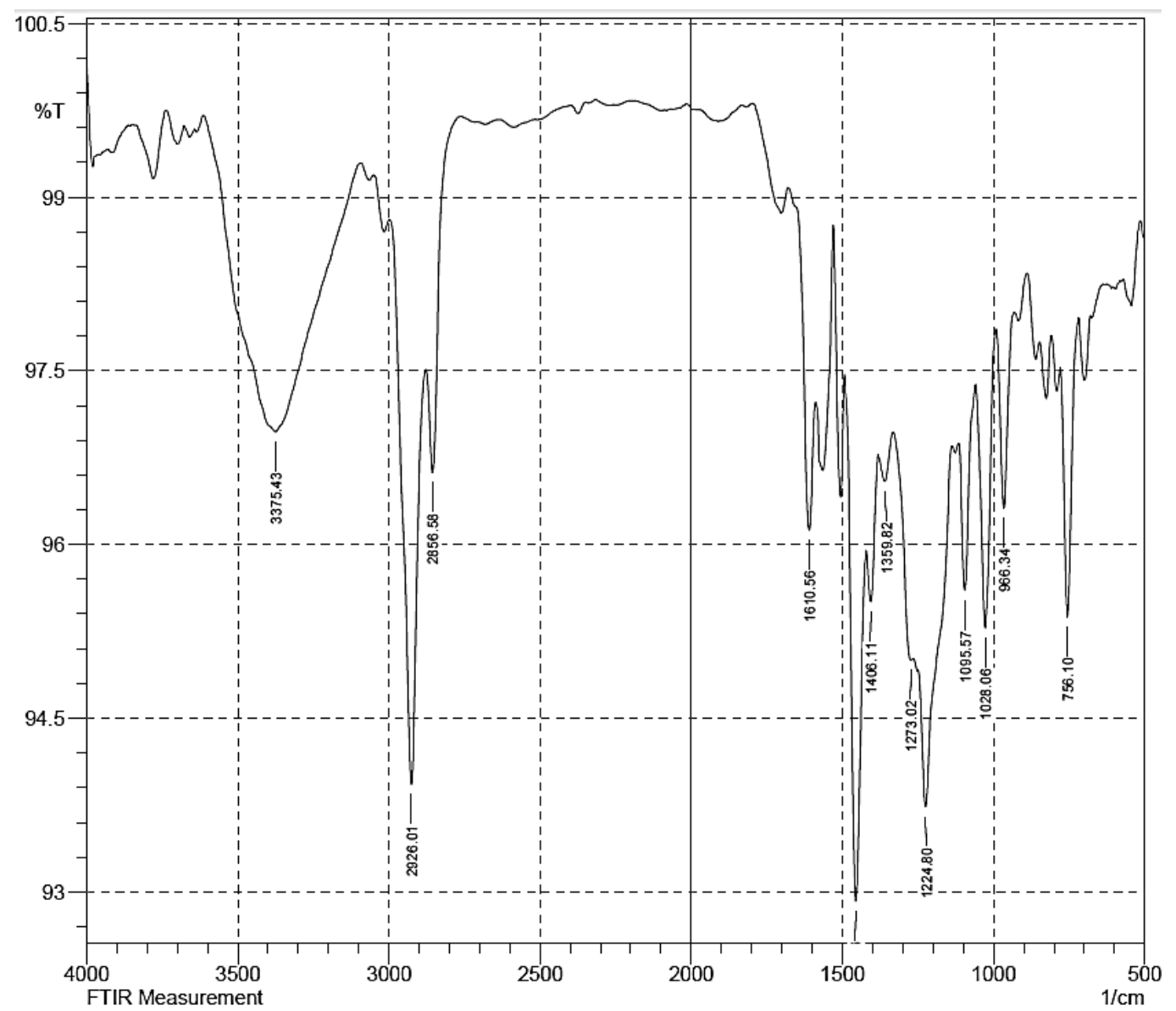




\section{S 18 HRESIMS spectrum of the new compound 2}

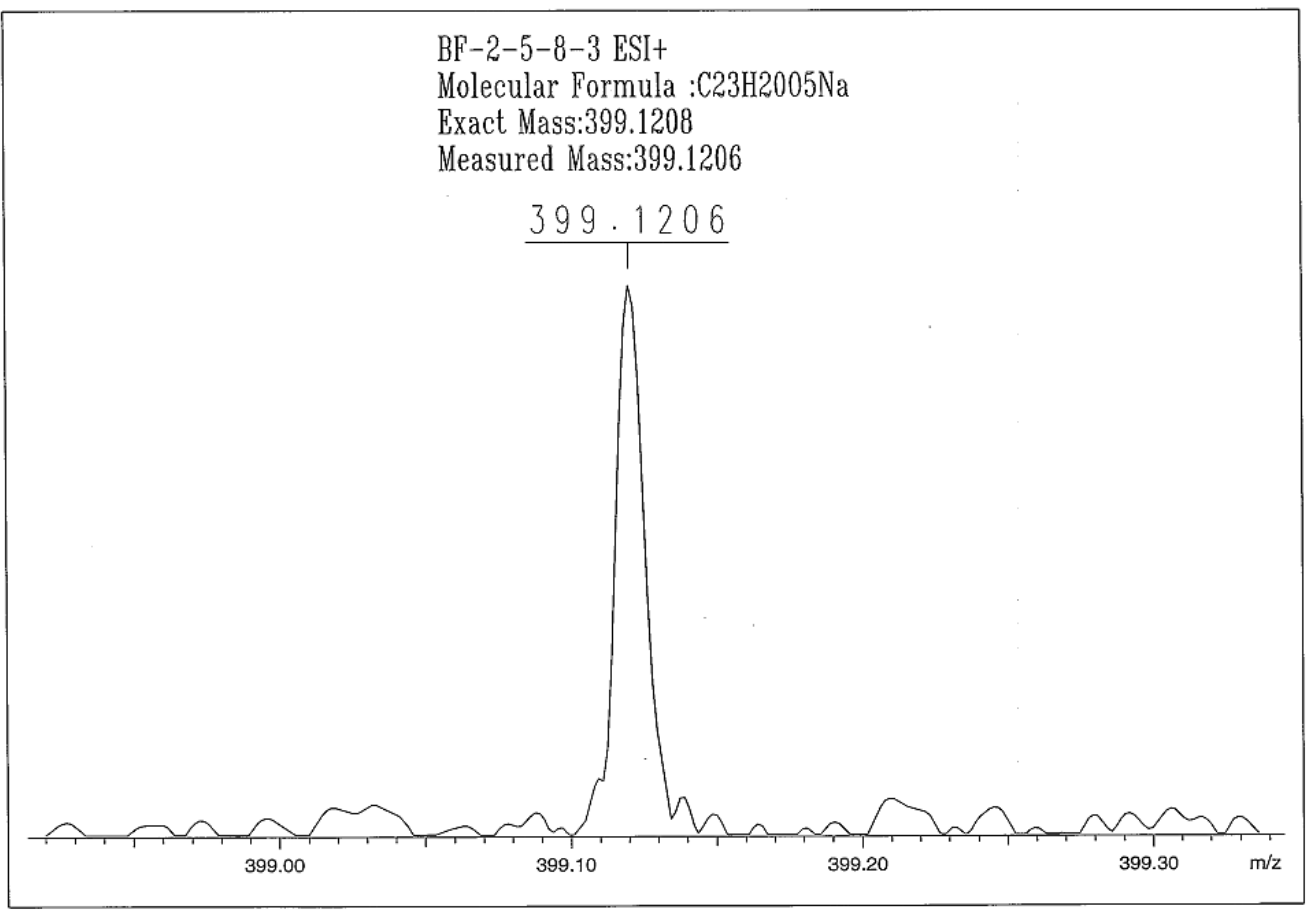

/d=/Data/yu/BF2583/1/pdata/1 Administrator Thu Aug 22 15:03:40 2013 
S $19{ }^{1} \mathrm{H}$ NMR (700 MHz, Acetone- $d_{6}$ ) spectrum of the new compound 3

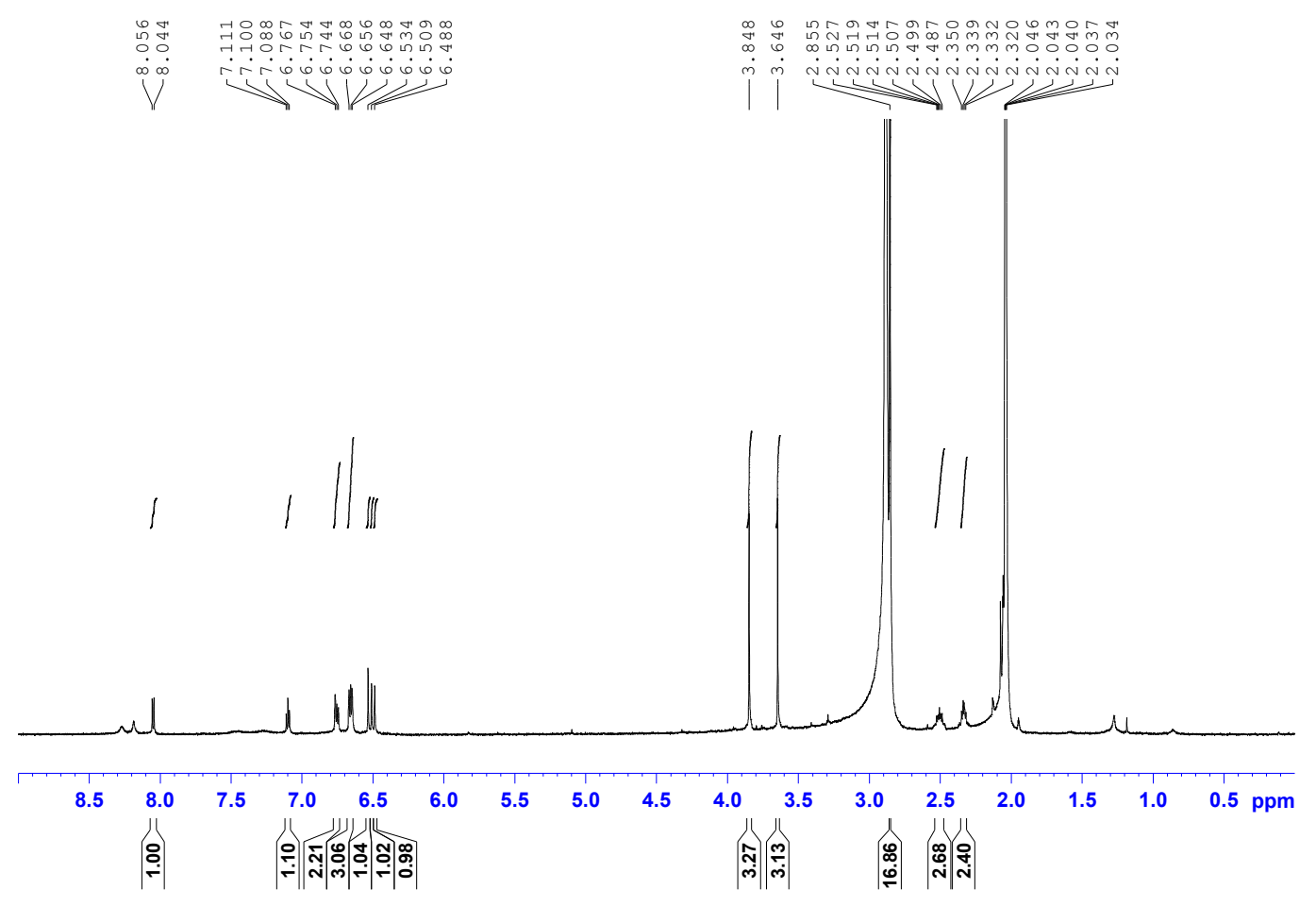


S $20{ }^{13} \mathrm{C}$ NMR (175 MHz, Acetone- $d_{6}$ ) spectrum of the new compound 3

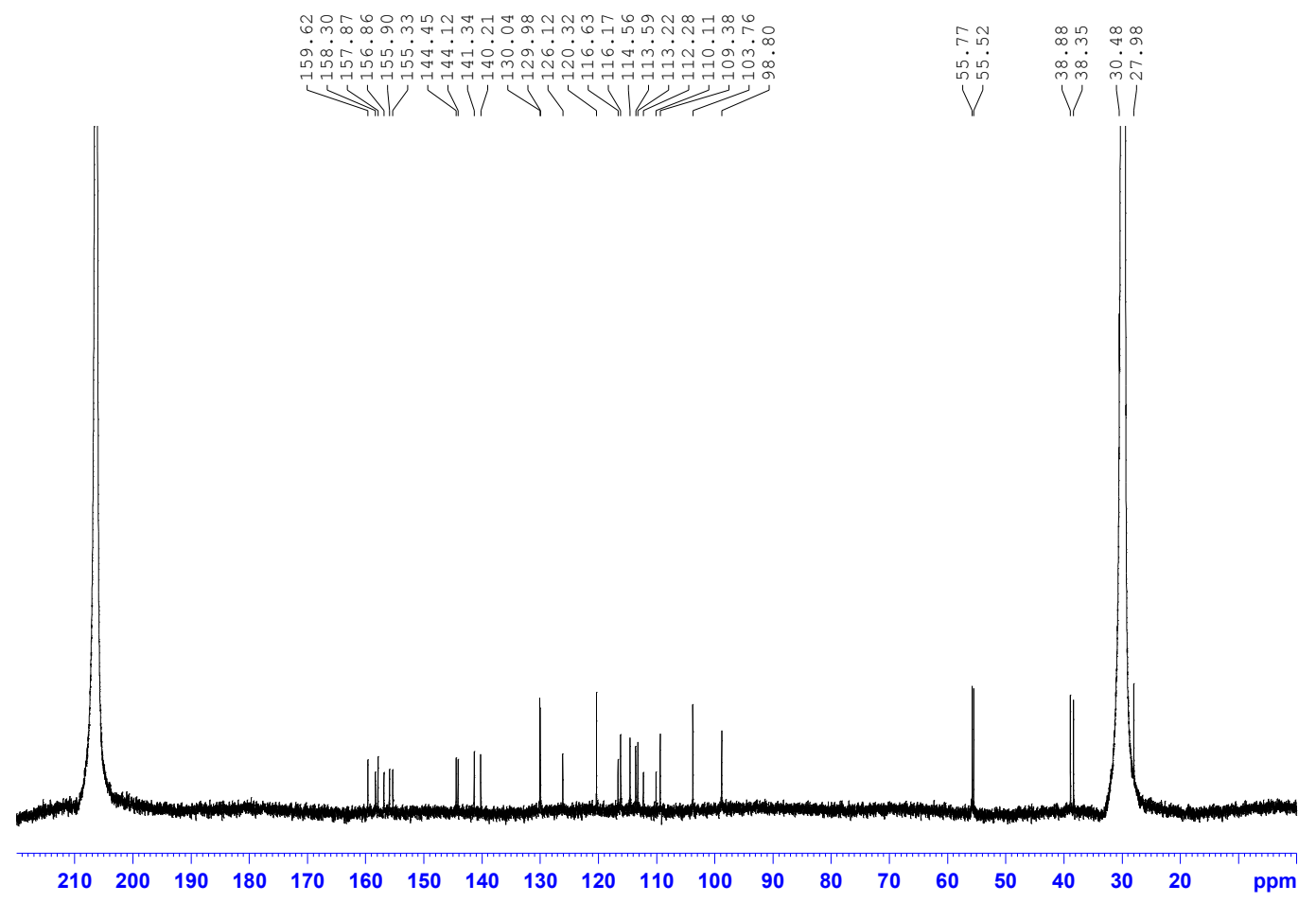


S 21 COSY spectrum of the new compound 3

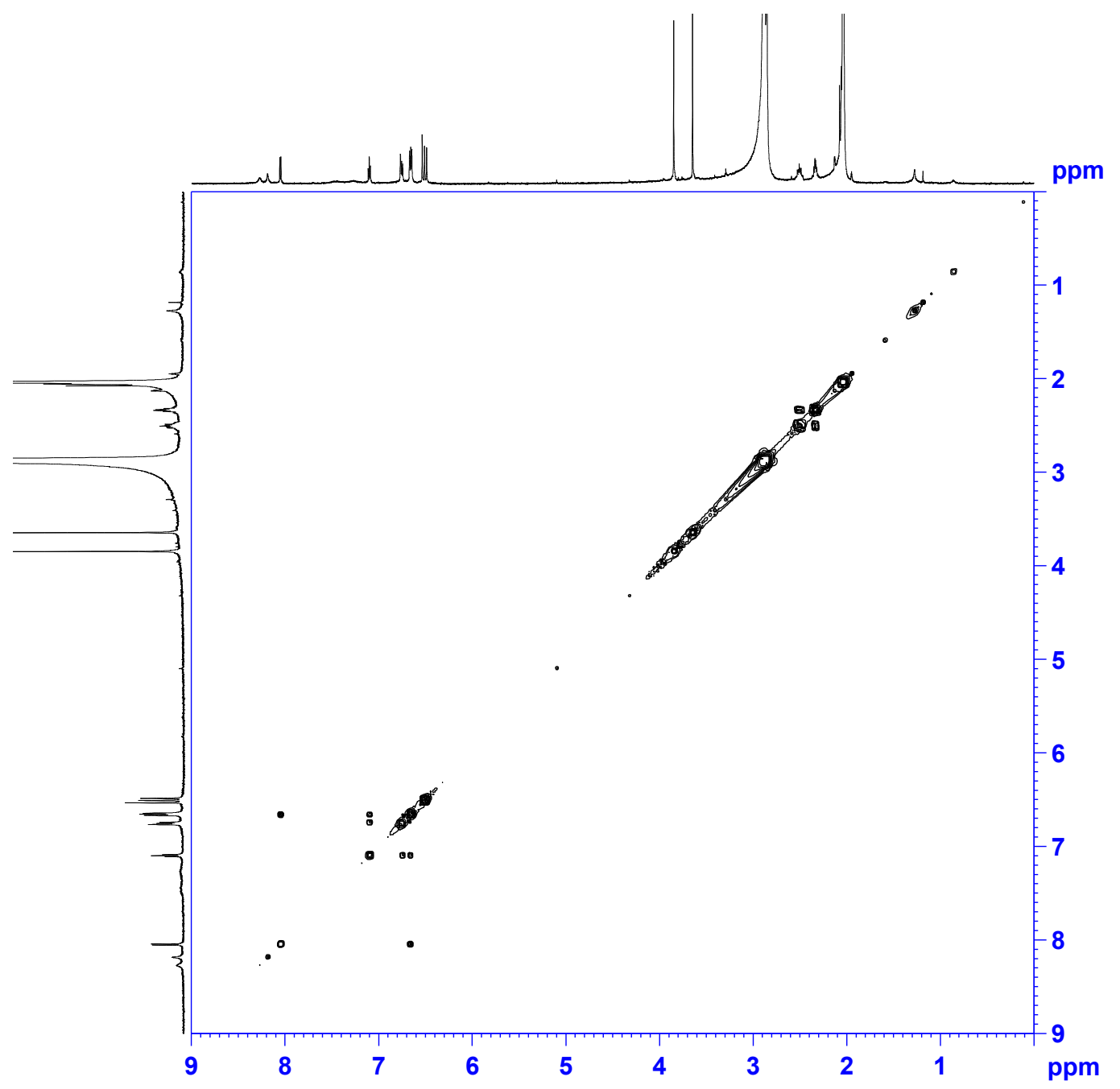


S 22 NOESY spectrum of the new compound 3

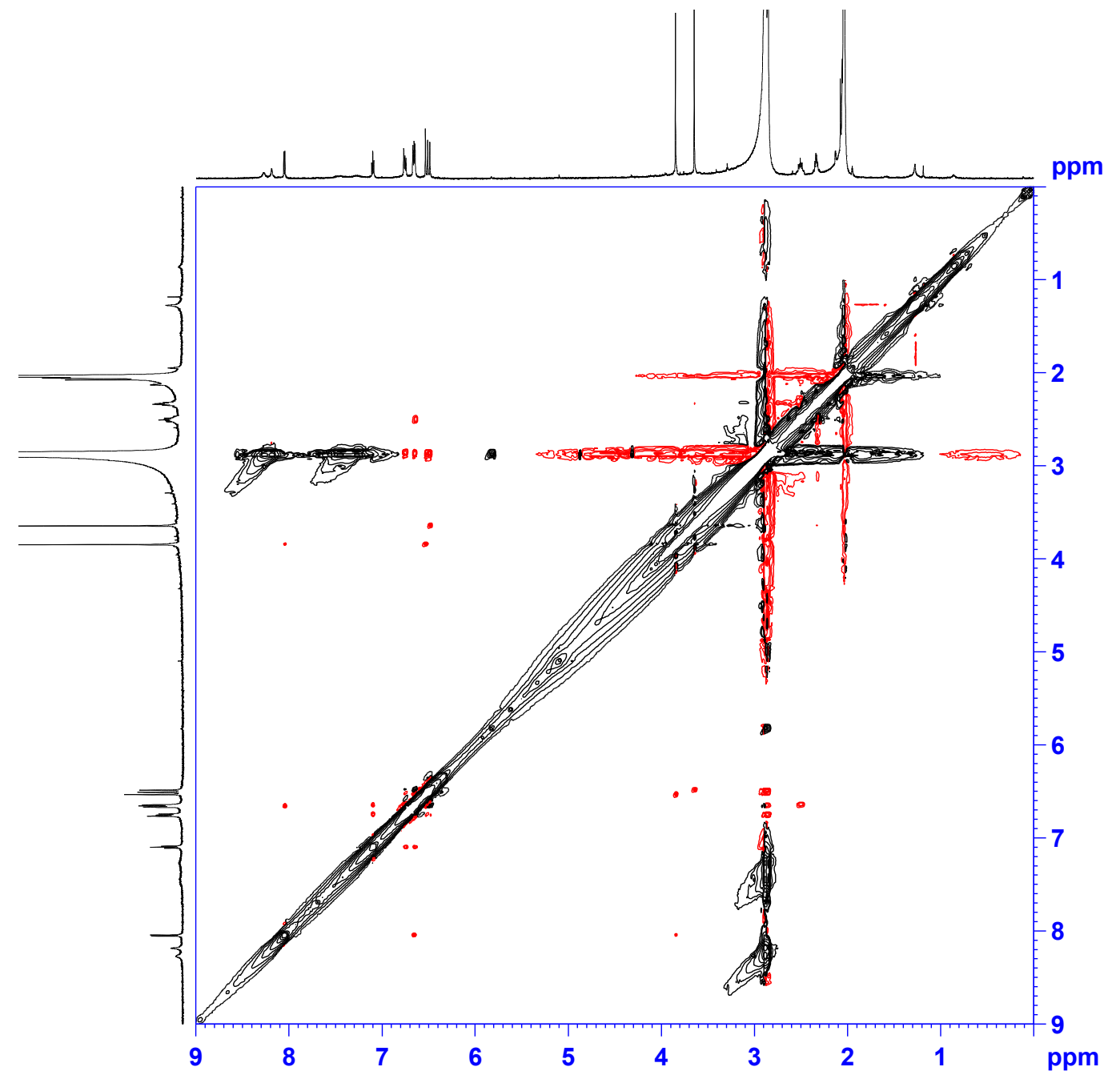


S 23 HSQC spectrum of the new compound 3

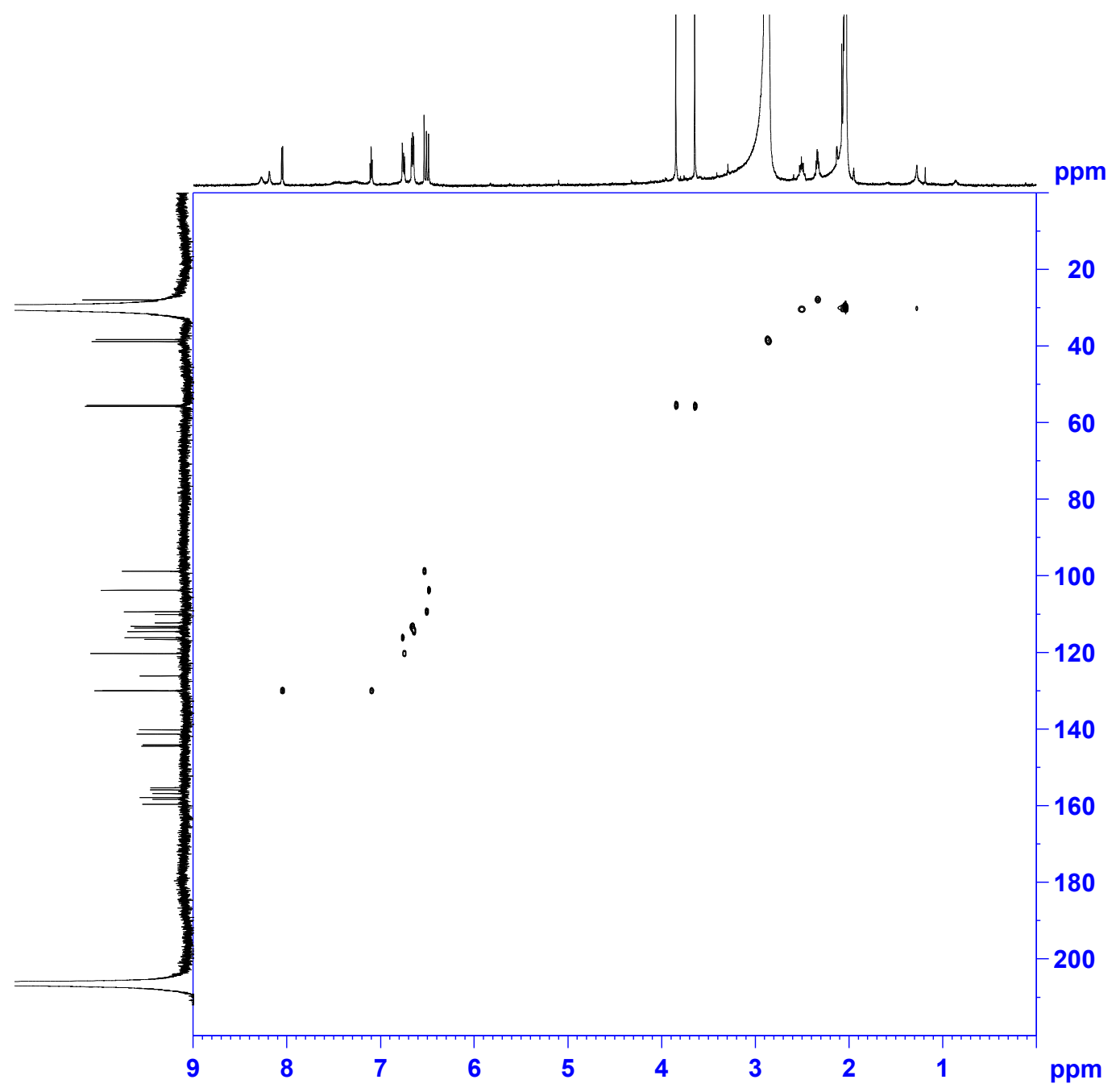


S 24 HMBC spectrum of the new compound 3

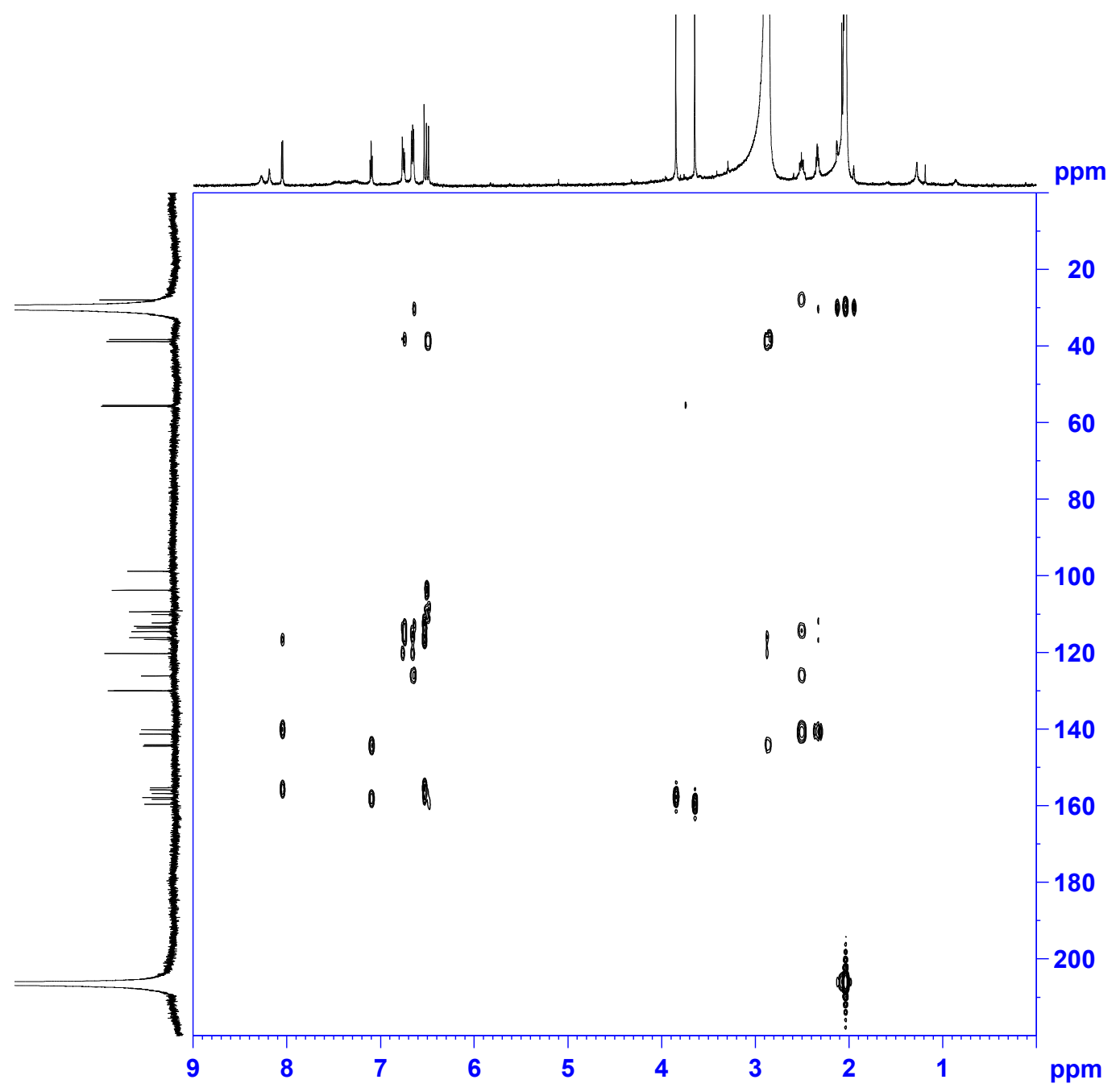


S 25 UV spectrum of the new compound 3

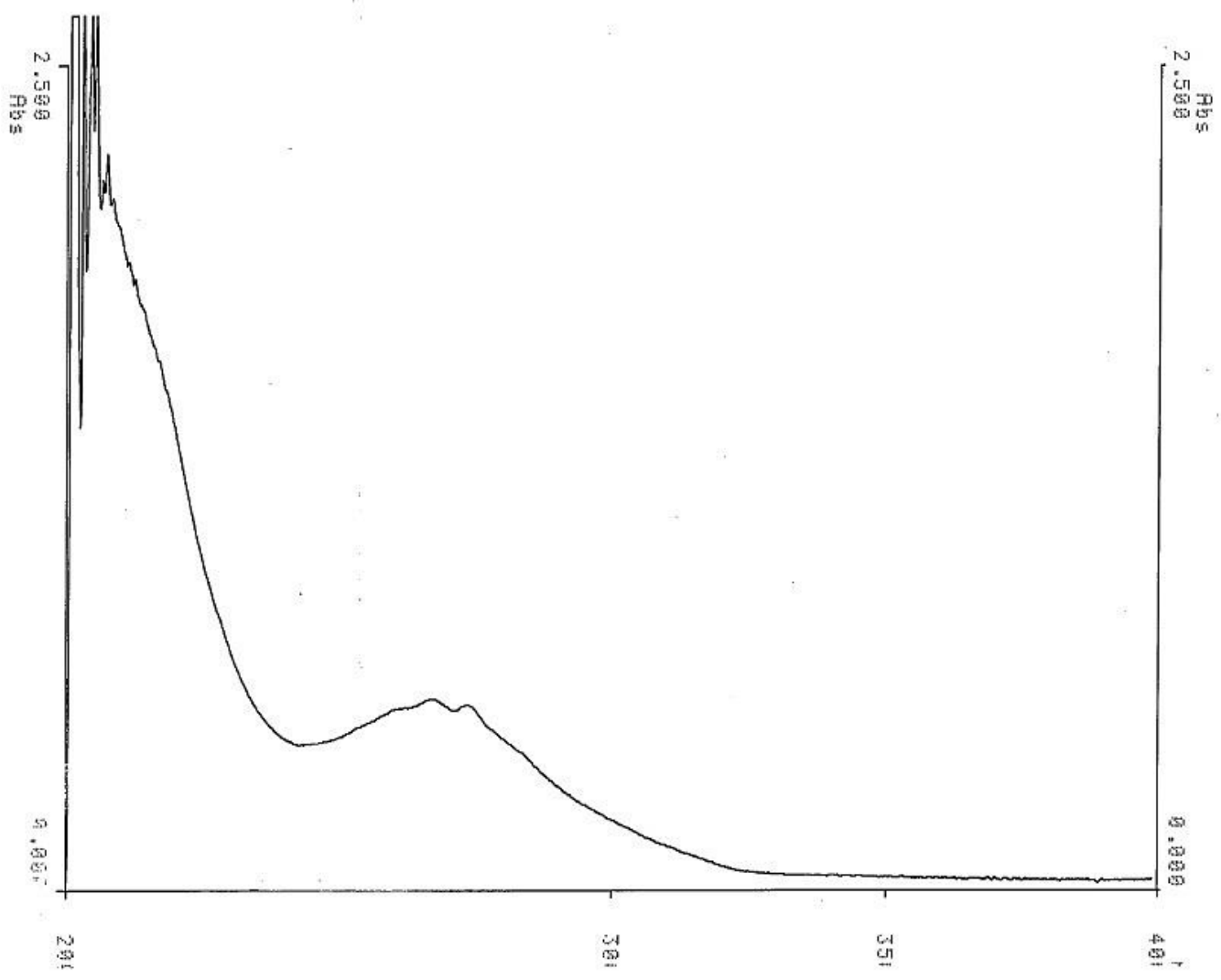




\section{S 26 IR spectrum of the new compound 3}

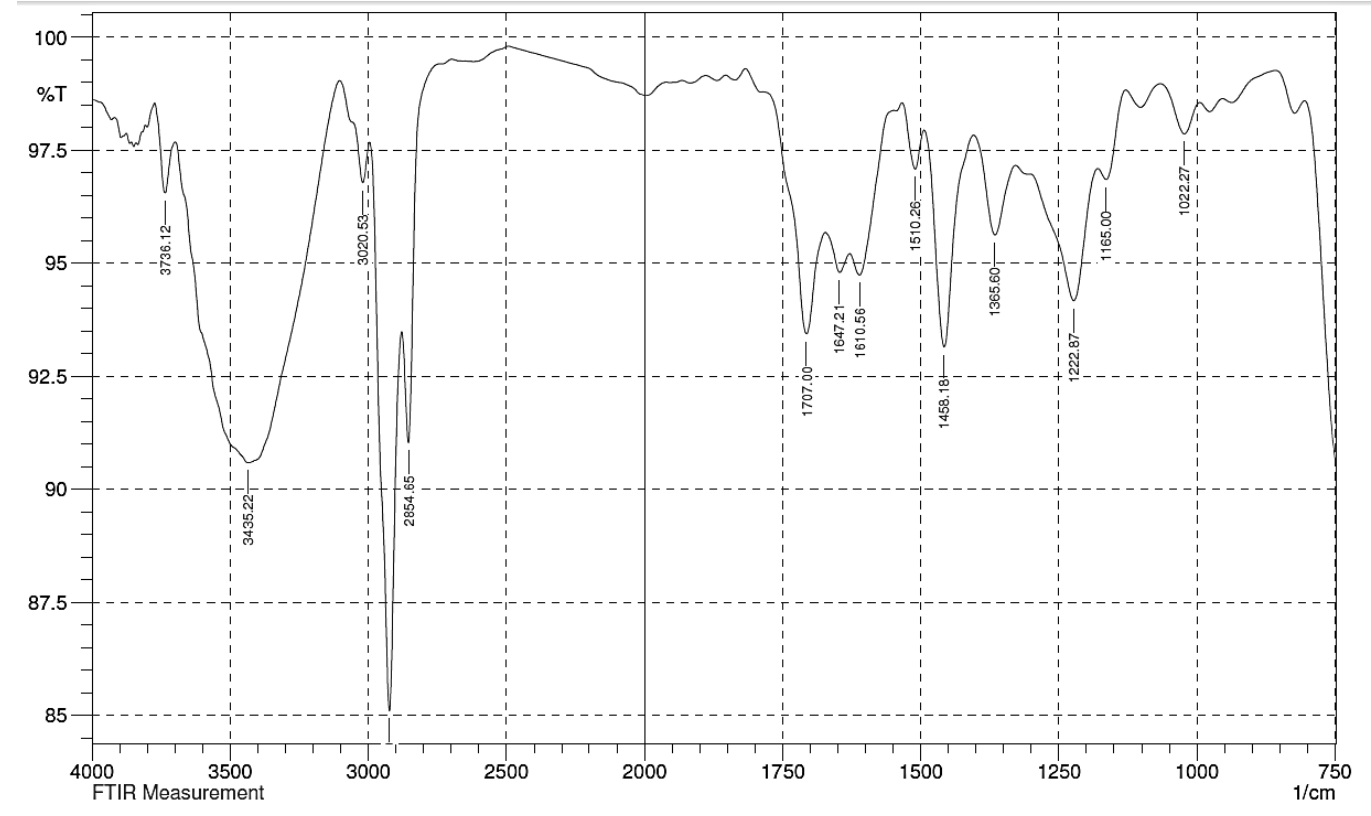


S 27 HRESIMS spectrum of the new compound 3

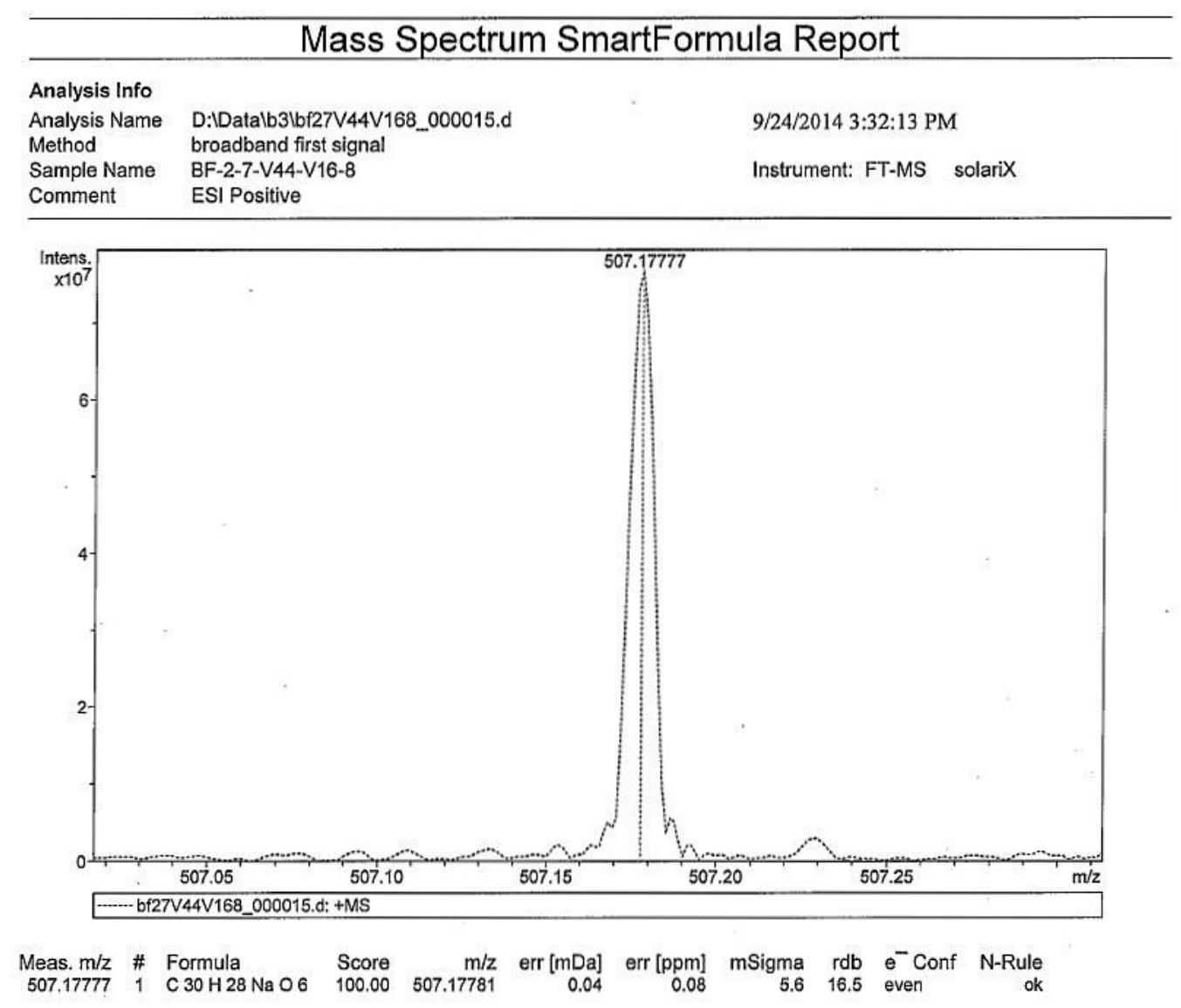


S 28 ECD spectrum of the new compound 3

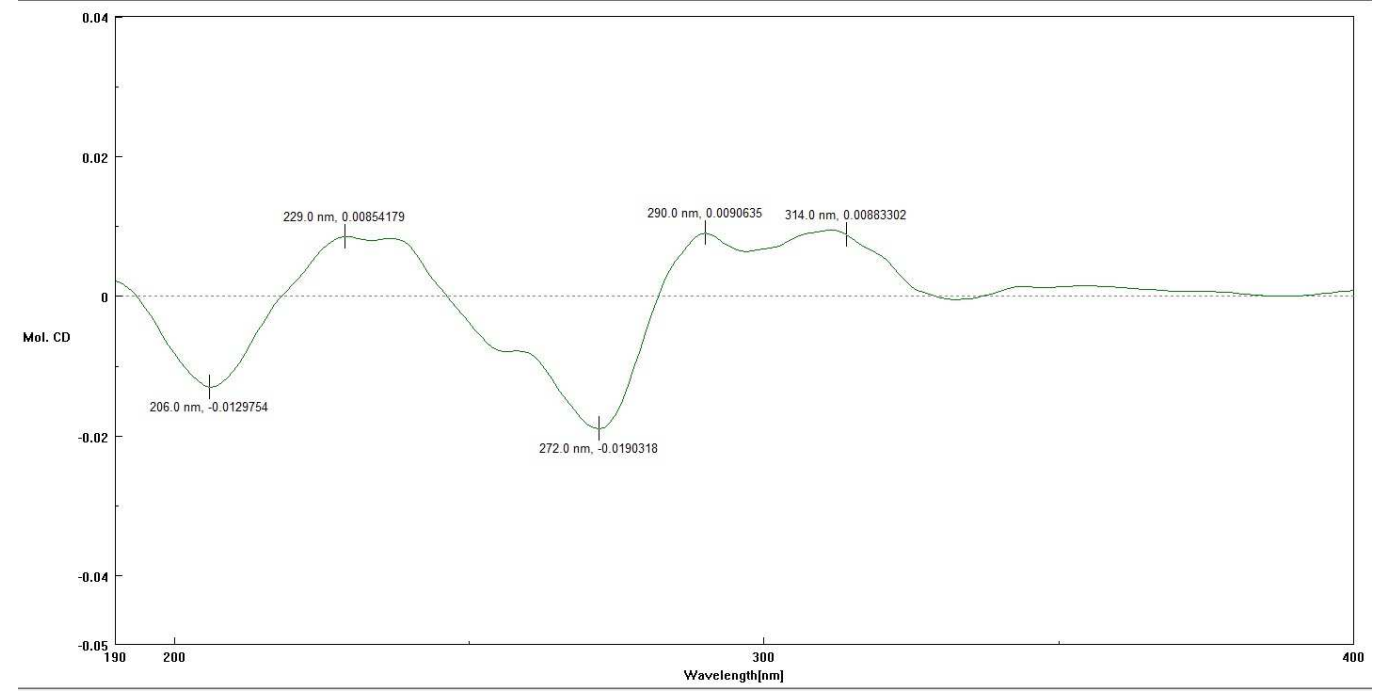


S $29{ }^{1} \mathrm{H}$ NMR (400 MHz, Acetone- $d_{6}$ ) spectrum of the new compound 4

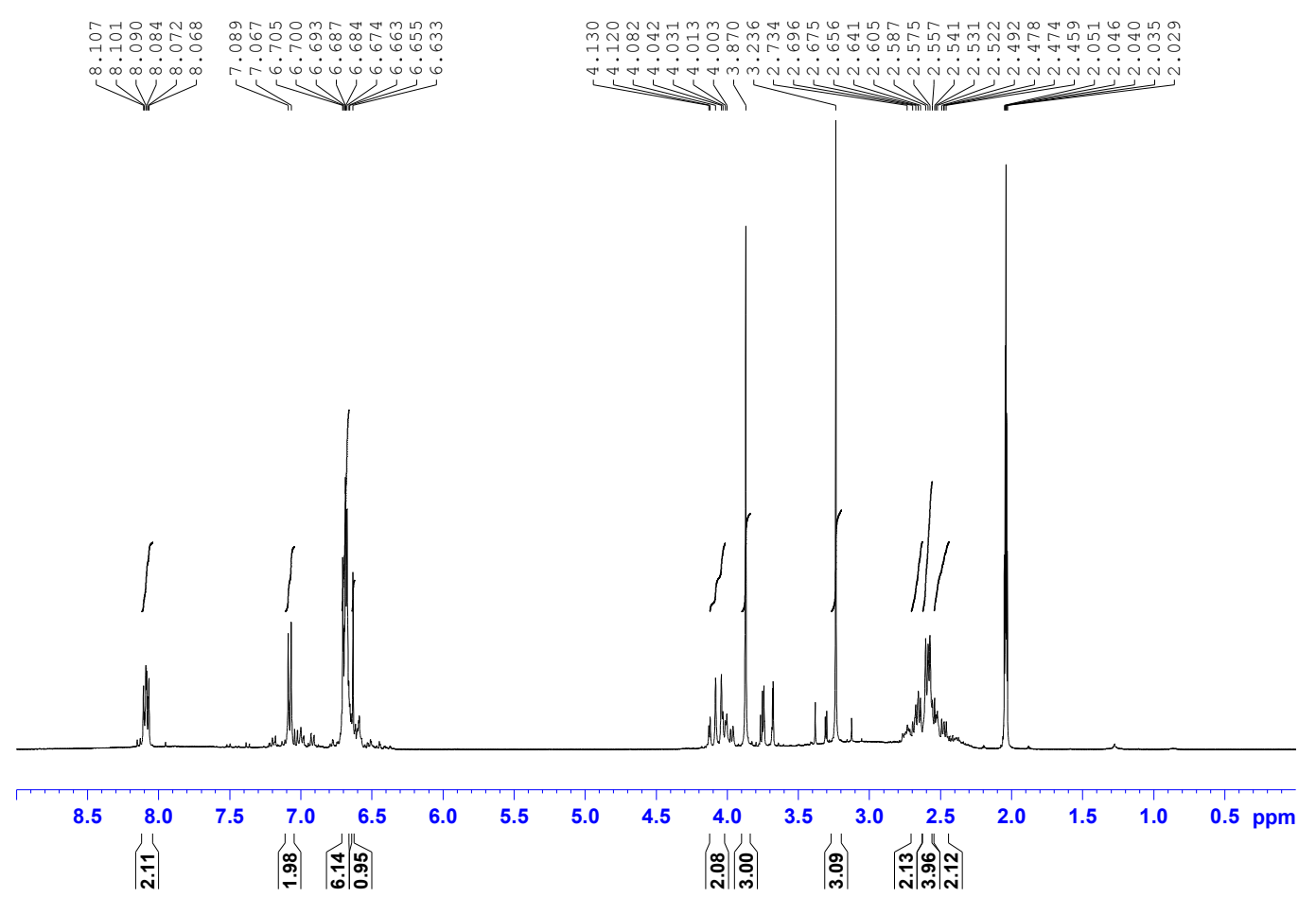


S $30{ }^{13} \mathrm{C}$ NMR (100 MHz, Acetone- $d_{6}$ ) spectrum of the new compound 4

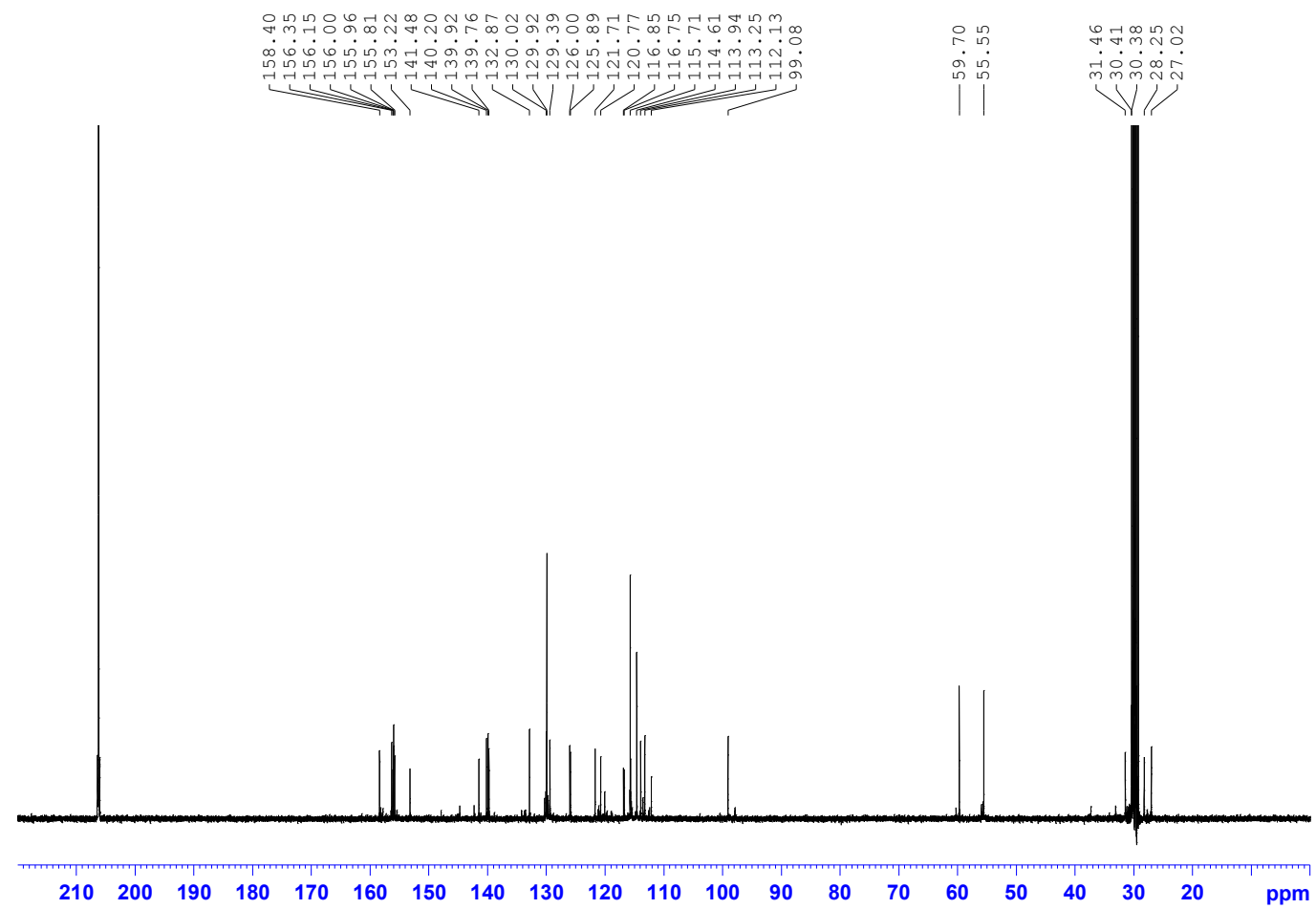


S 31 COSY spectrum of the new compound 4

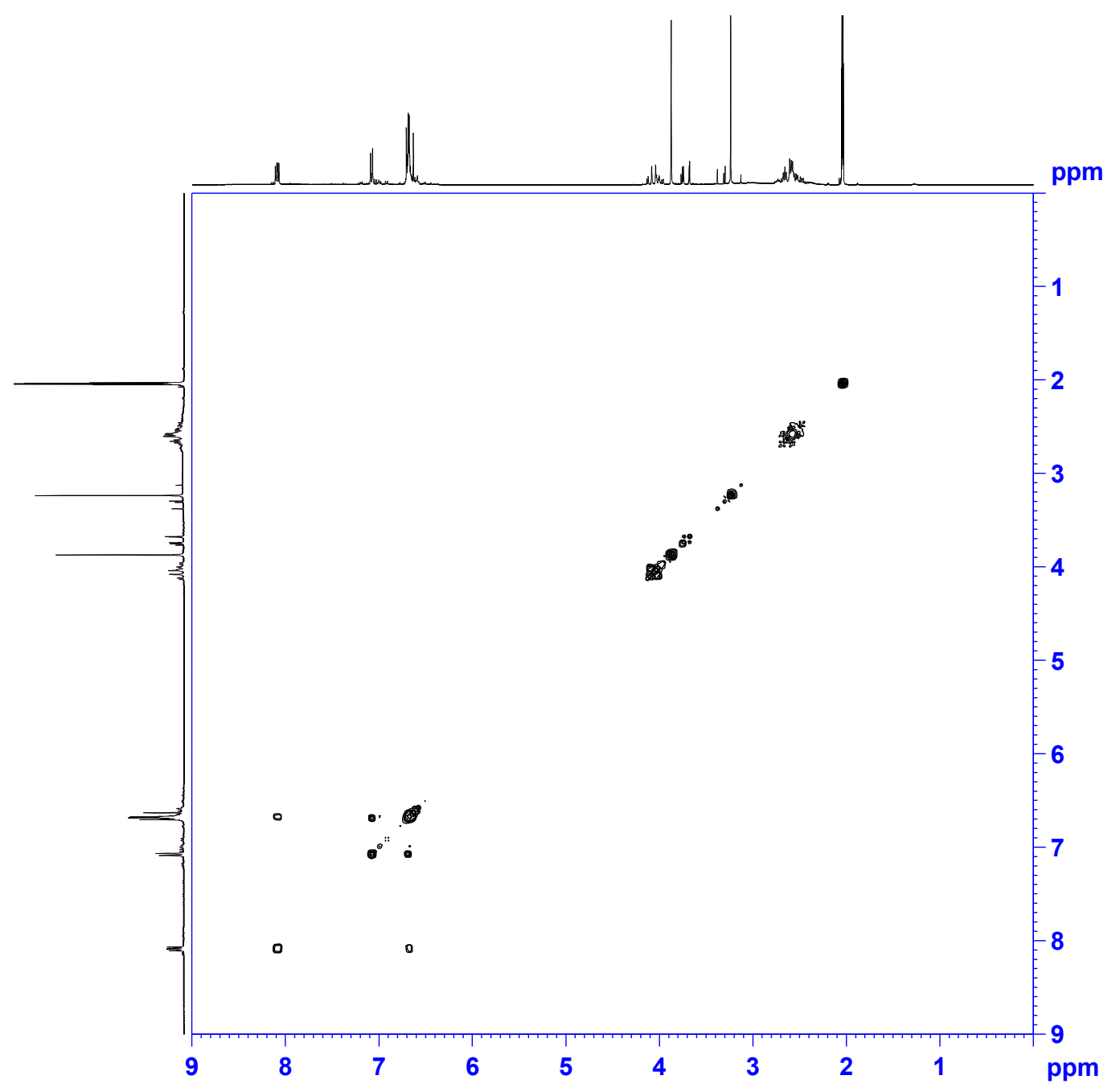


S 32 NOESY spectrum of the new compound 4

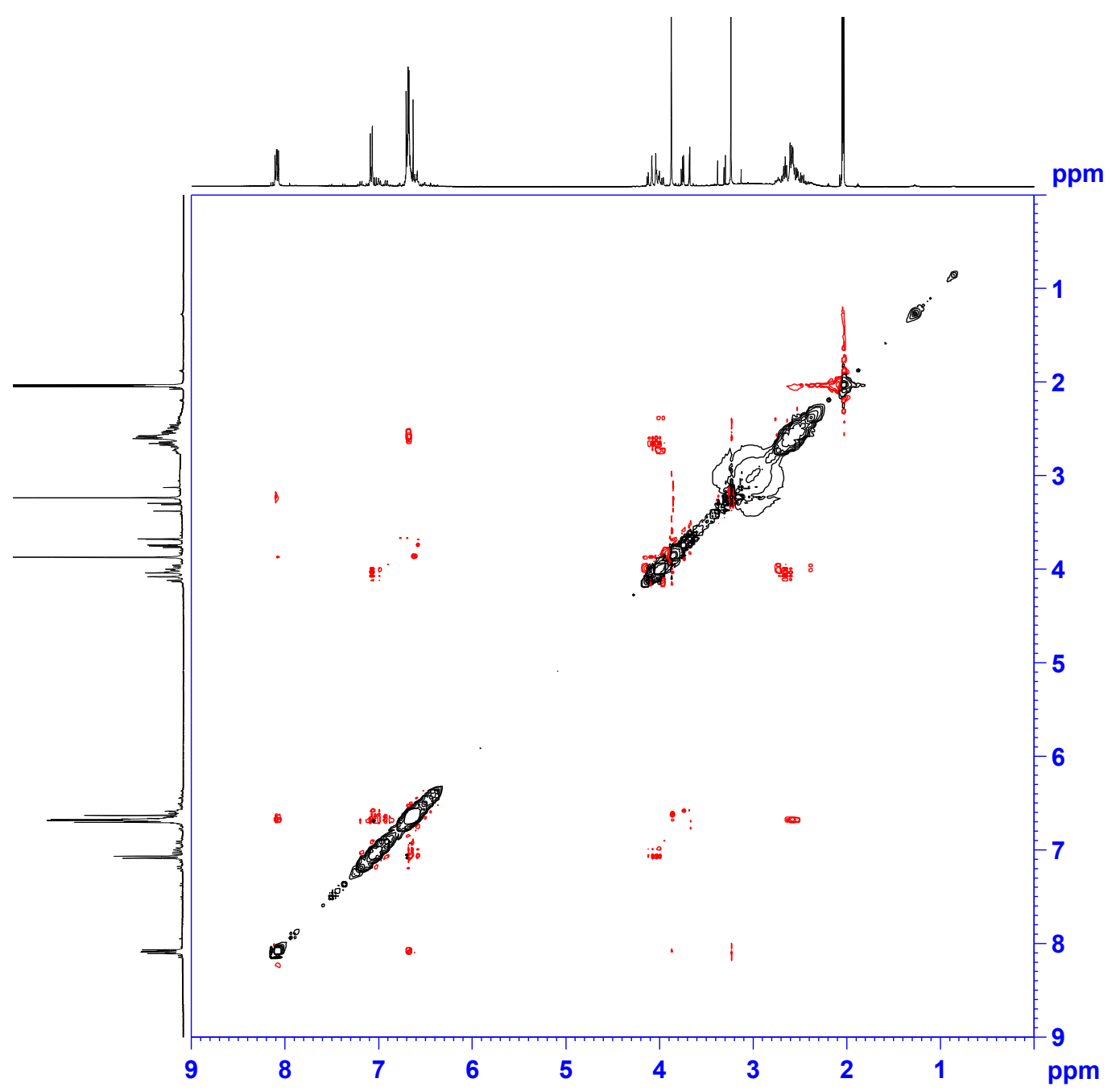


S 33 HSQC spectrum of the new compound 4

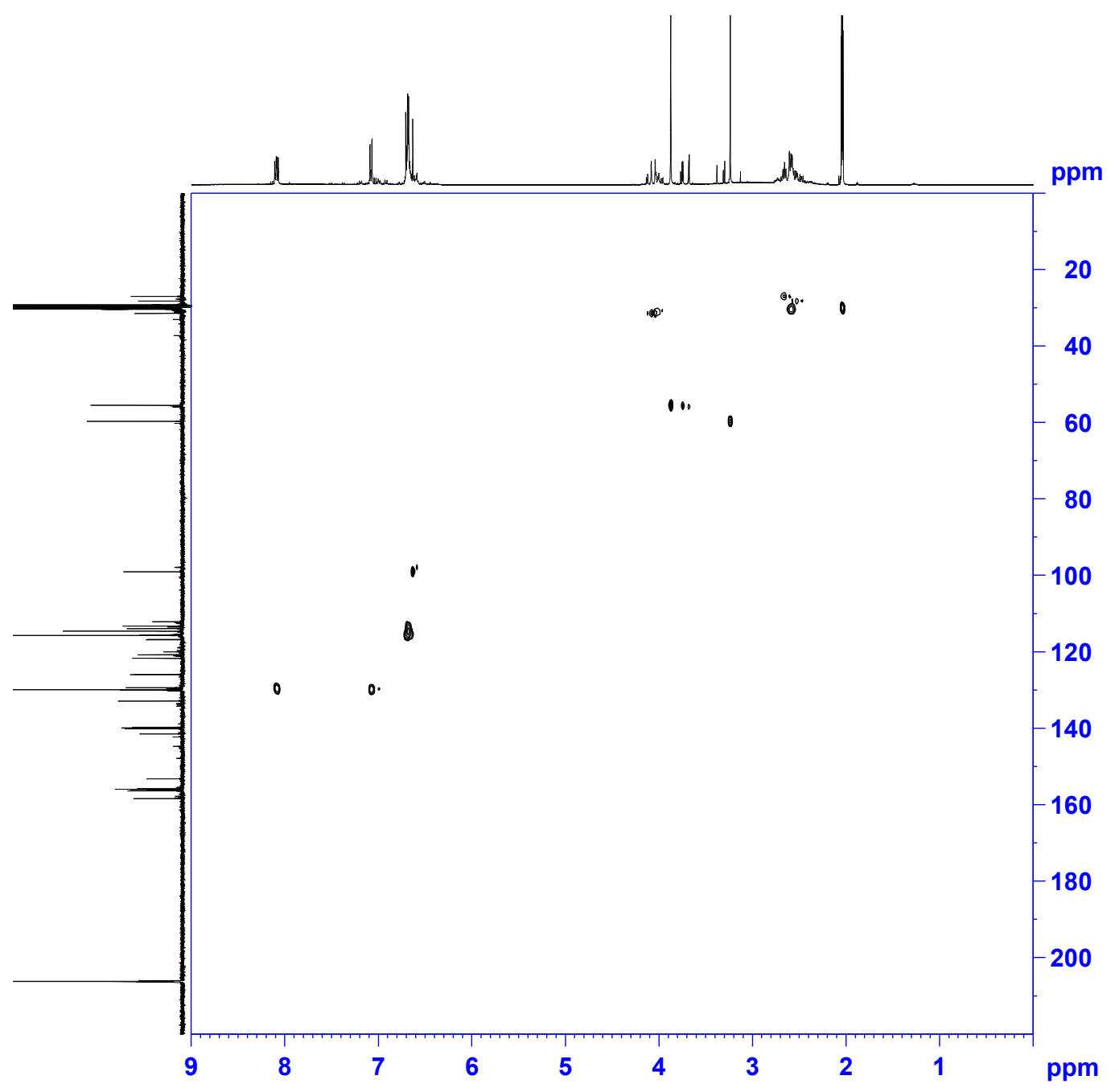


S 34 HMBC spectrum of the new compound 4

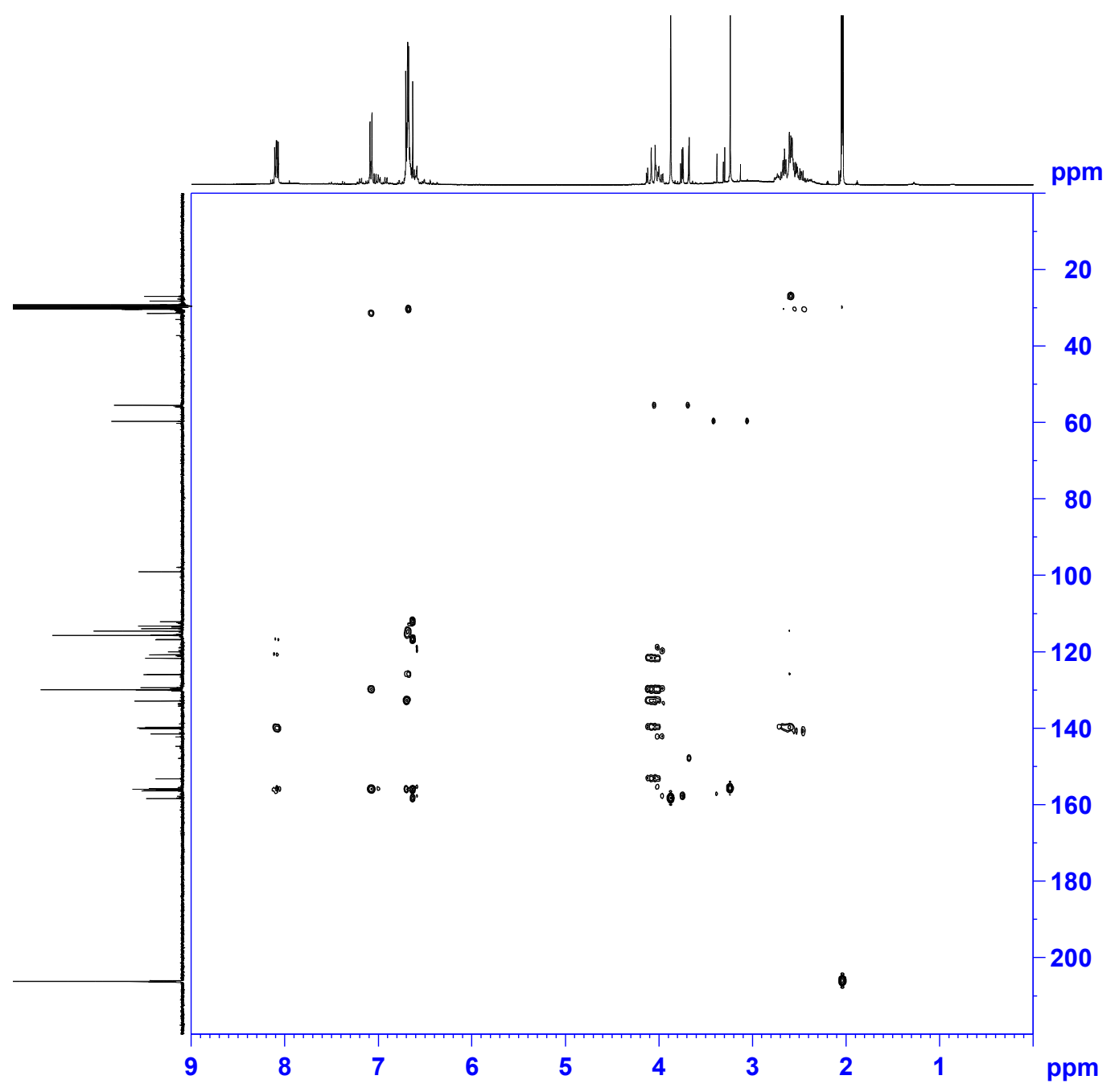


S 35 UV spectrum of the new compound 4

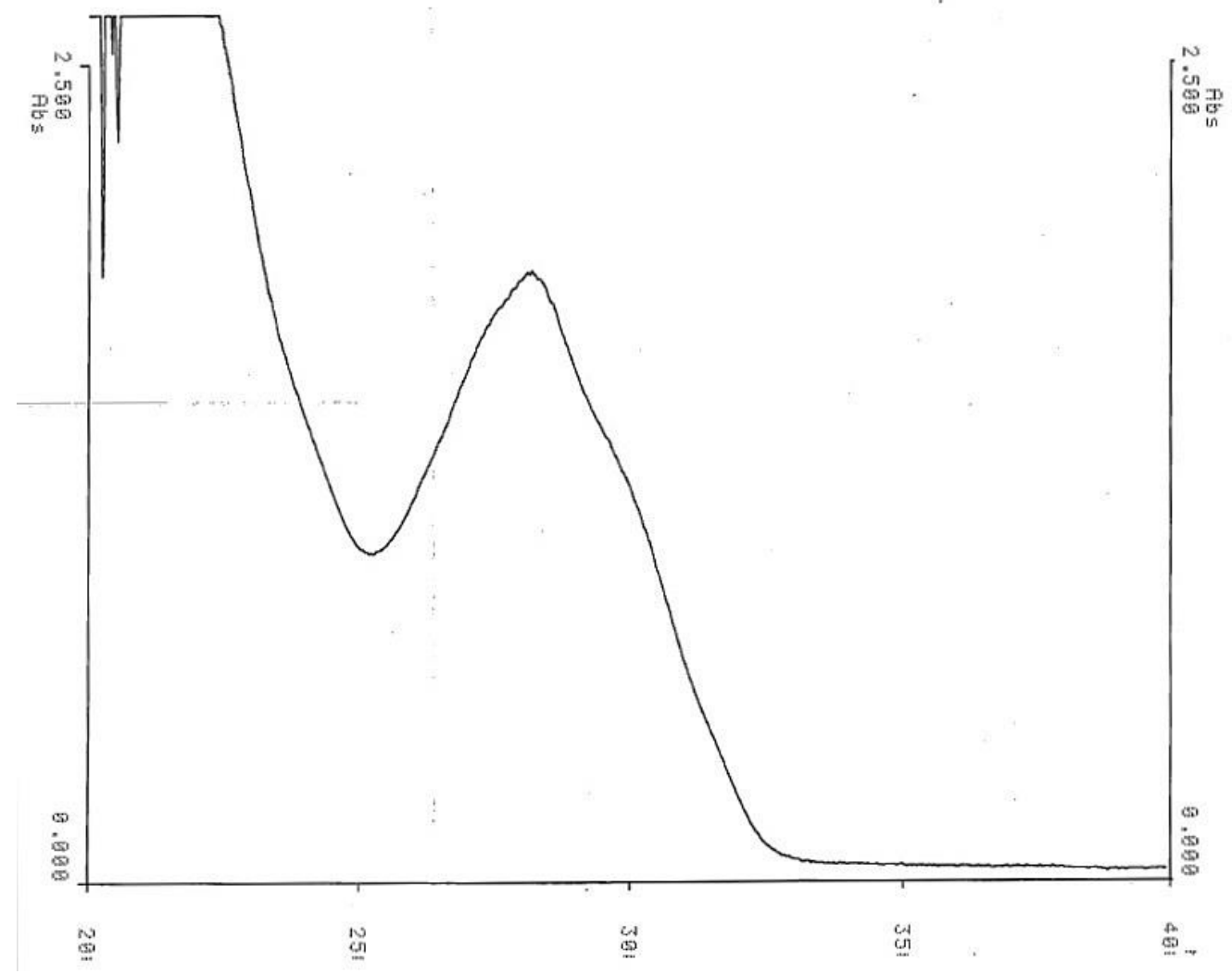




\section{S 36 IR spectrum of the new compound 4}

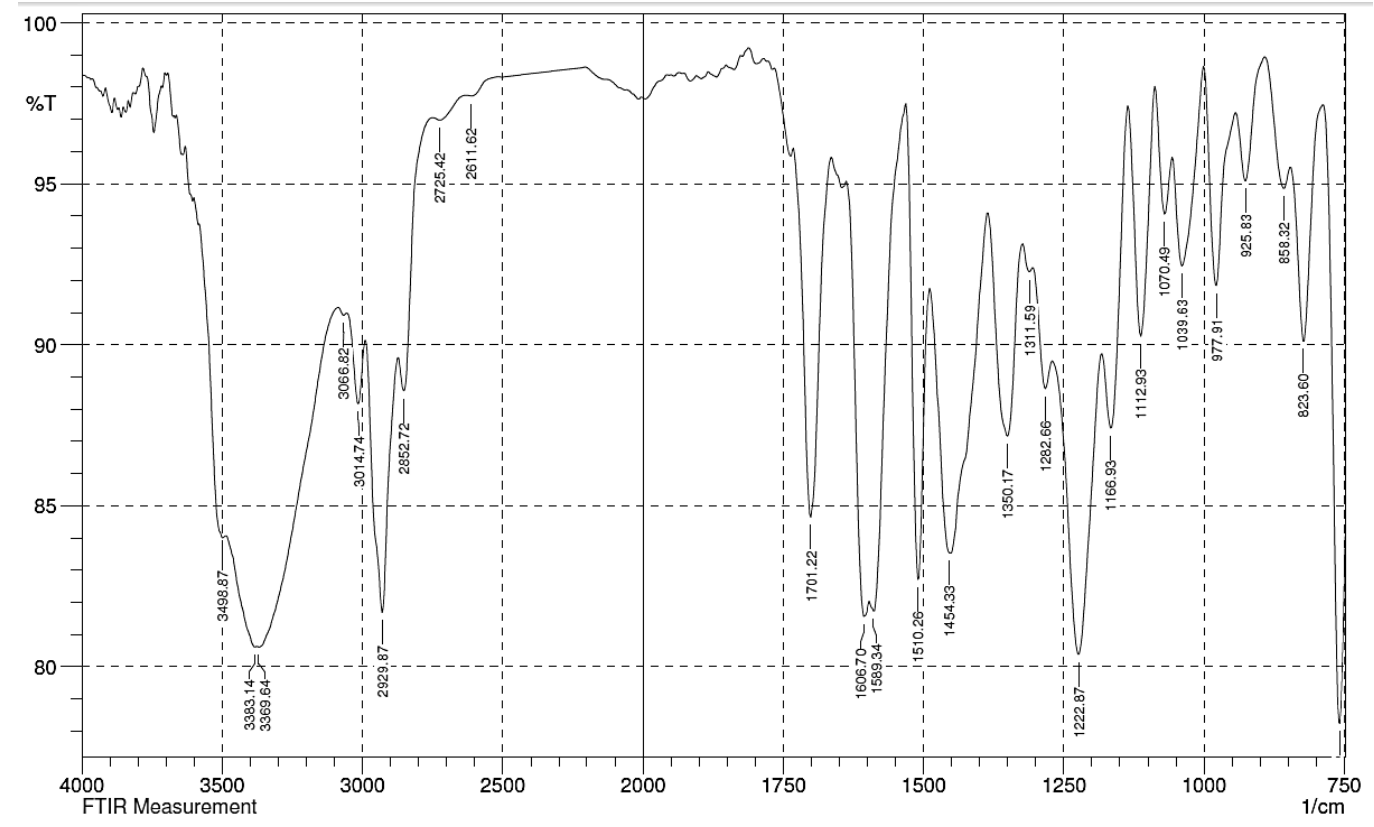


S 37 HRESIMS spectrum of the new compound 4

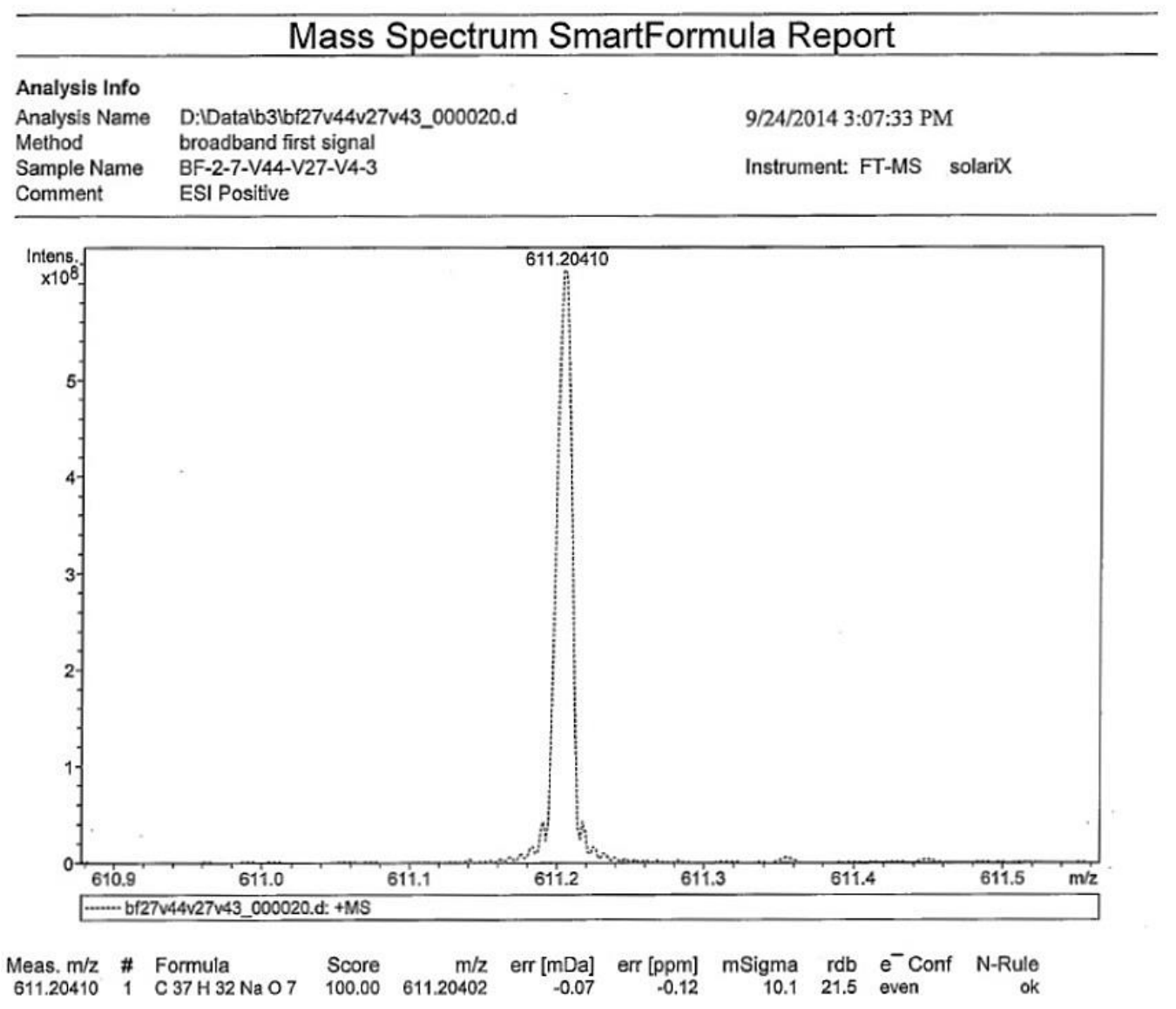


S 38 ECD spectrum of the new compound 4

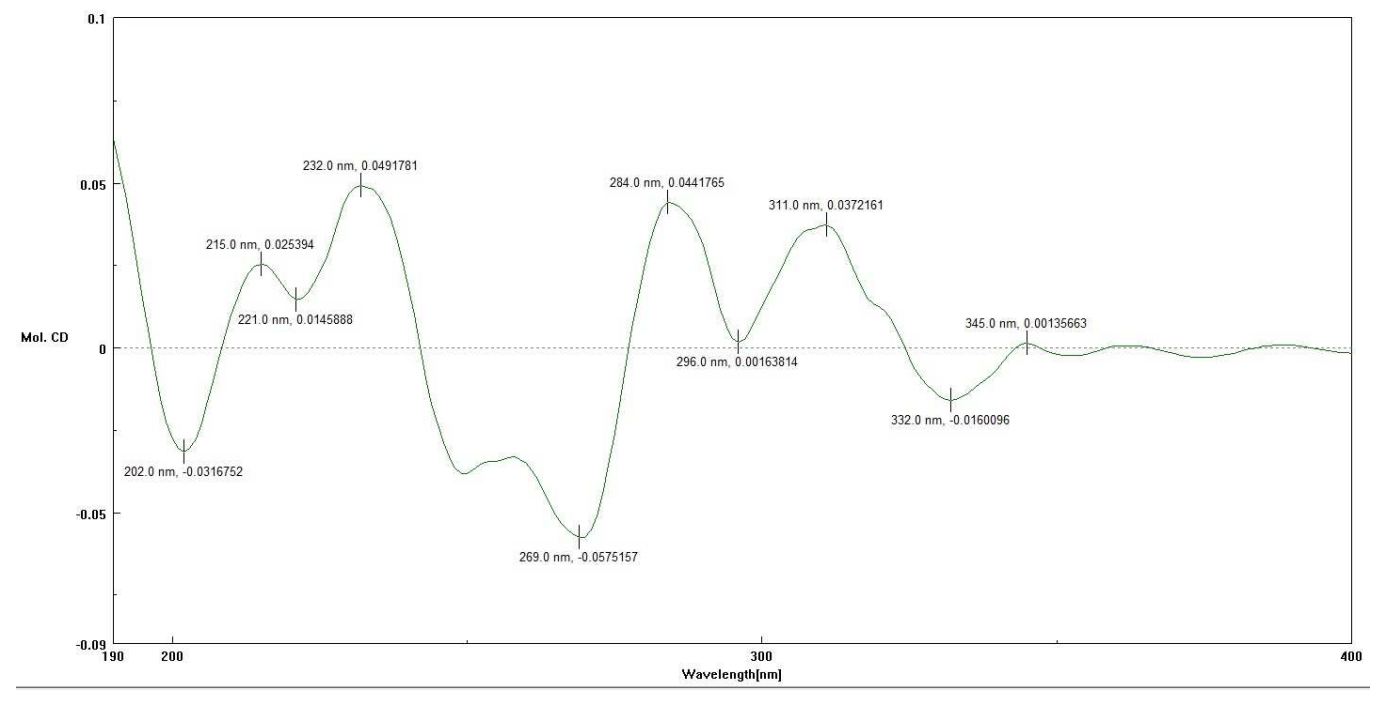


S $39{ }^{1} \mathrm{H}$ NMR (400 MHz, Acetone- $d_{6}$ ) spectrum of the new compound 5

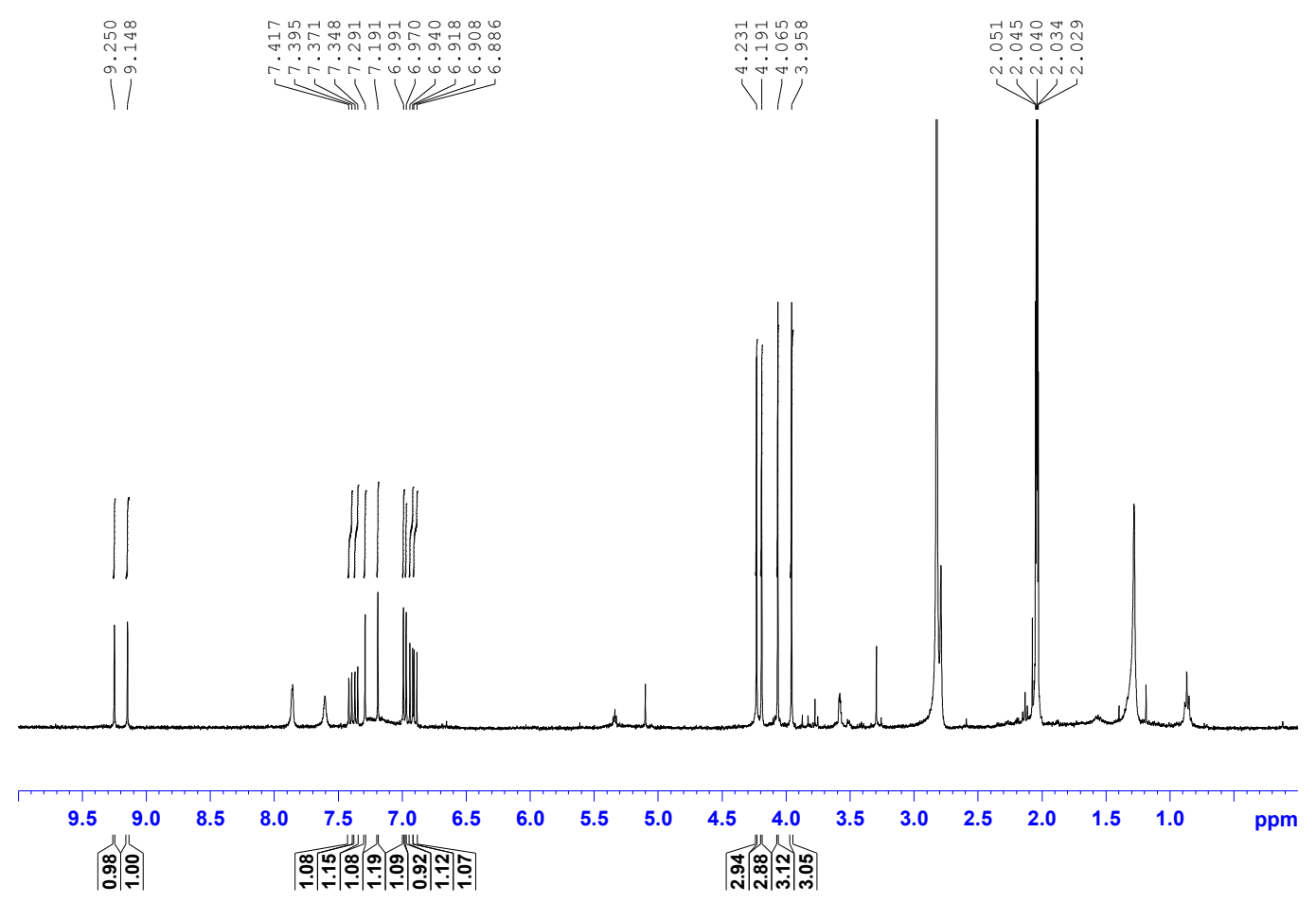


S $40{ }^{13} \mathrm{C}$ NMR (100 MHz, Acetone- $d_{6}$ ) spectrum of the new compound 5

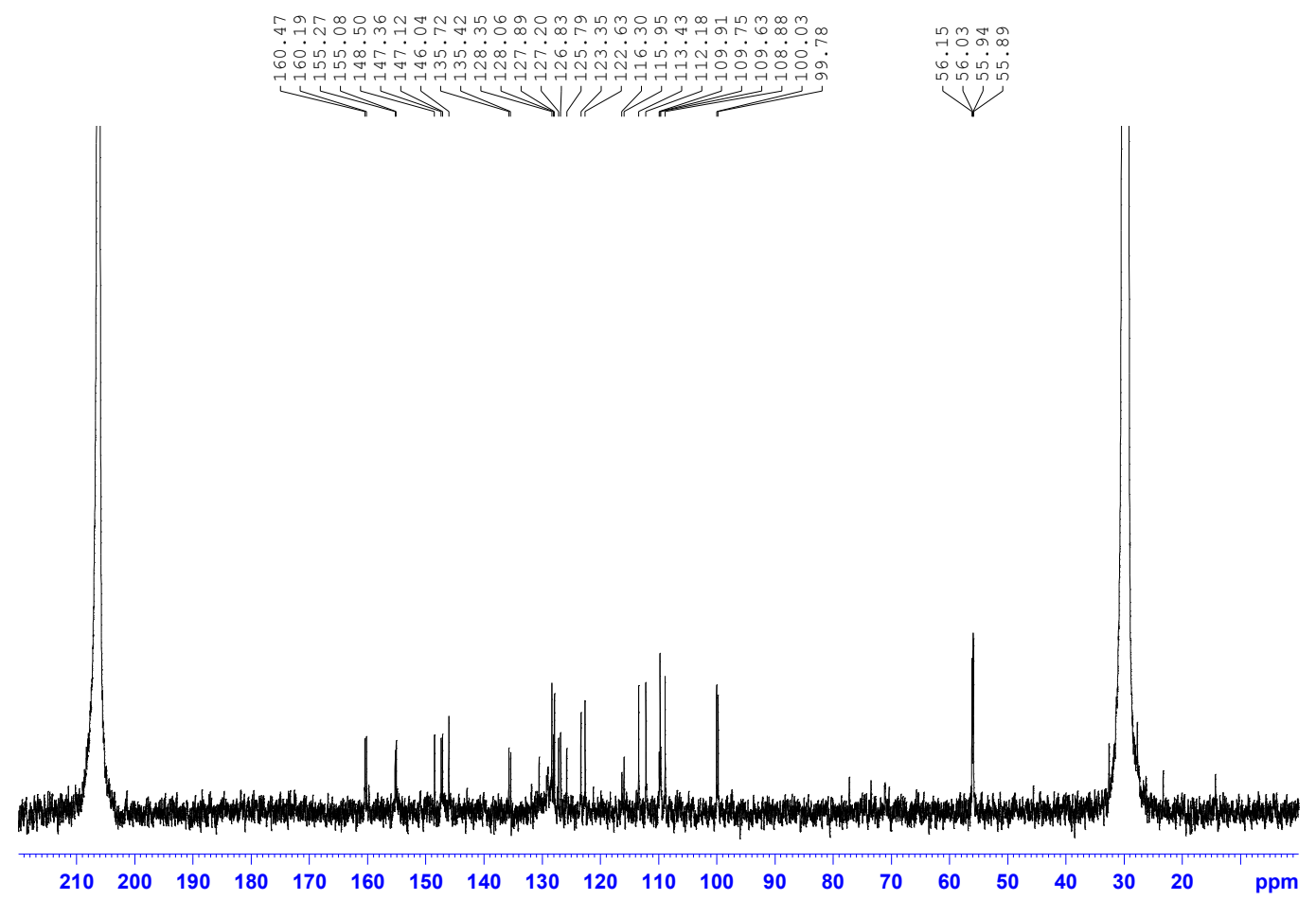


S 41 COSY spectrum of the new compound 5

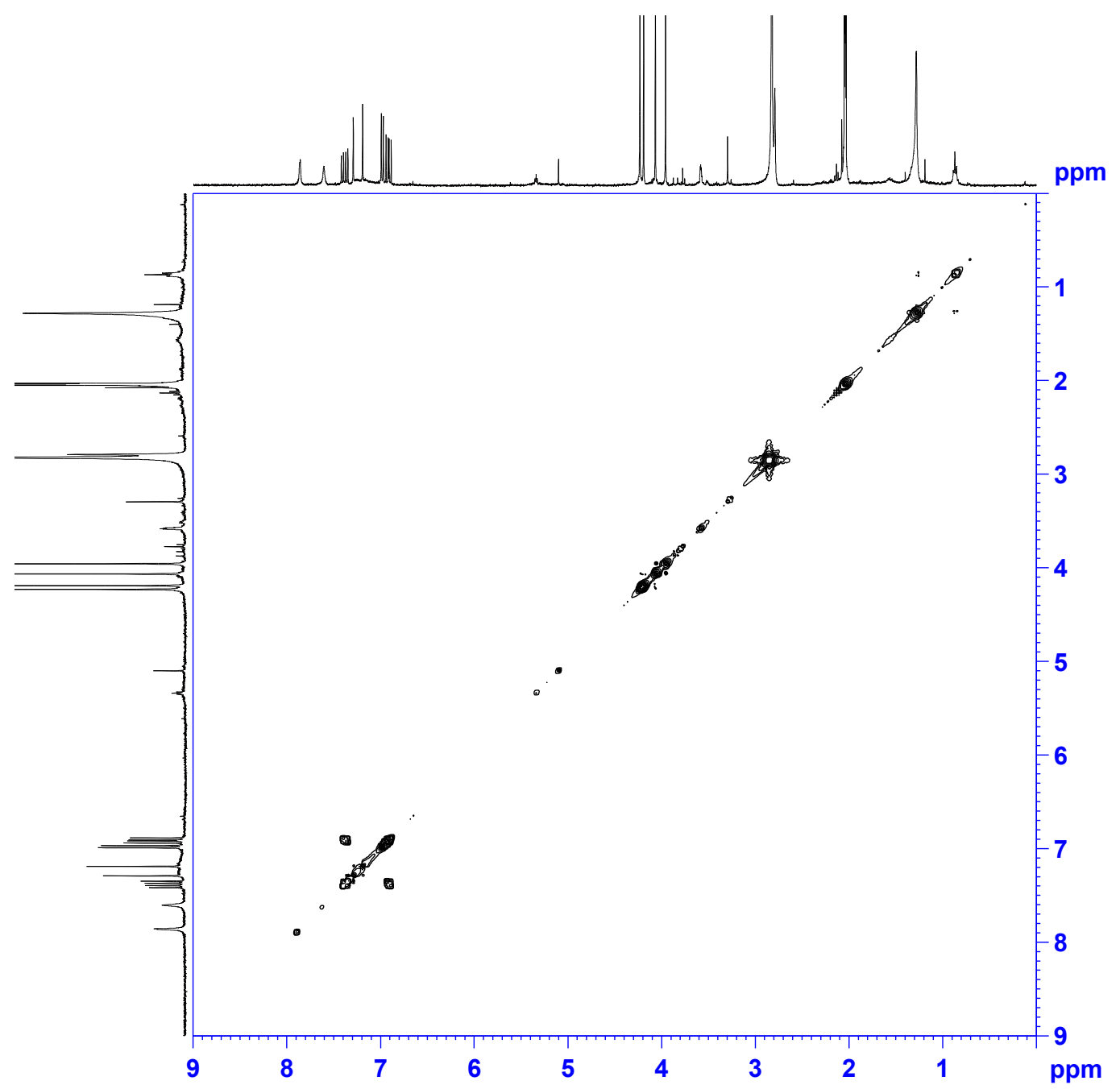


S 42 NOESY spectrum of the new compound 5

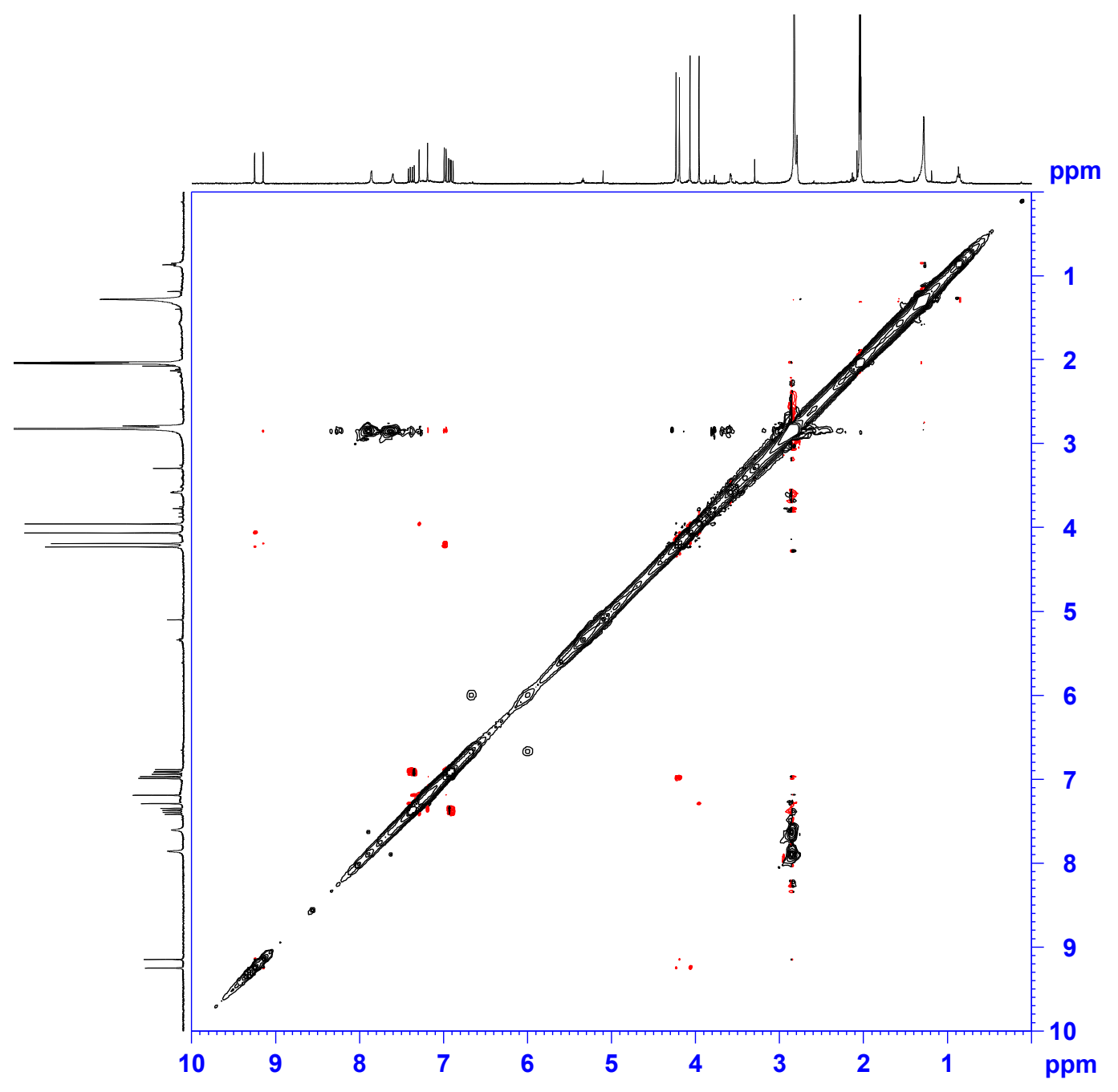


S 43 HSQC spectrum of the new compound $\mathbf{5}$

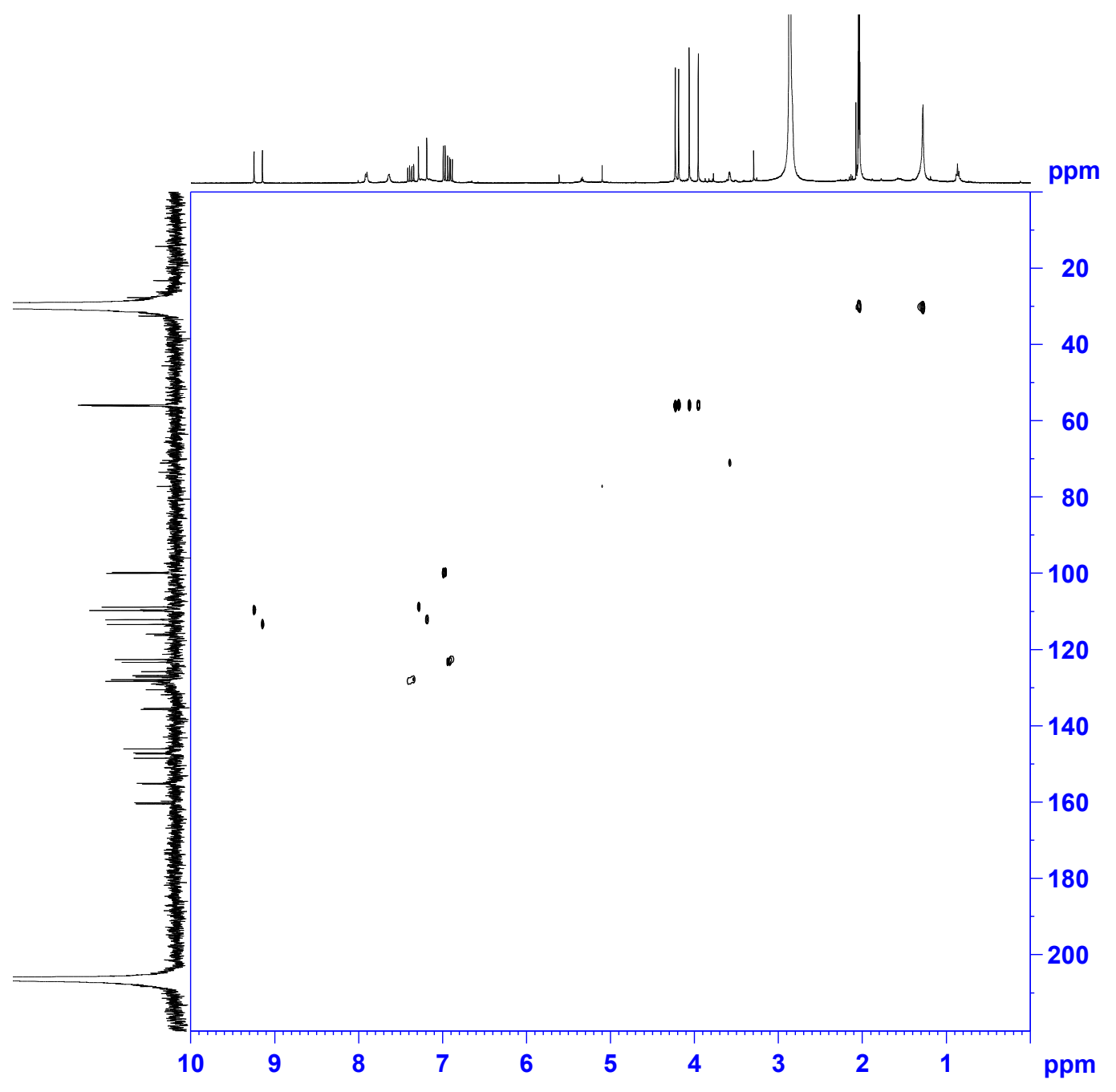


S 44 HMBC spectrum of the new compound 5

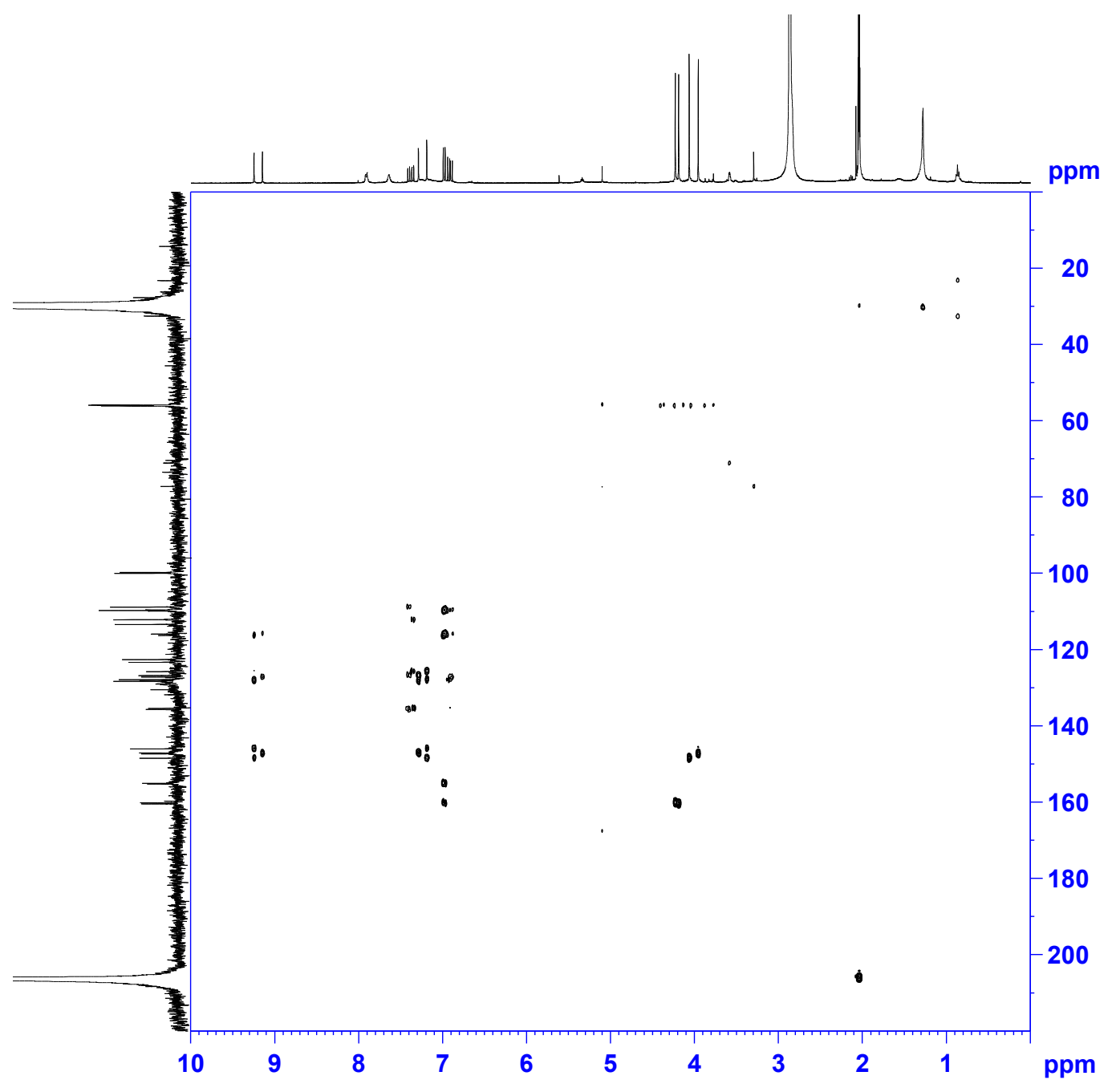


S 45 UV spectrum of the new compound 5

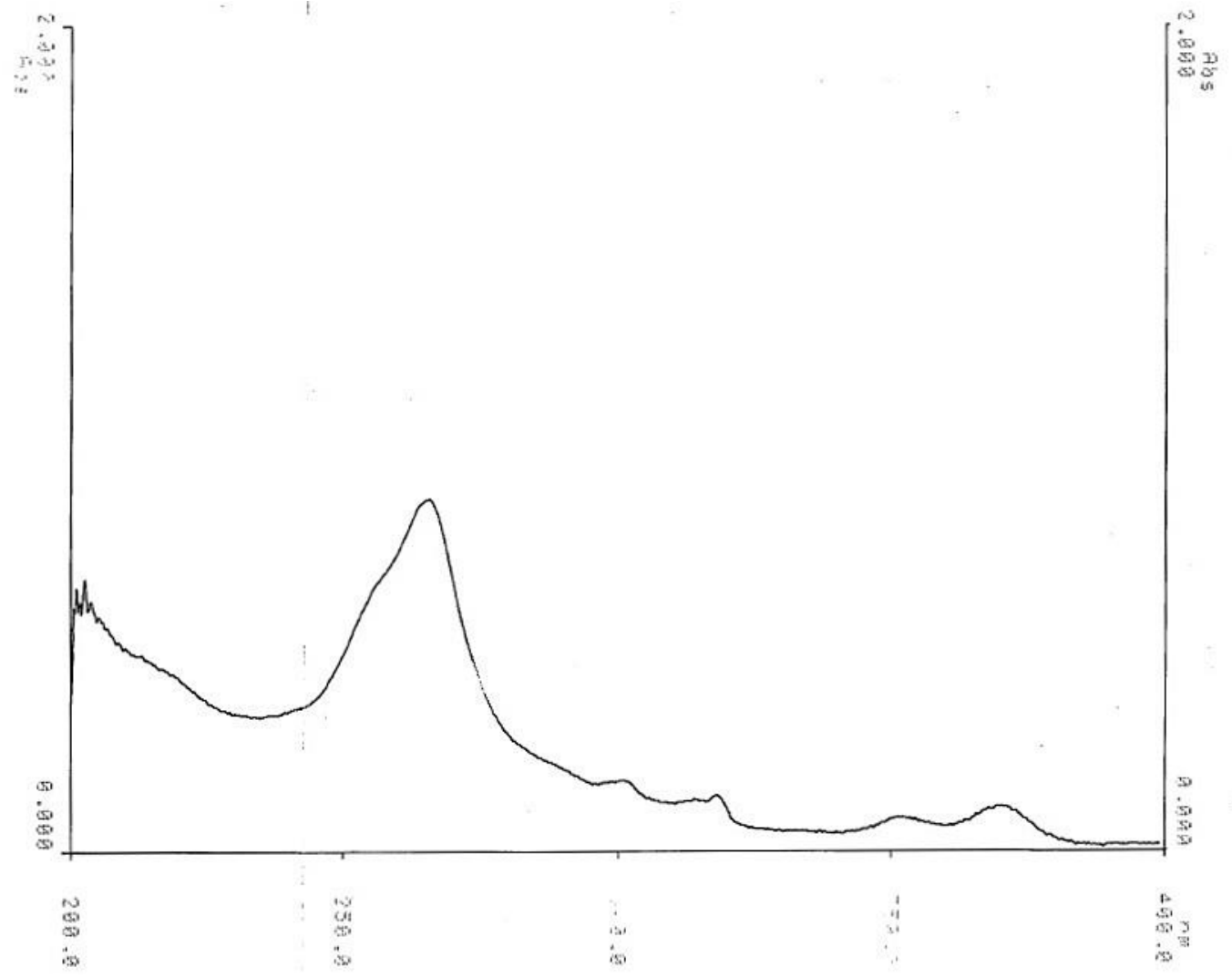


S 46 IR spectrum of the new compound 5

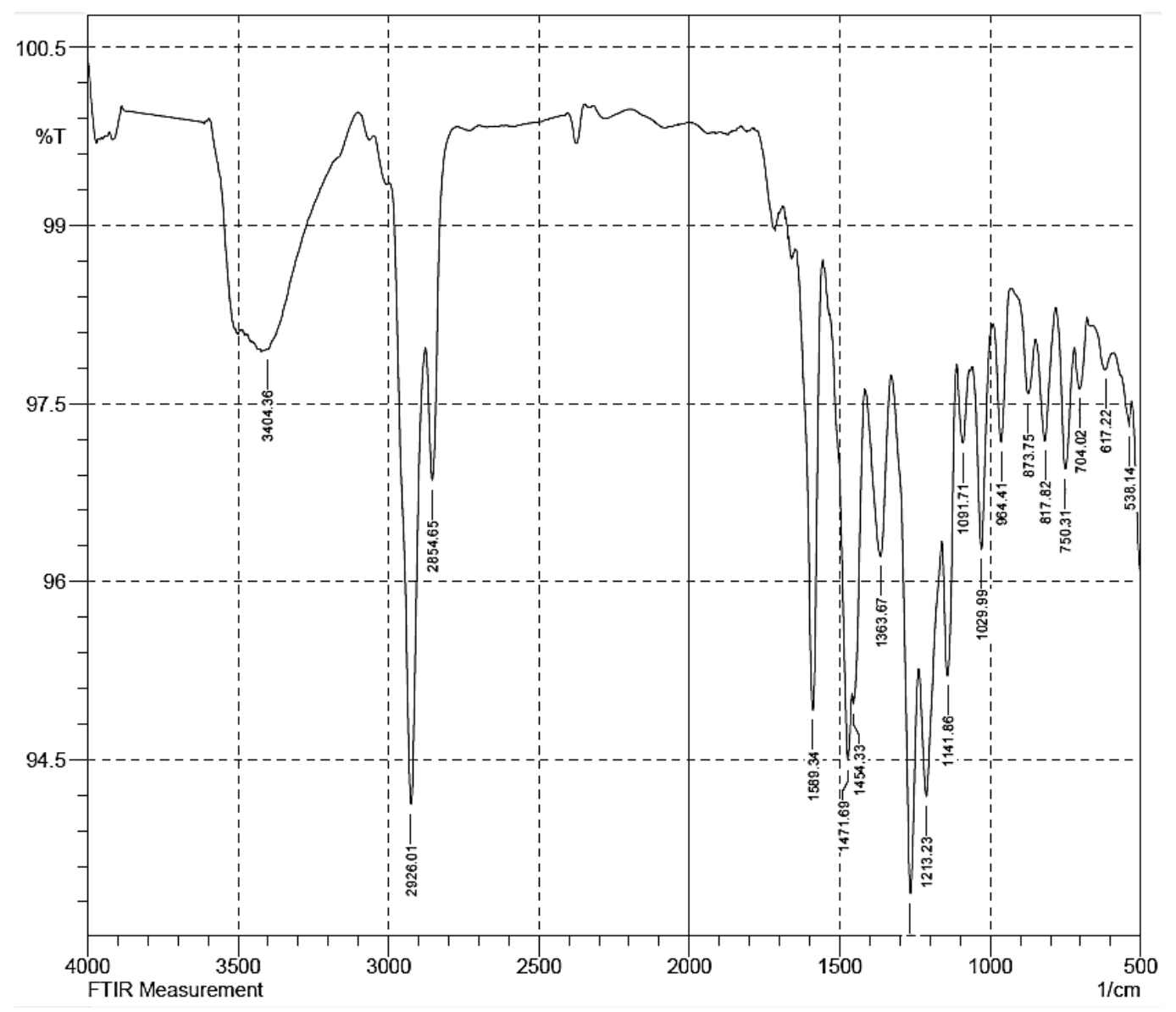




\section{S 47 HRESIMS spectrum of the new compound $\mathbf{5}$}

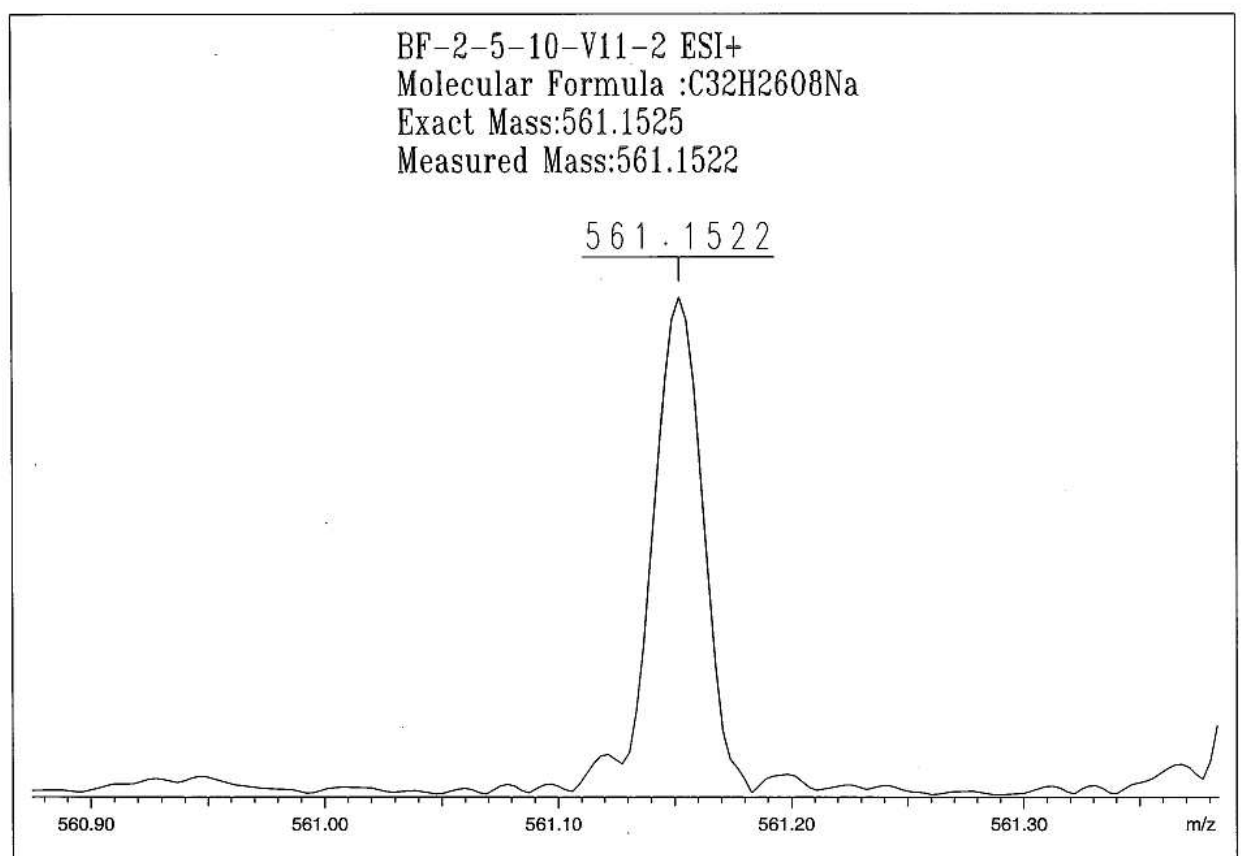


S 48 ECD spectrum of the new compound 5

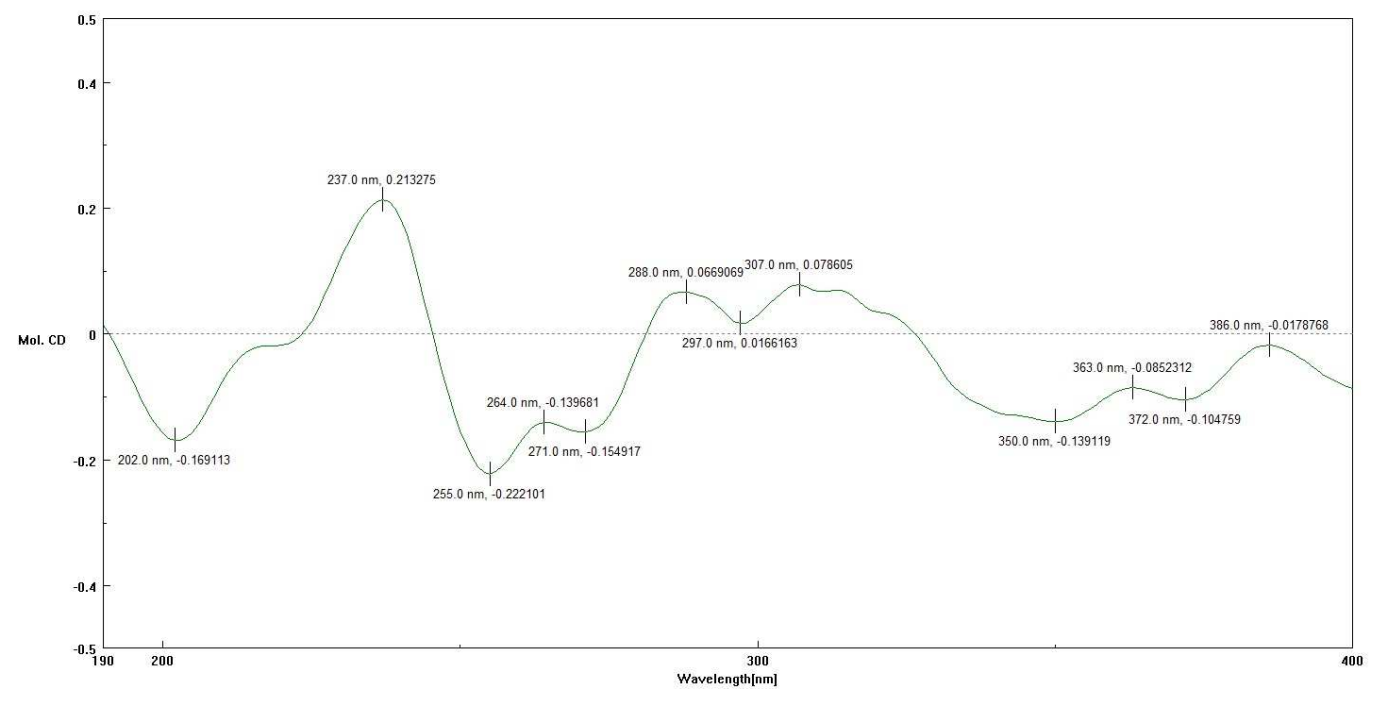


S $49{ }^{1} \mathrm{H}$ NMR (400 MHz, Acetone- $d_{6}$ ) spectrum of the new compound 6

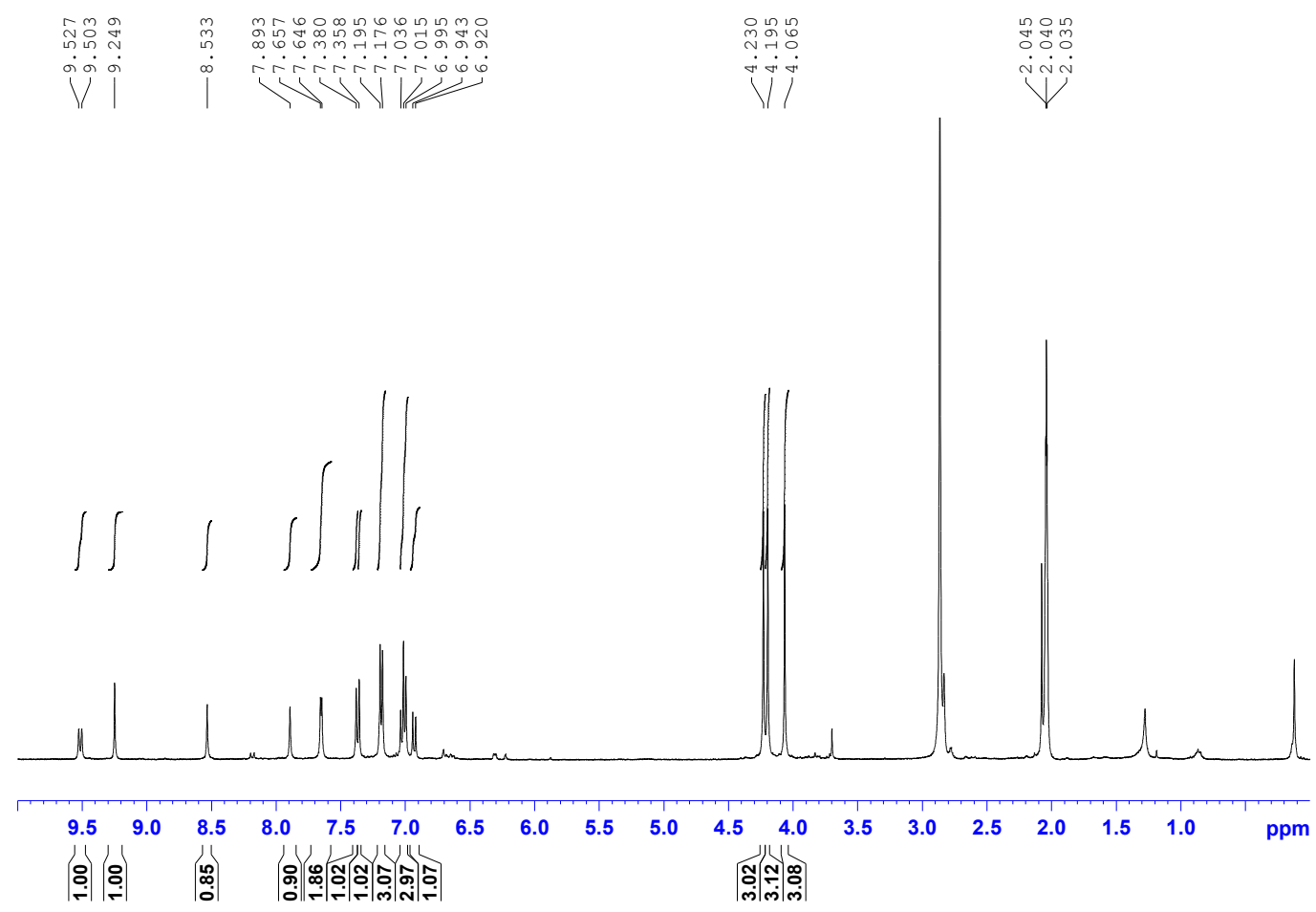


S $50{ }^{13} \mathrm{C}$ NMR (100 MHz, Acetone- $d_{6}$ ) spectrum of the new compound 6

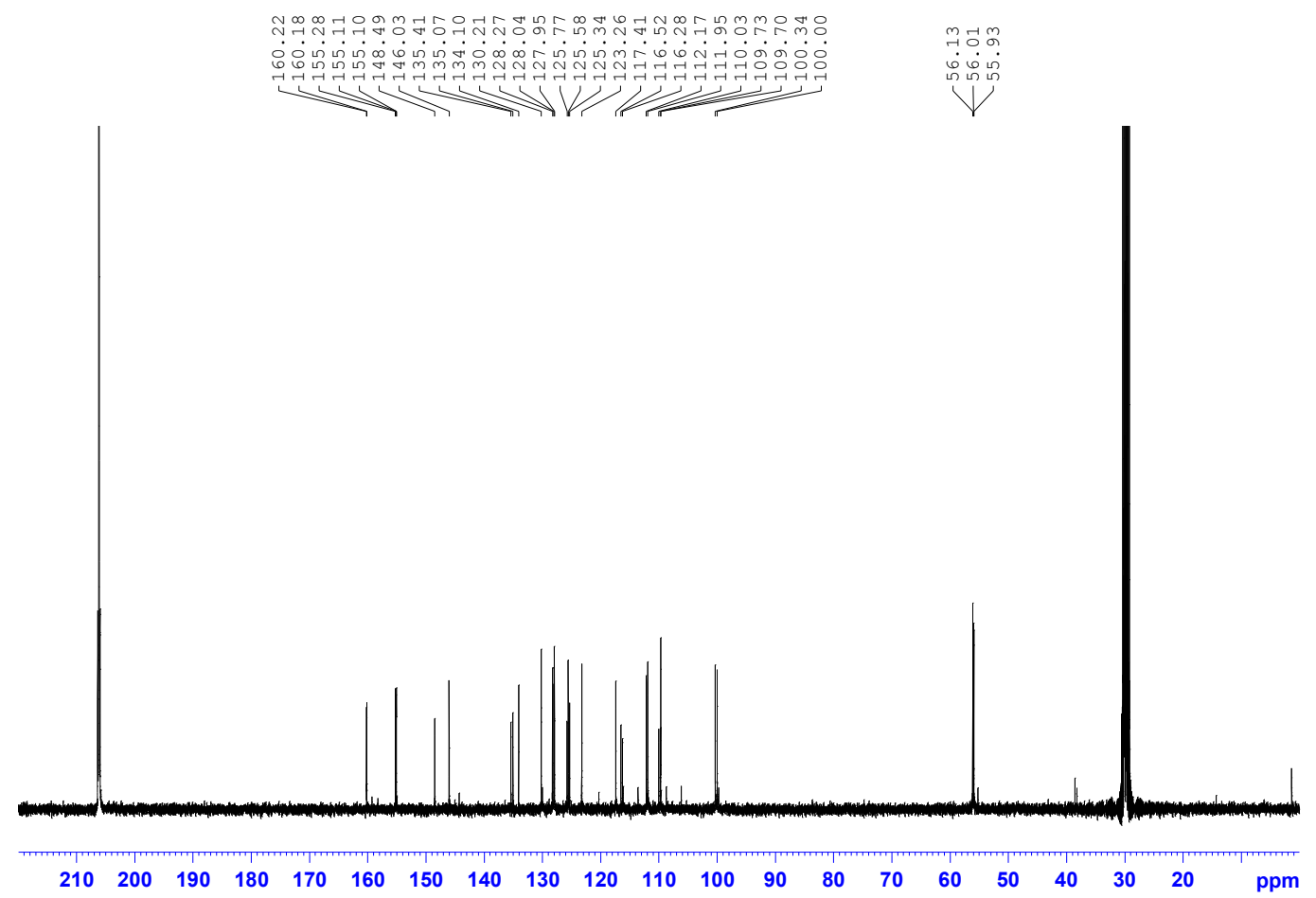


S 51 COSY spectrum of the new compound 6

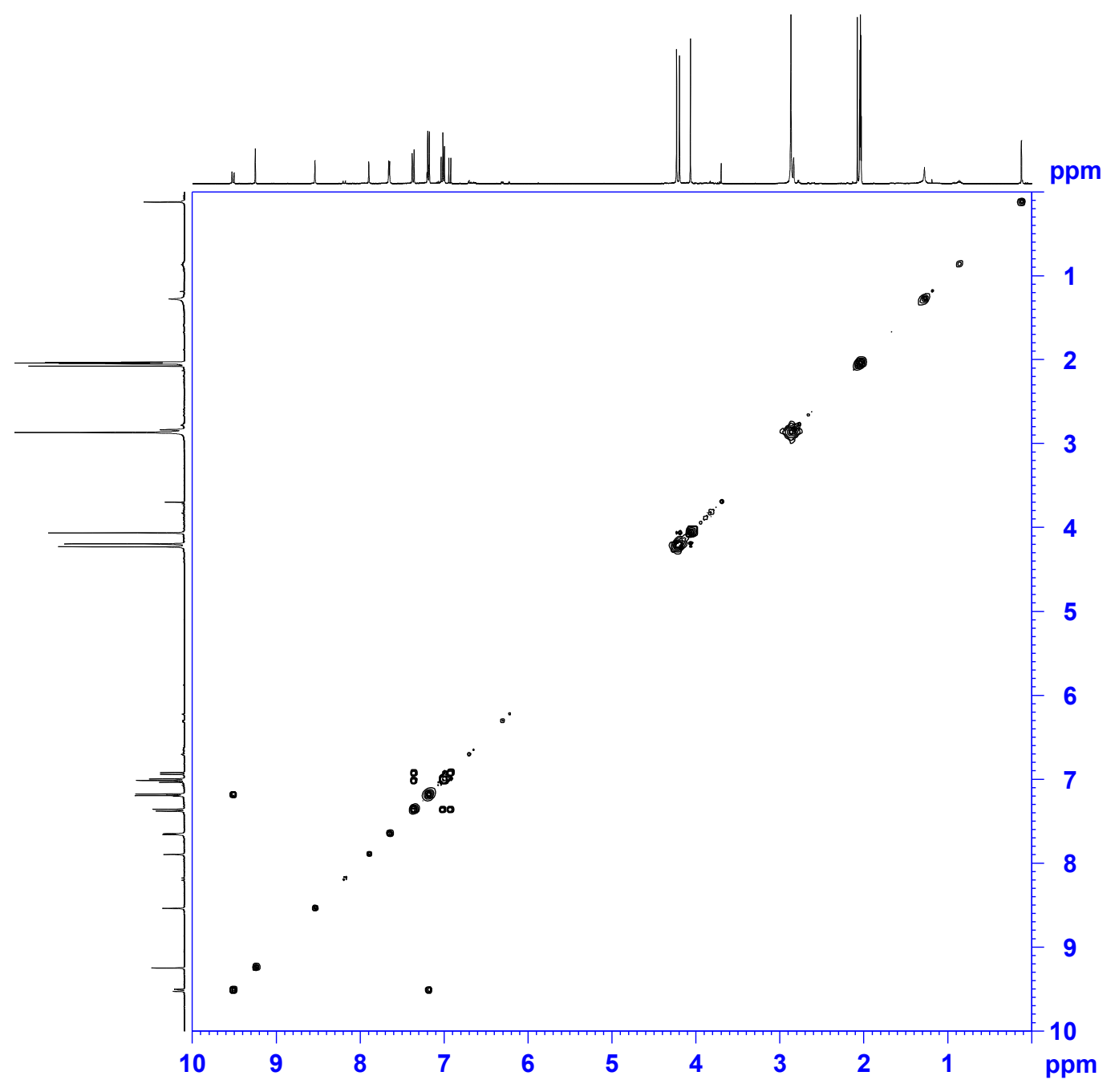


S 52 NOESY spectrum of the new compound 6

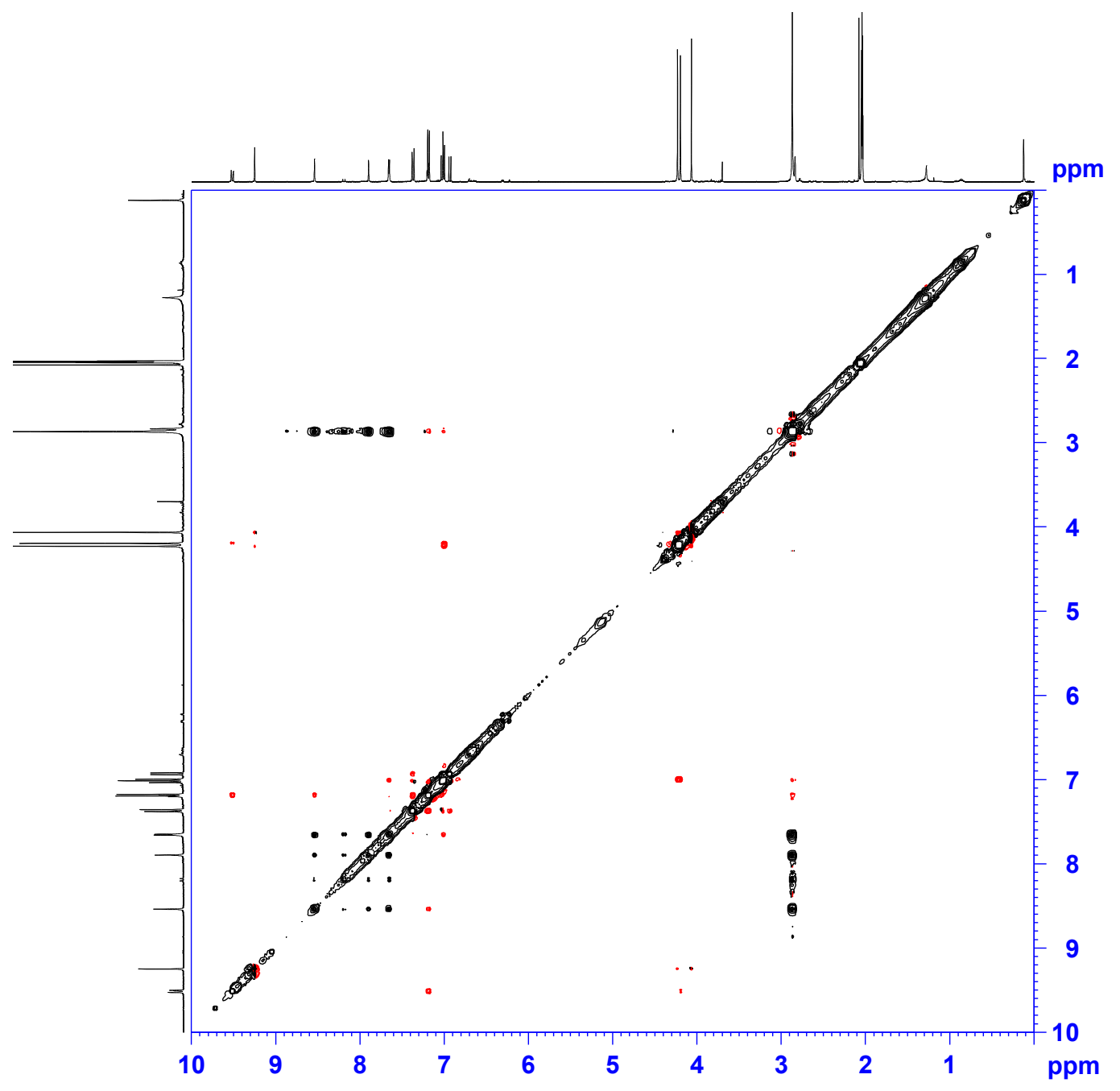


S 53 HSQC spectrum of the new compound $\mathbf{6}$

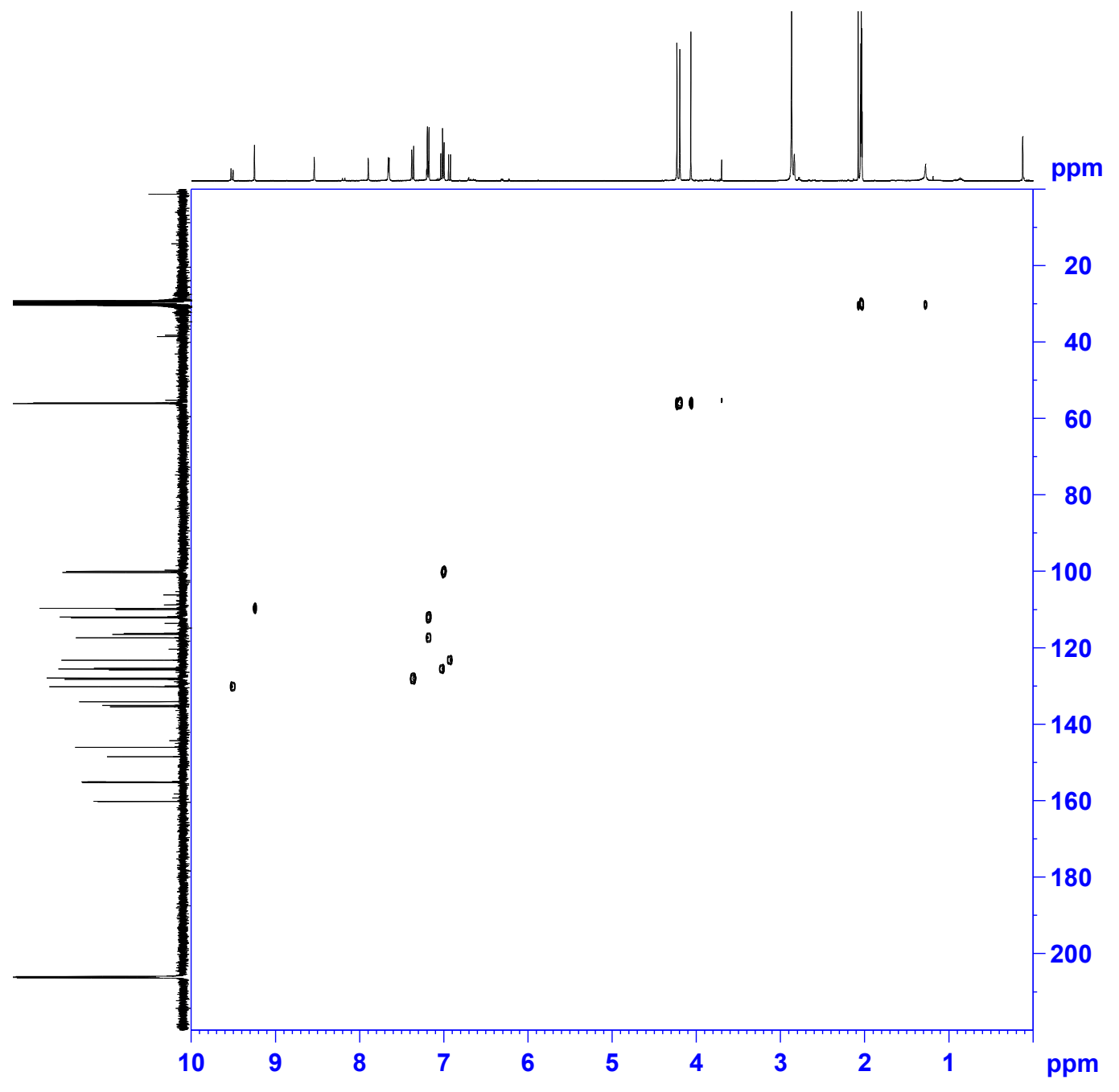


S 54 HMBC spectrum of the new compound 6

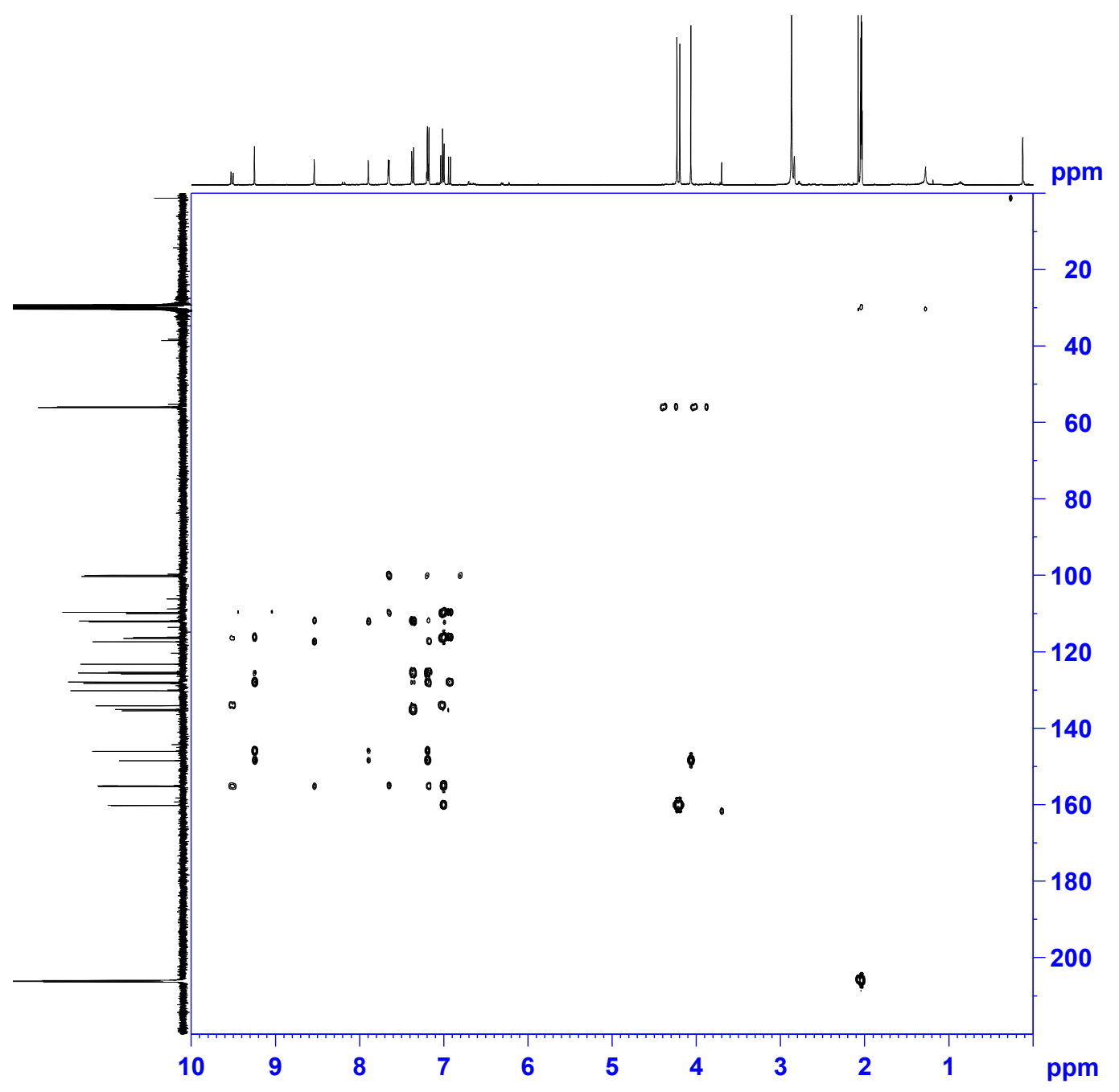

S 55 UV spectrum of the new compound 6 


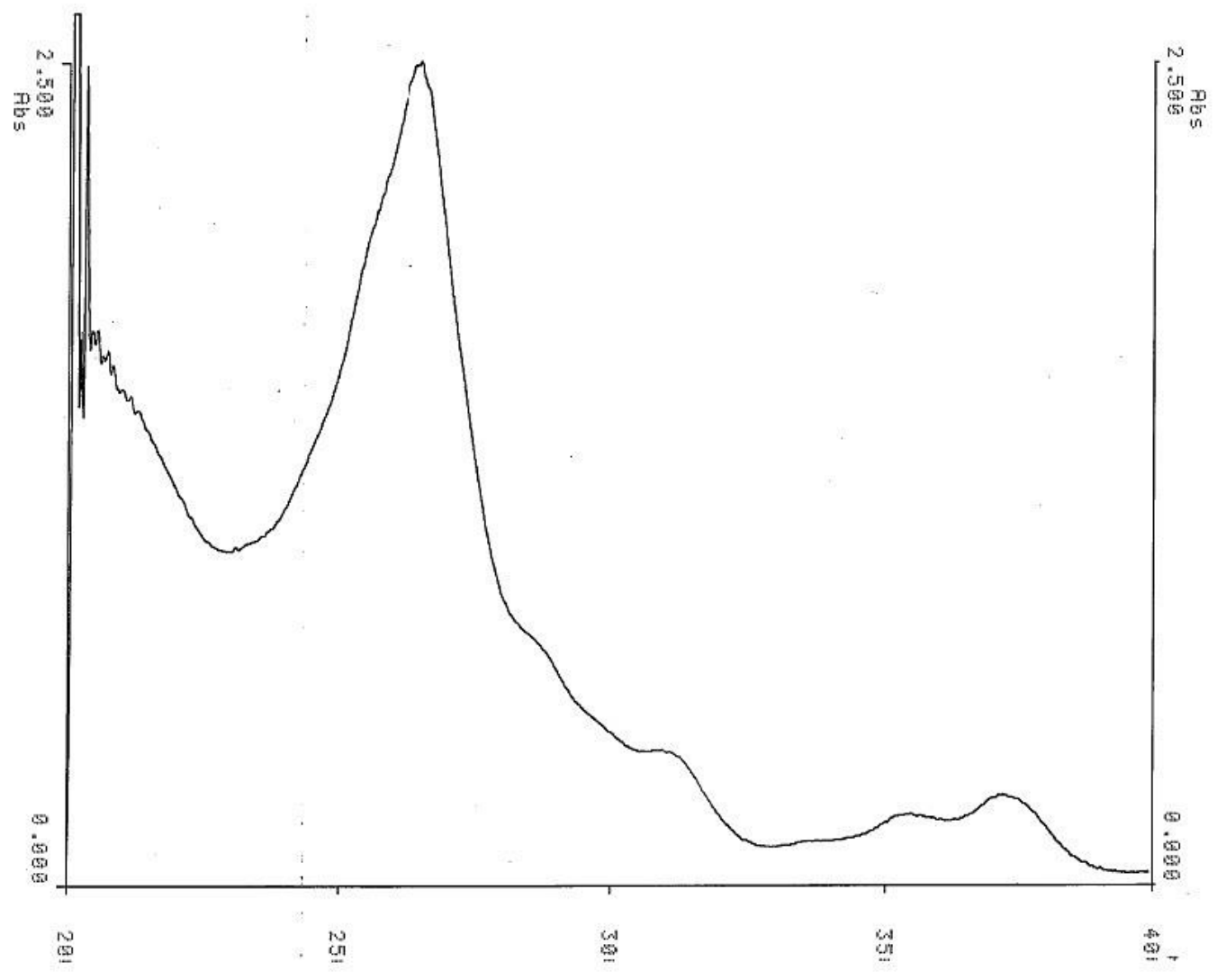




\section{S 56 IR spectrum of the new compound 6}

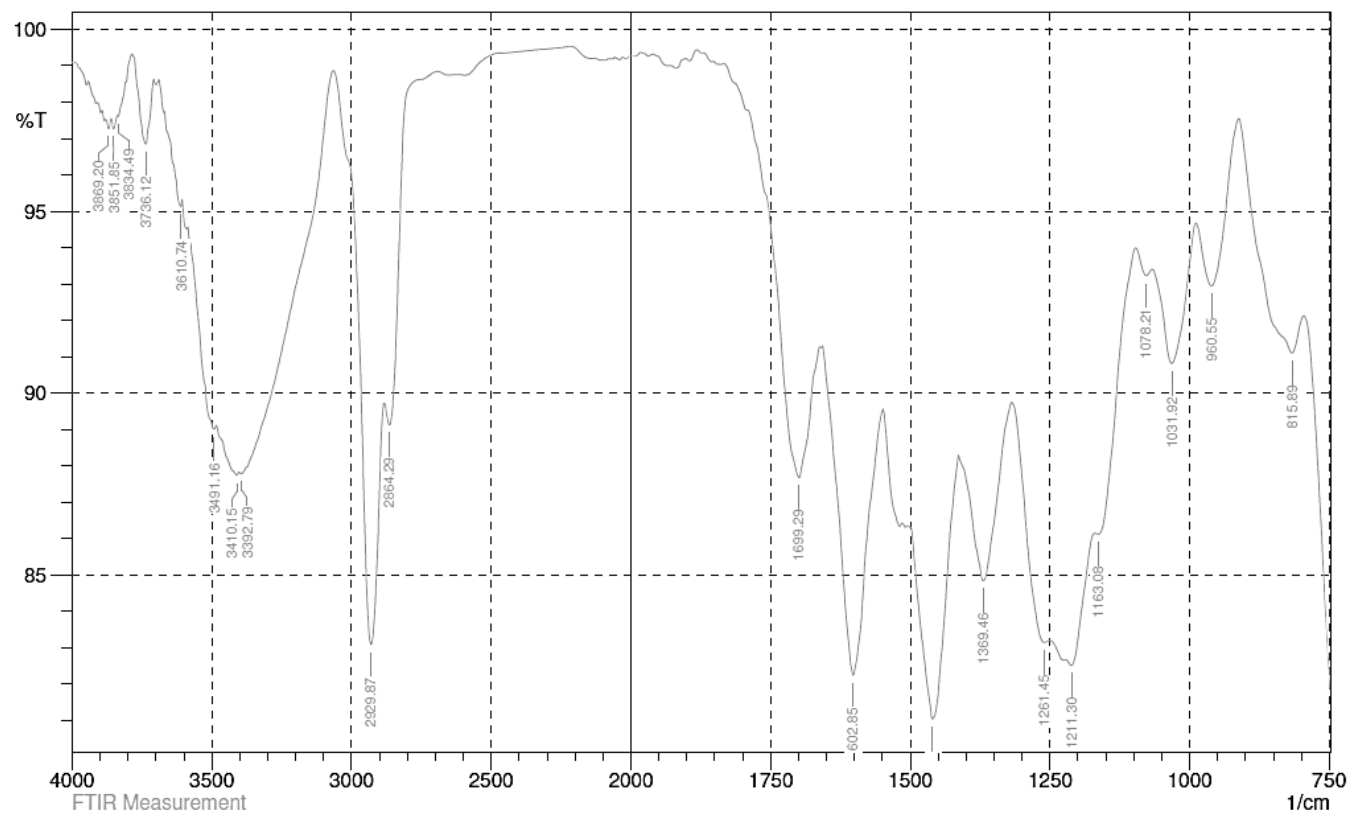


S 57 HRESIMS spectrum of the new compound 6

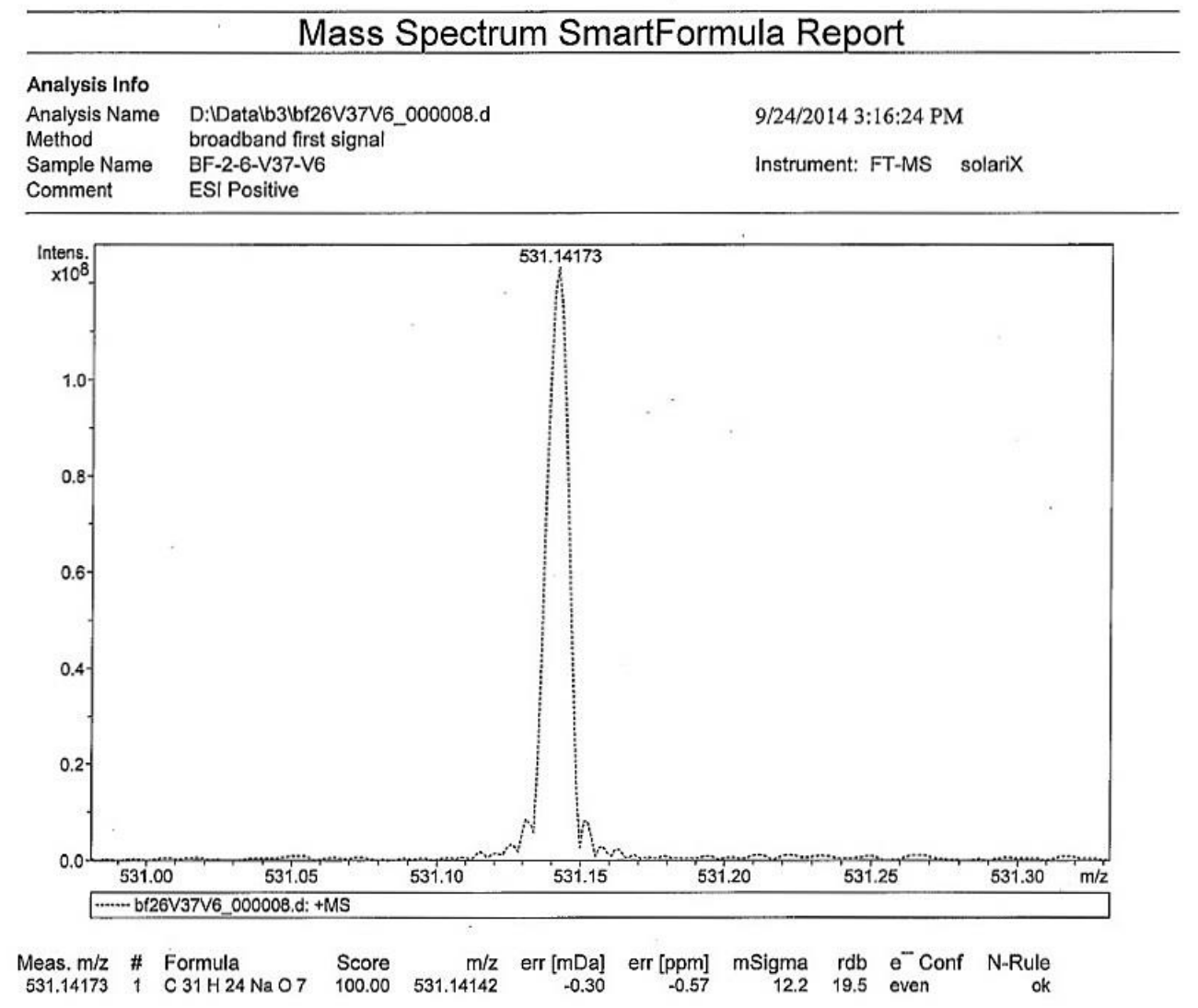


S 58 ECD spectrum of the new compound 6

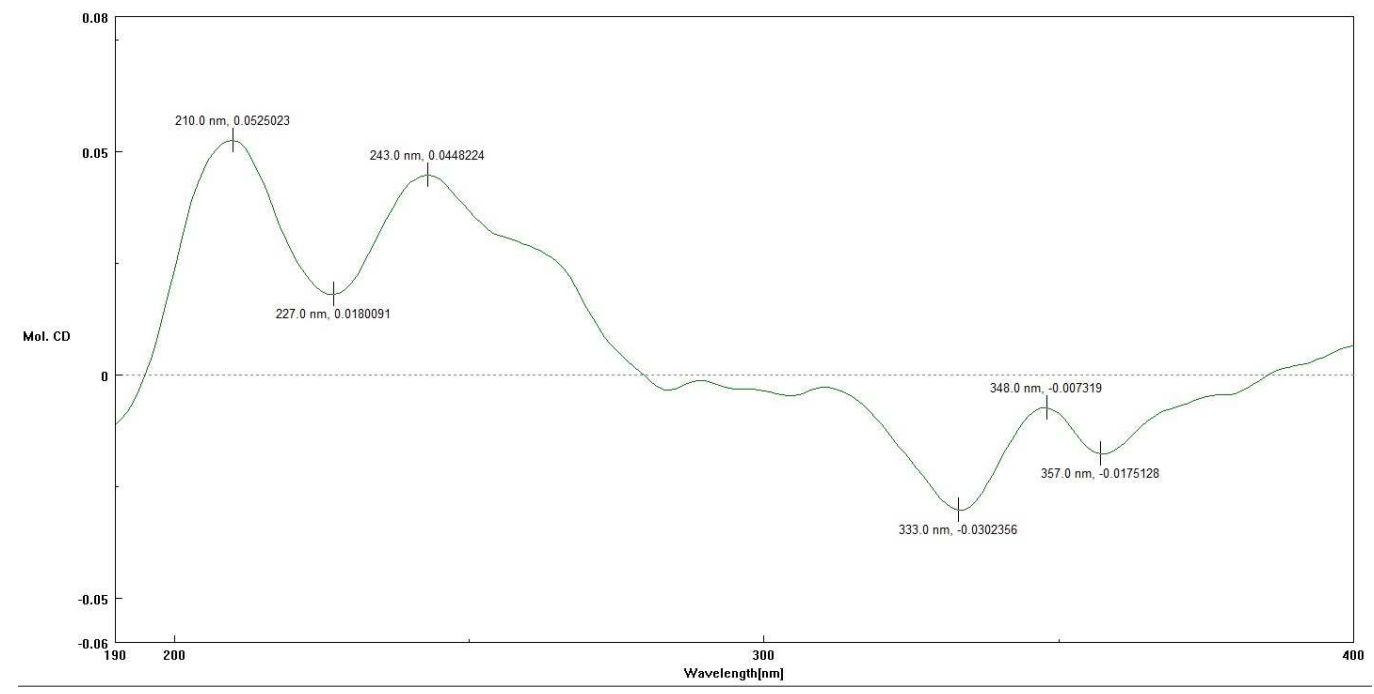


S $59{ }^{1} \mathrm{H}$ NMR $\left(700 \mathrm{MHz}\right.$, Acetone- $\left.d_{6}\right)$ spectrum of the new compound 7

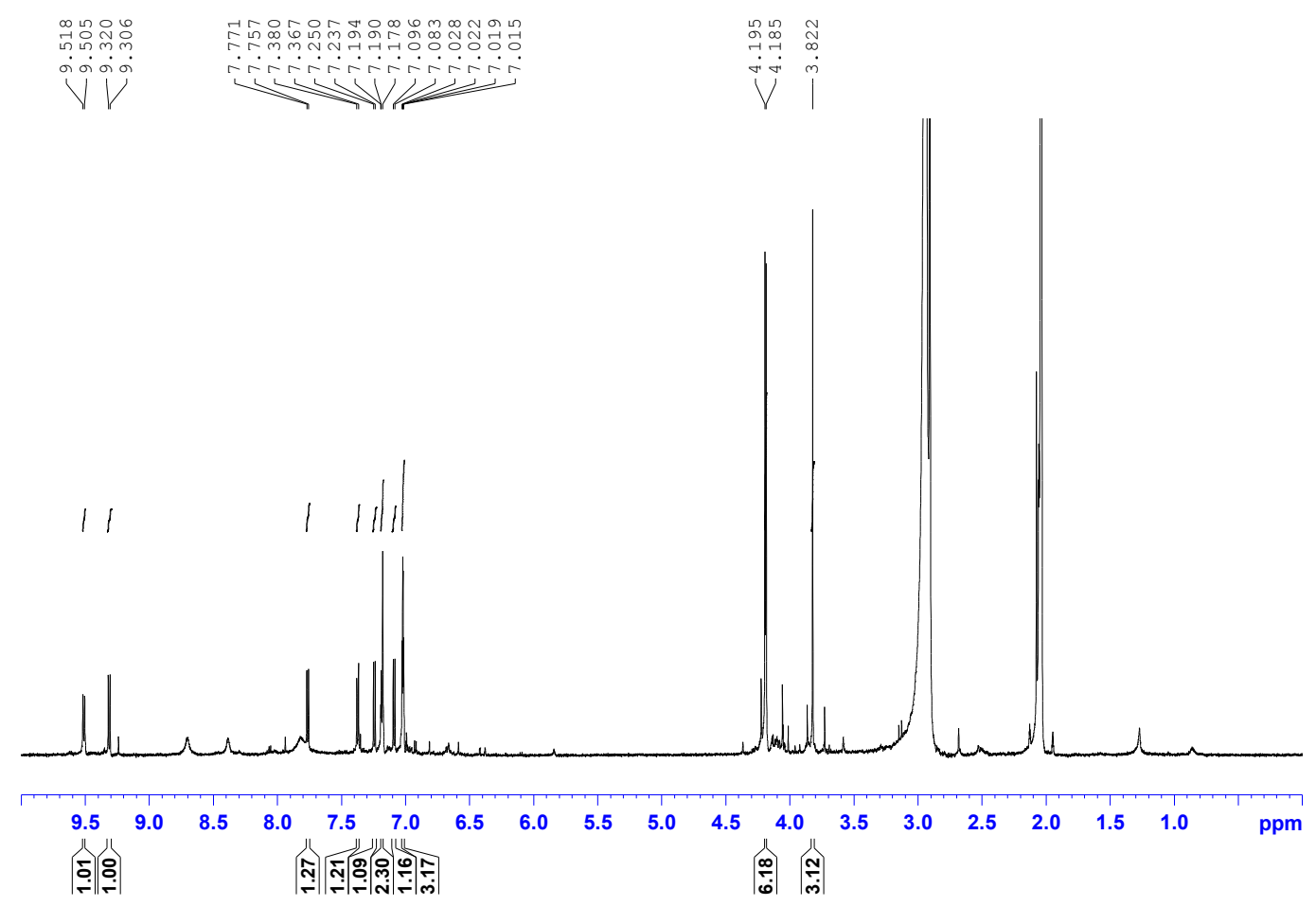


S $60{ }^{13} \mathrm{C}$ NMR (175 MHz, Acetone- $d_{6}$ ) spectrum of the new compound 7

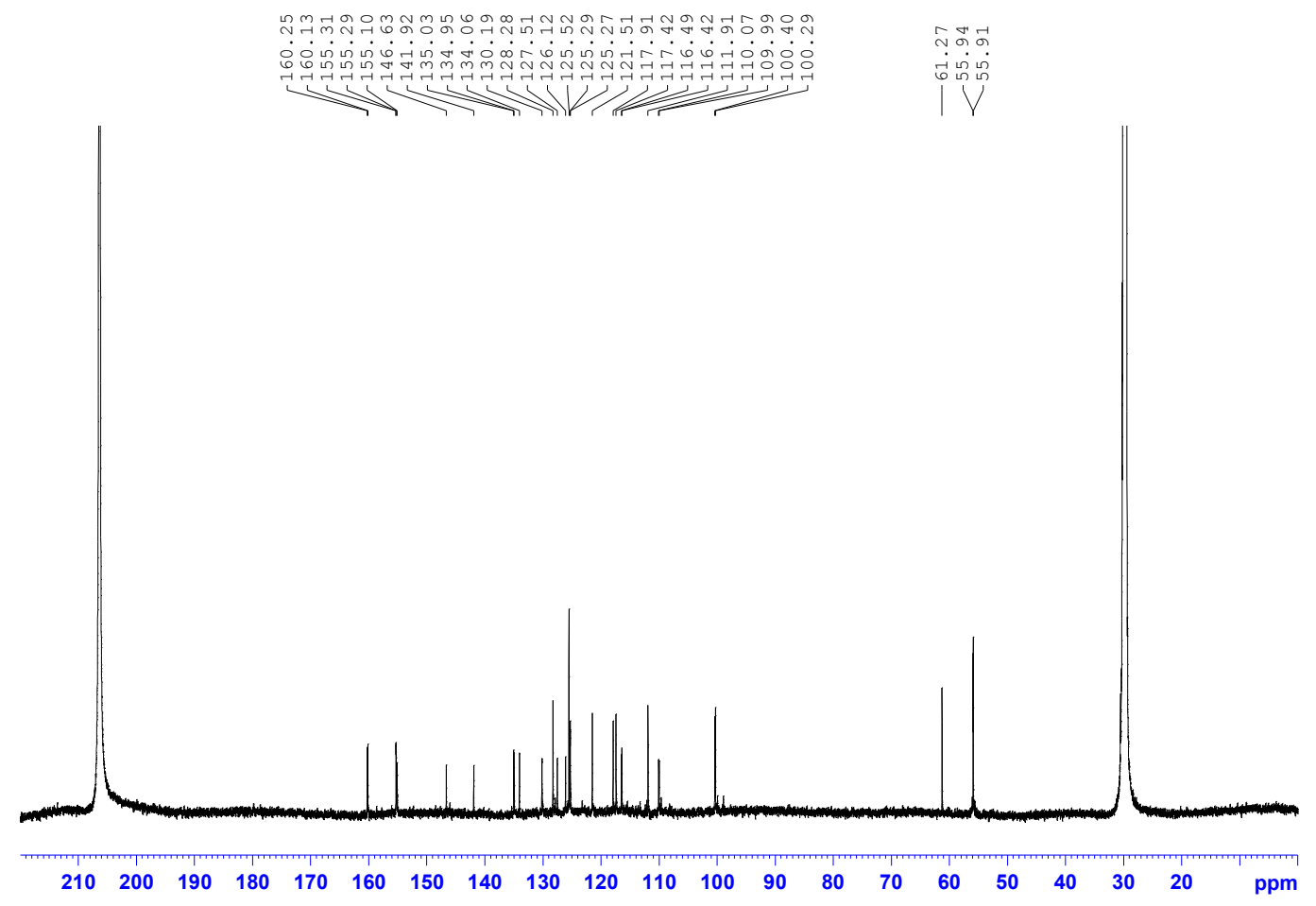


S 61 COSY spectrum of the new compound 7

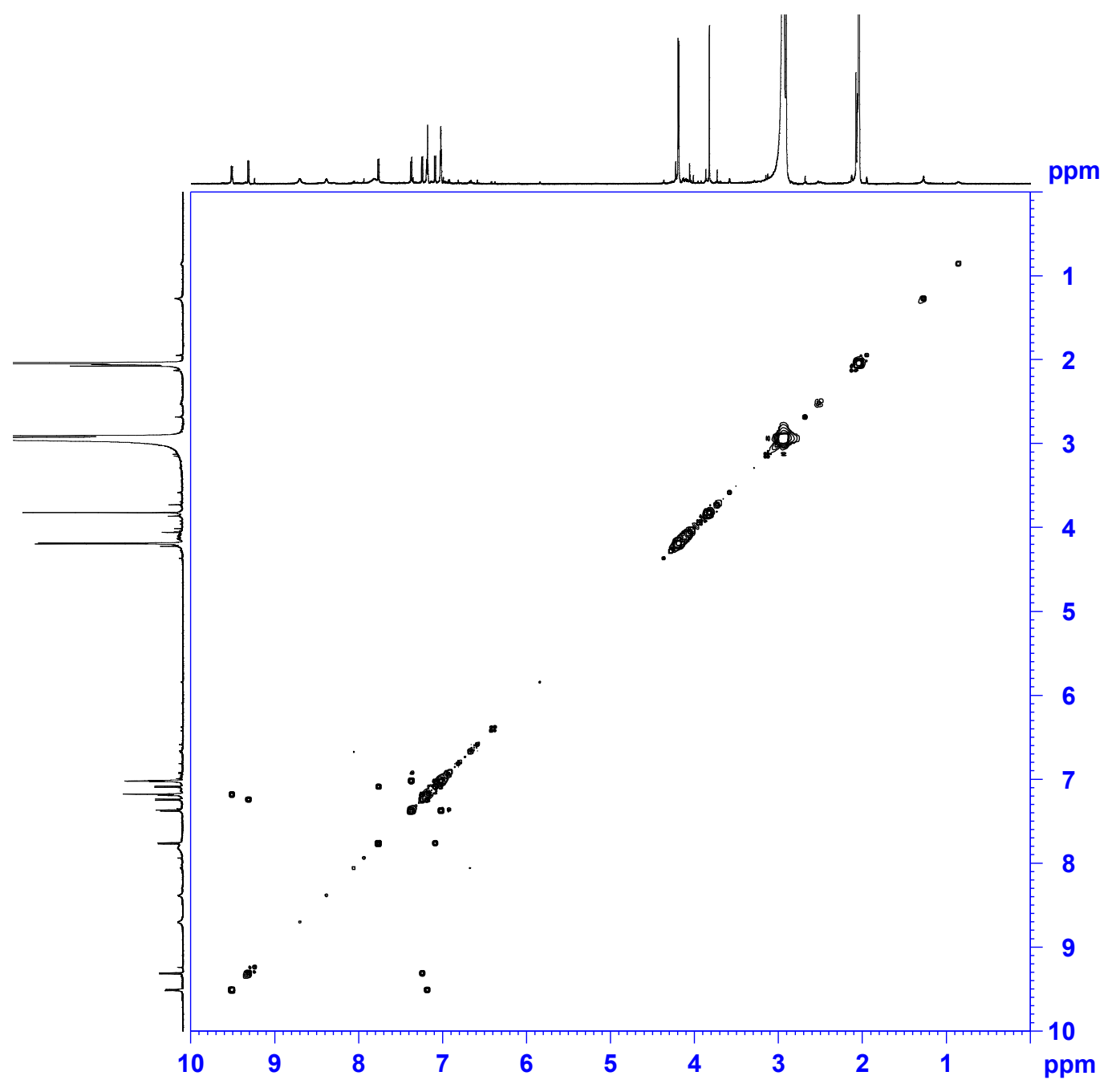


S 62 NOESY spectrum of the new compound 7

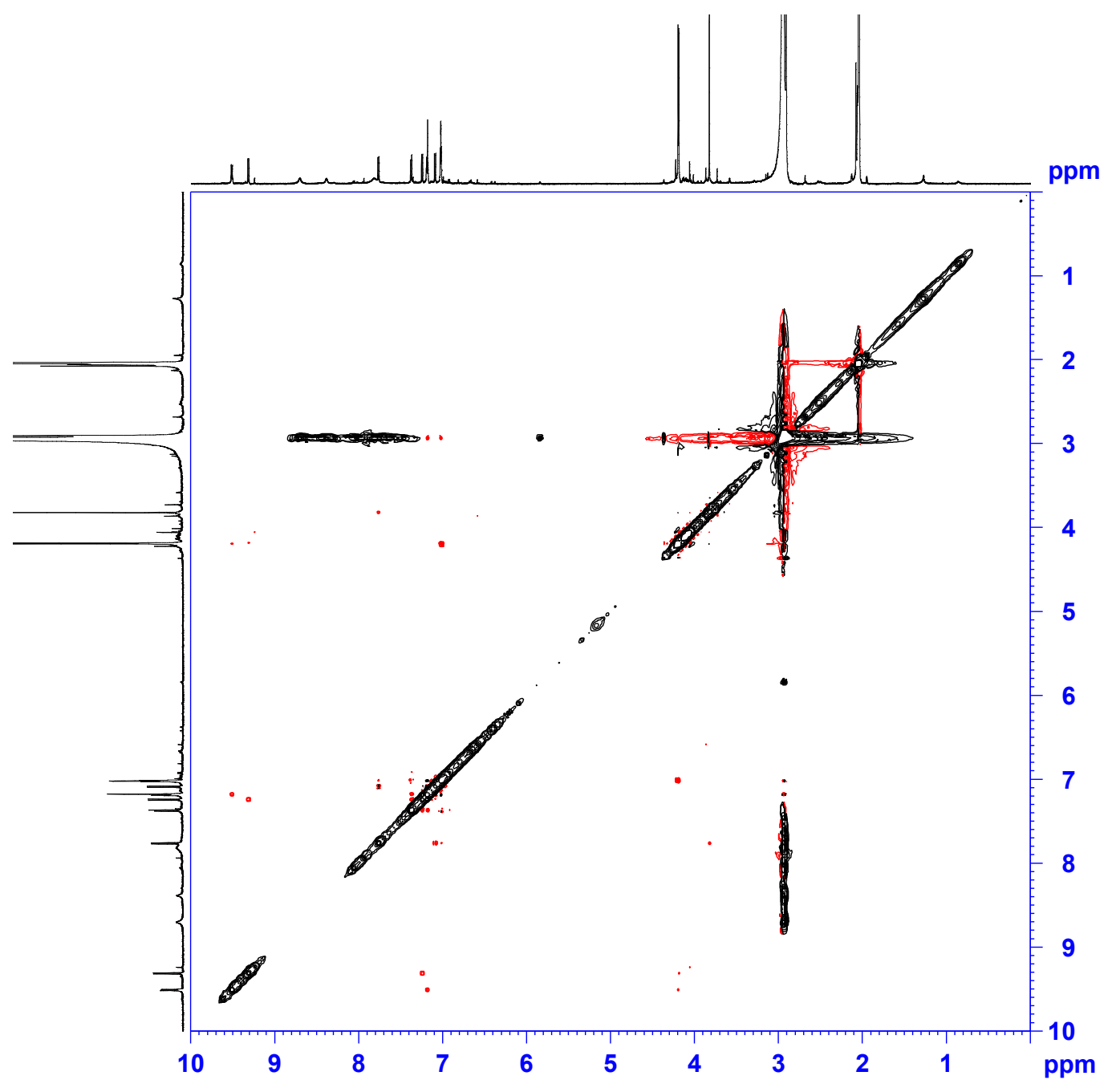


S 63 HSQC spectrum of the new compound 7

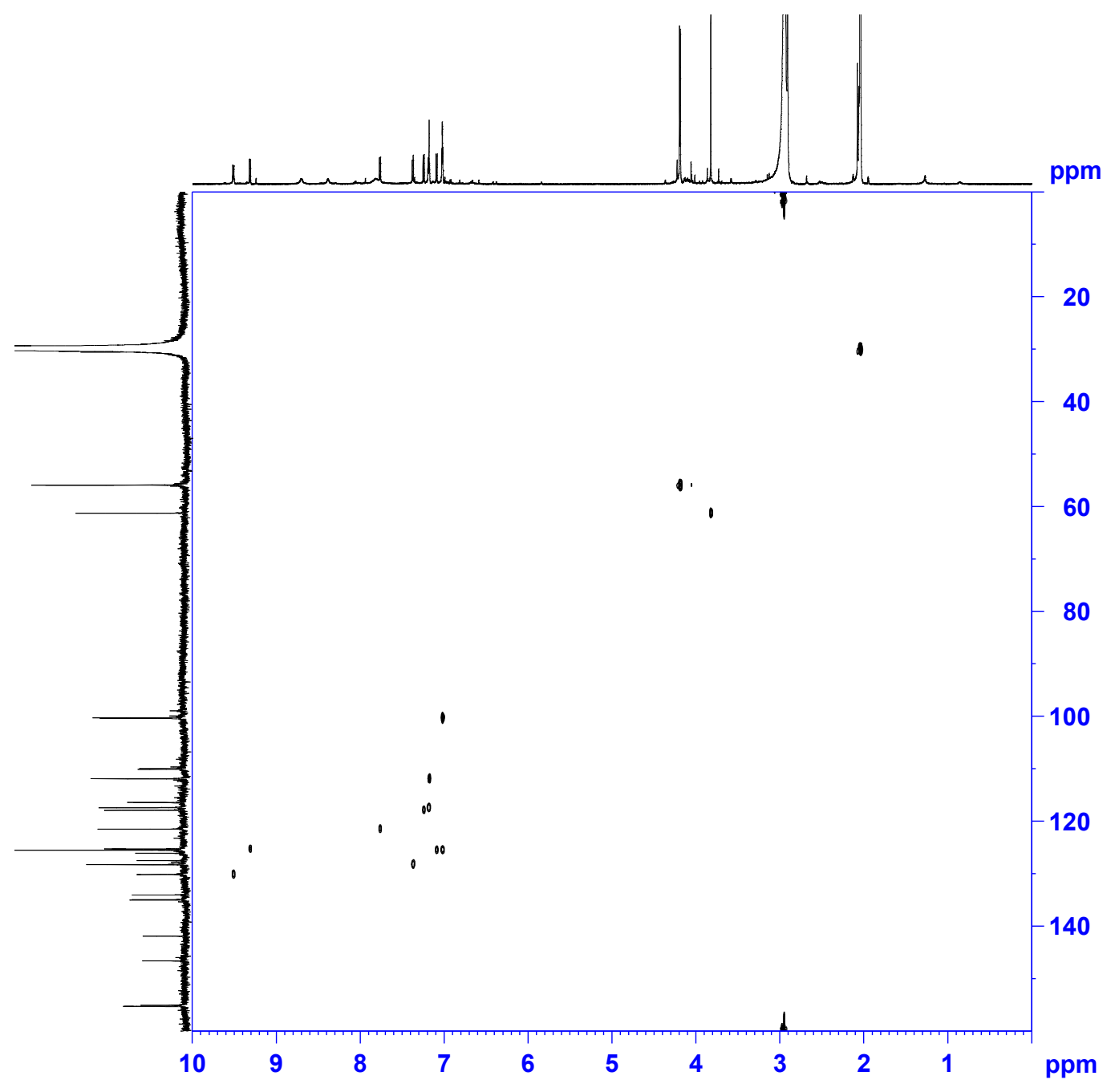


S 64 HMBC spectrum of the new compound 7

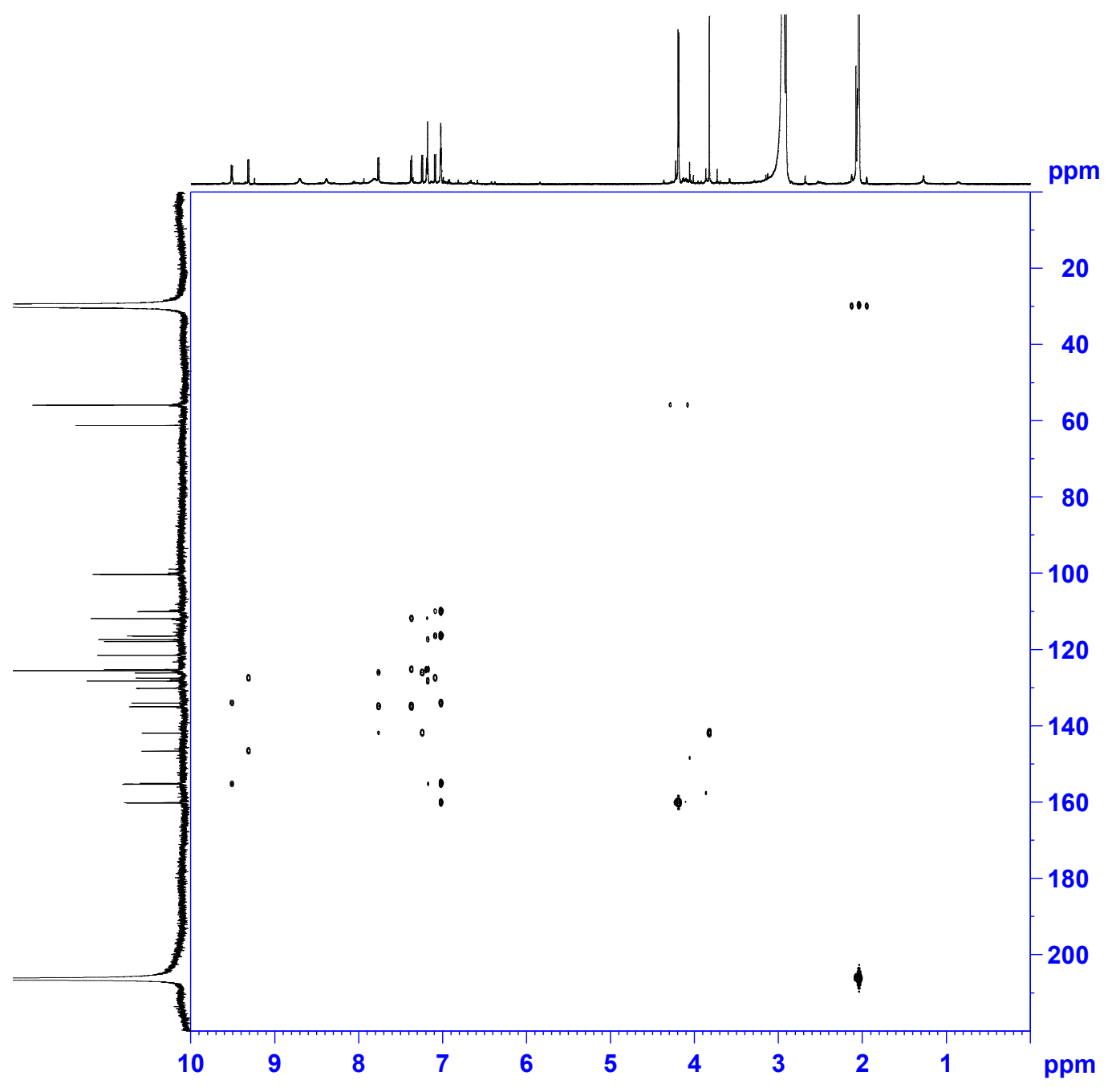


S 65 UV spectrum of the new compound 7

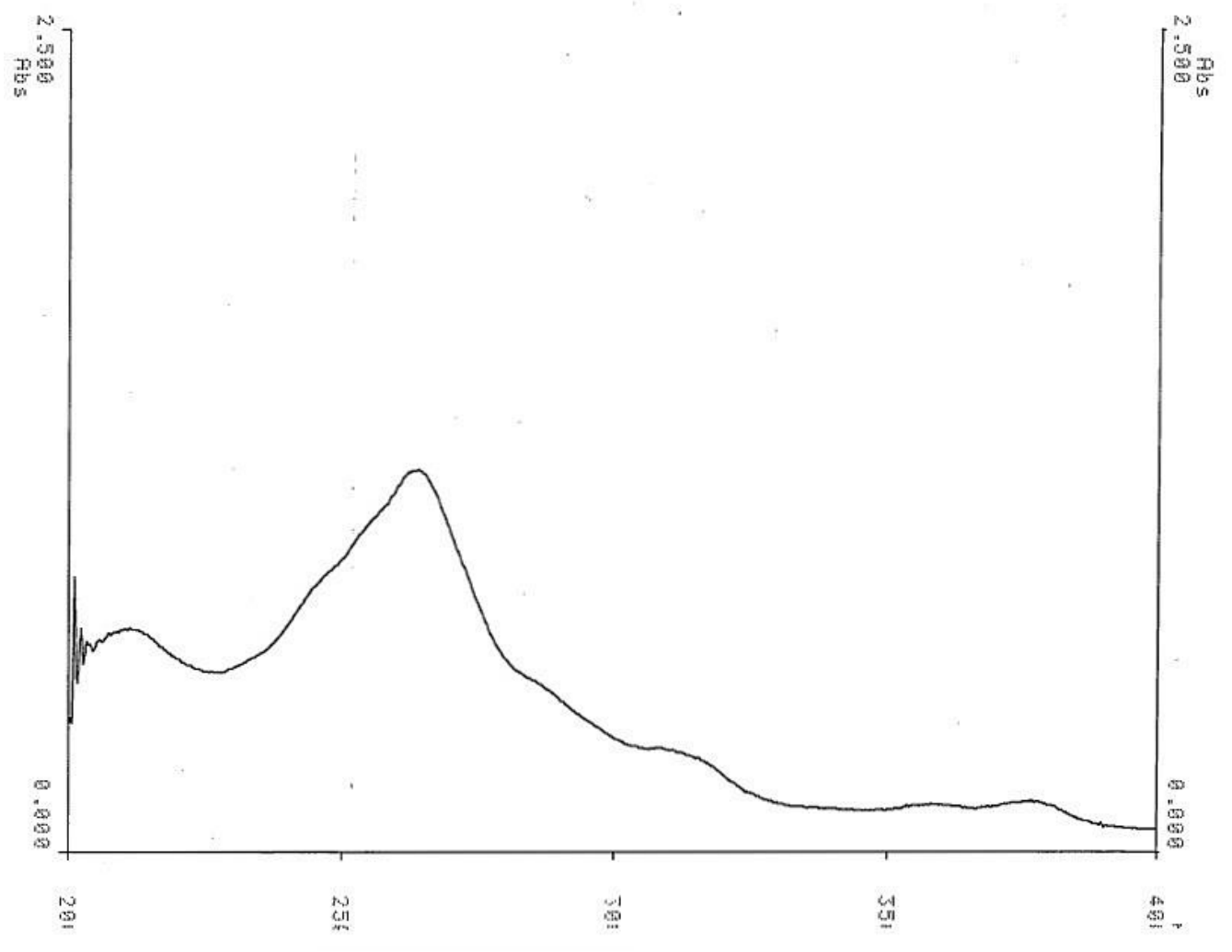


S 66 IR spectrum of the new compound 7

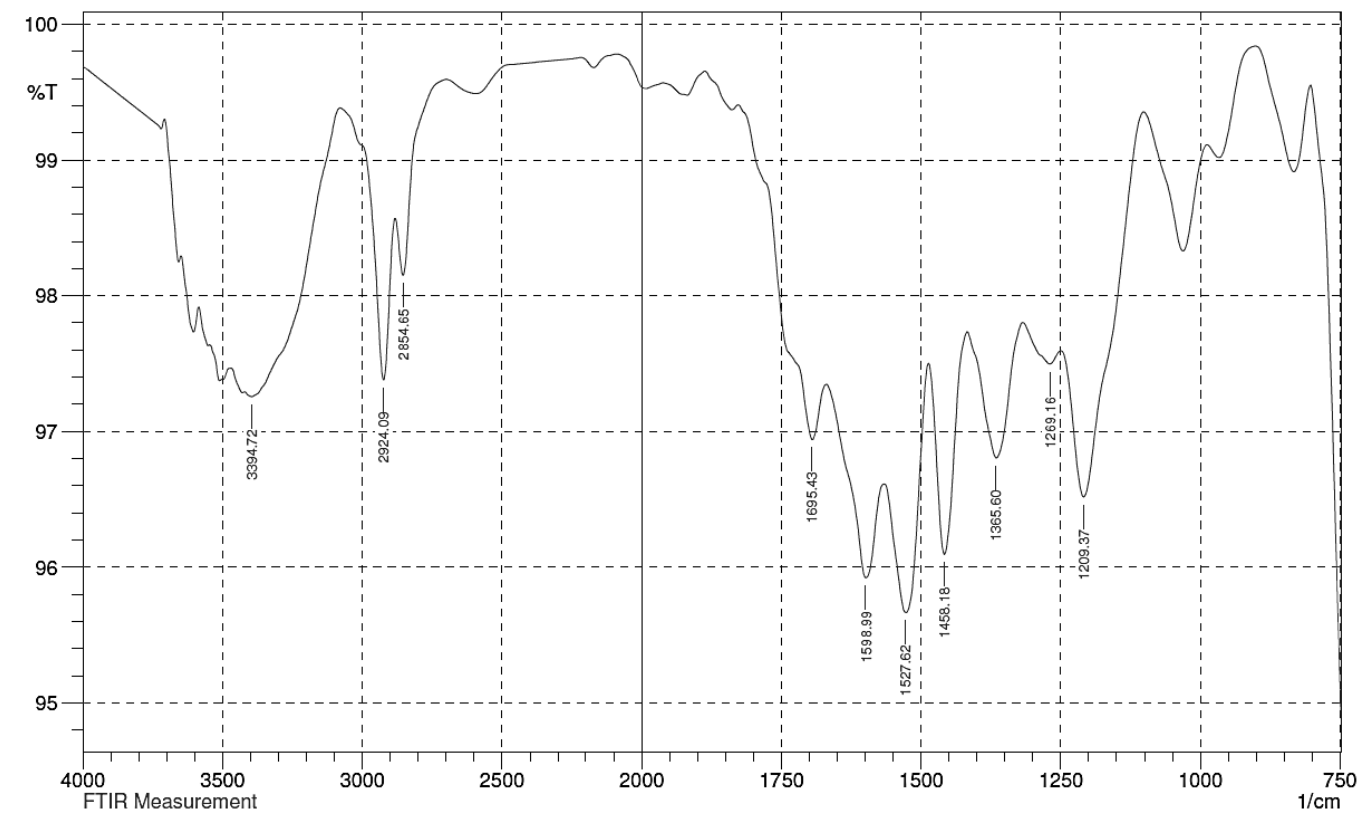


S 67 HRESIMS spectrum of the new compound 7

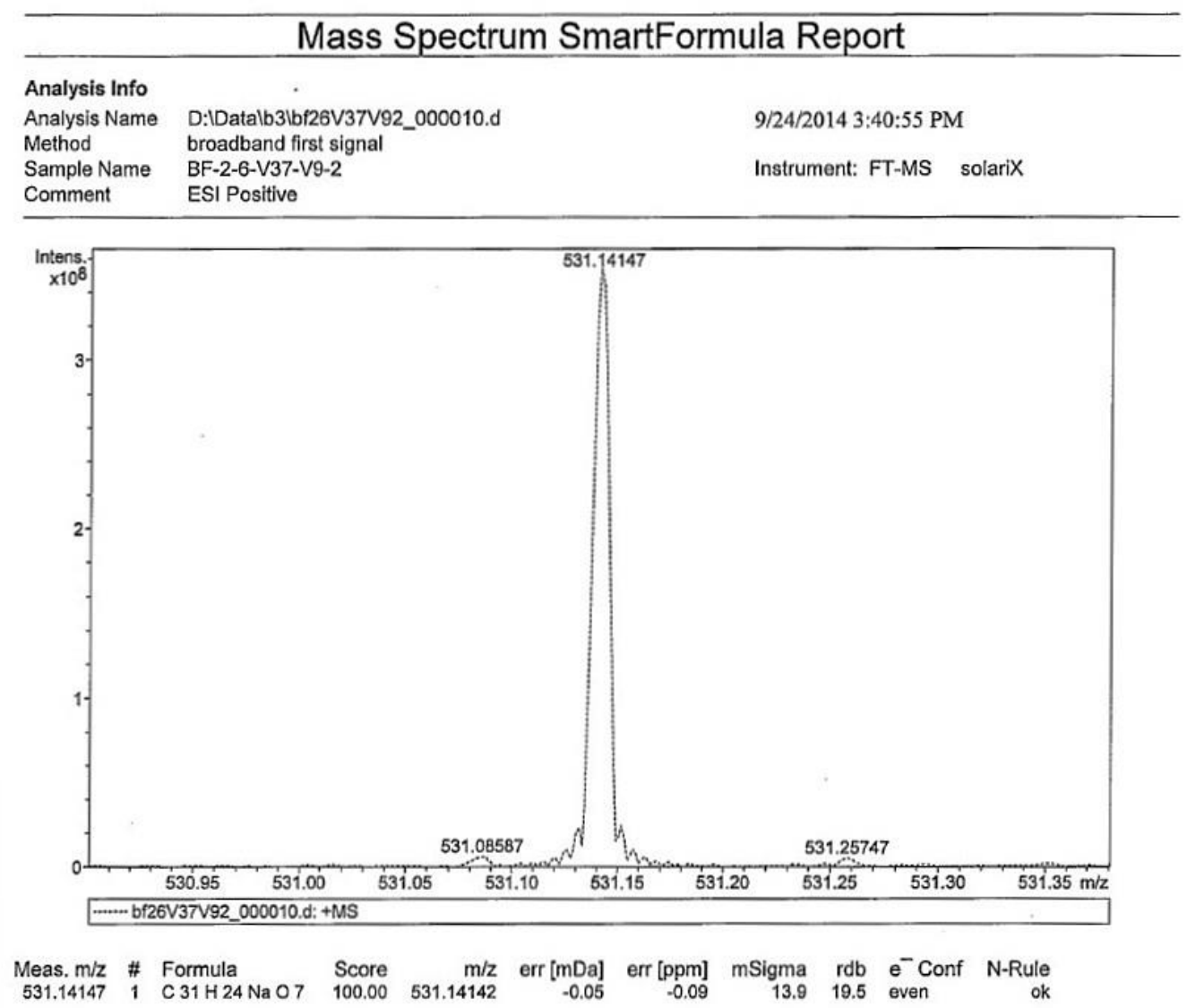


S 68 ECD spectrum of the new compound 7

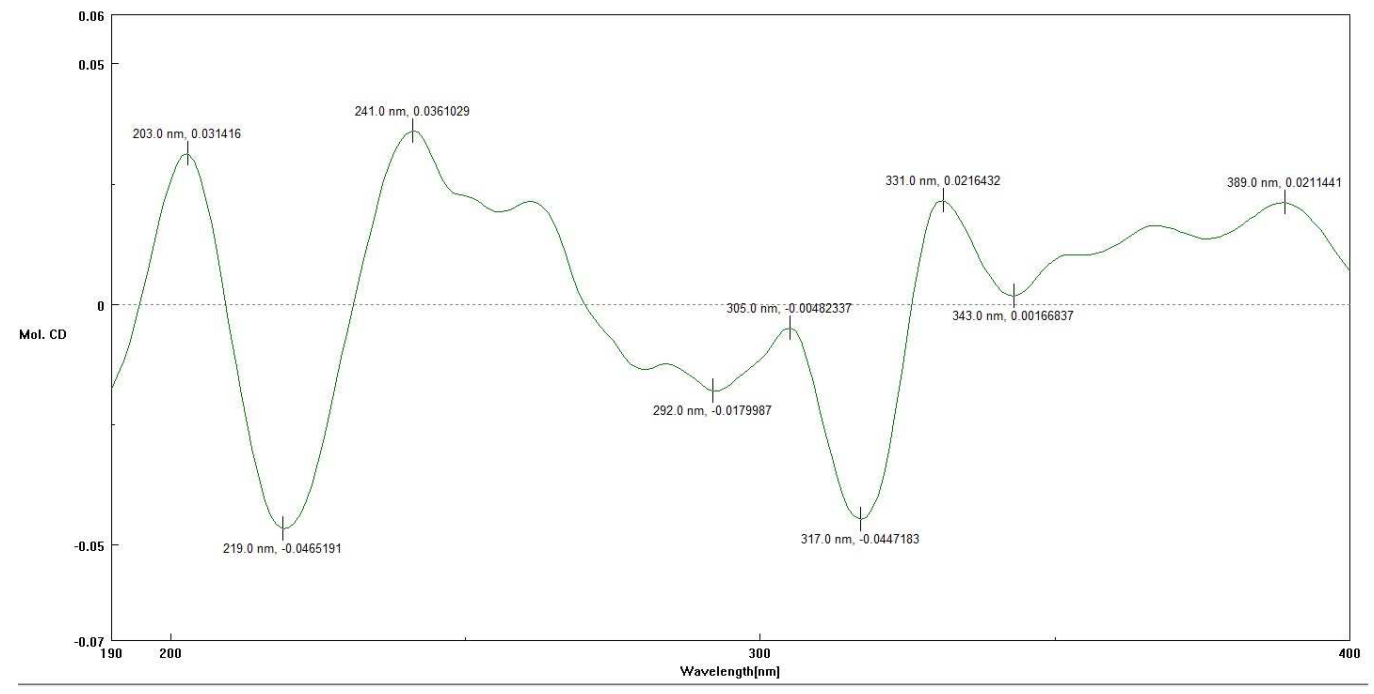


S $69{ }^{1}$ H NMR (400 MHz, Acetone- $d_{6}$ ) spectrum of the new compound 8

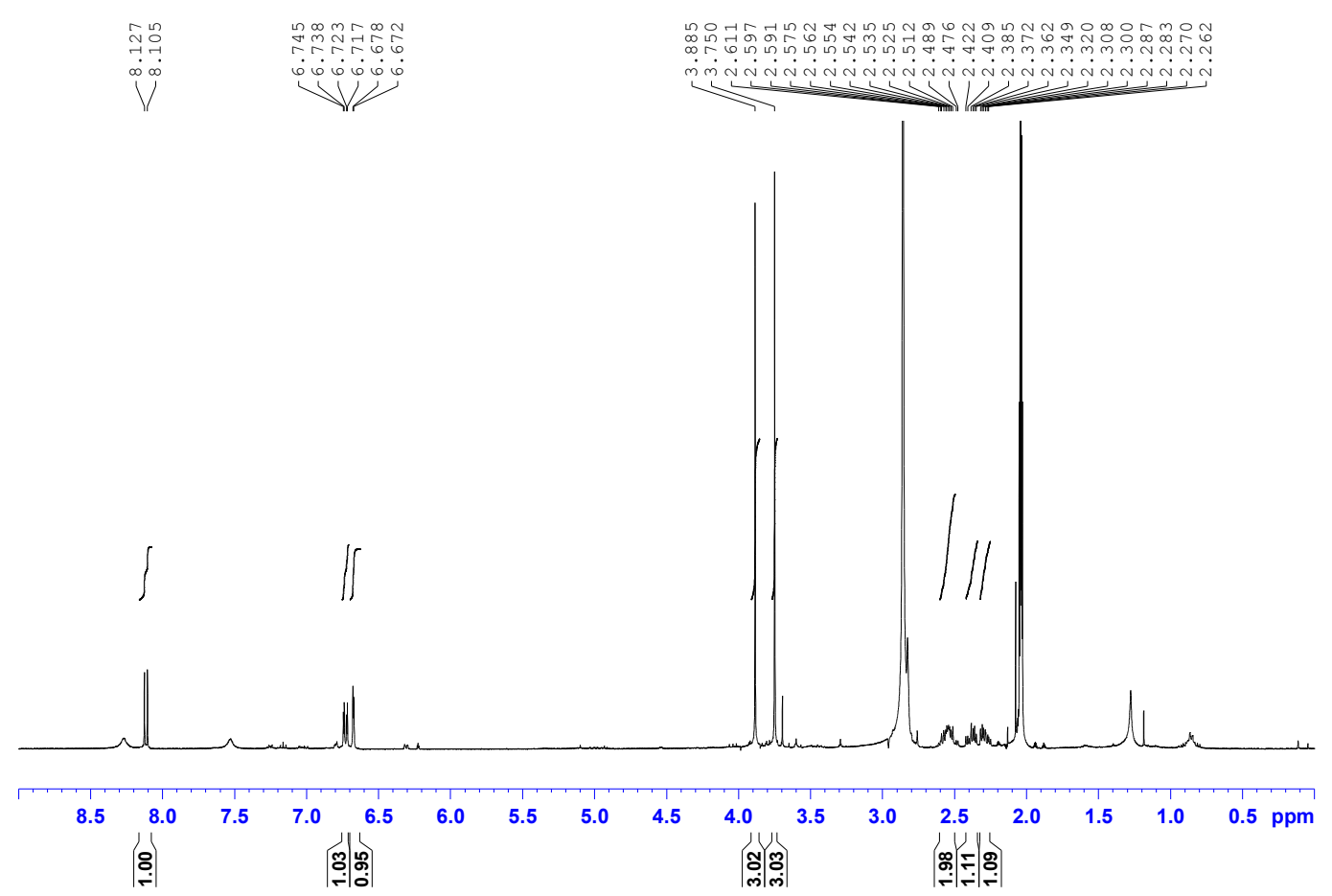


S $70{ }^{13} \mathrm{C}$ NMR (100 MHz, Acetone- $d_{6}$ ) spectrum of the new compound 8

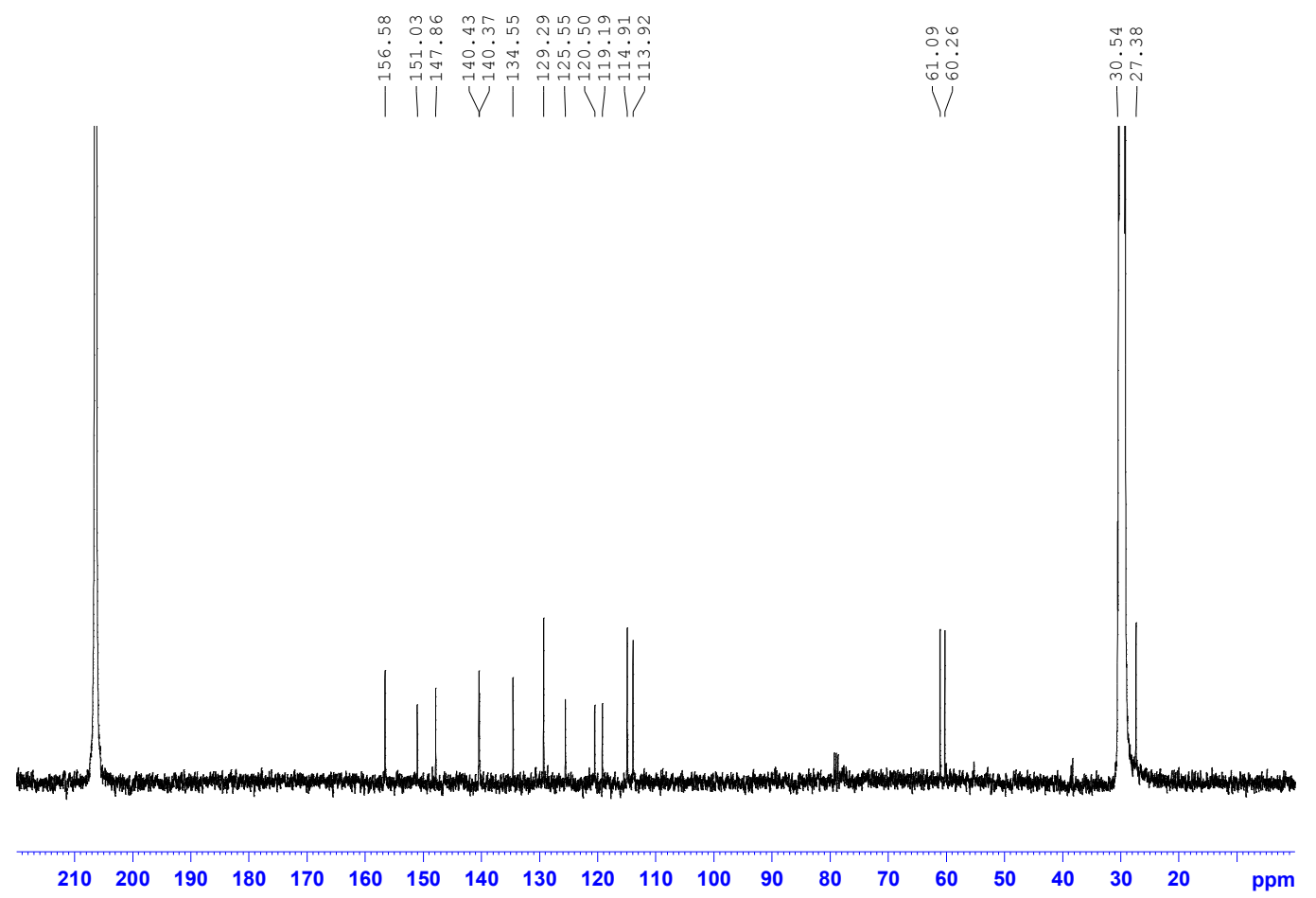


S 71 COSY spectrum of the new compound 8

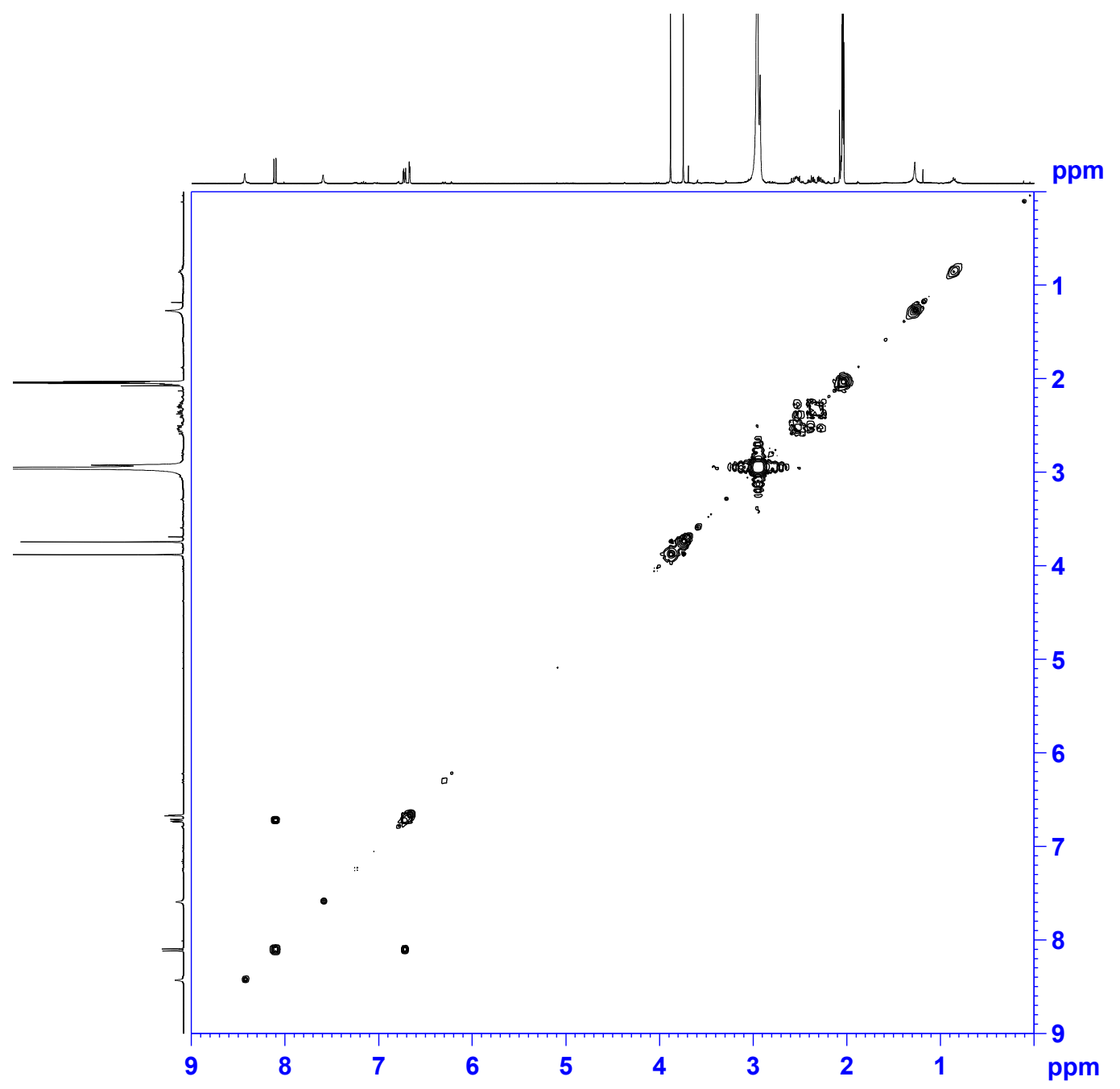


S 72 NOESY spectrum of the new compound $\mathbf{8}$

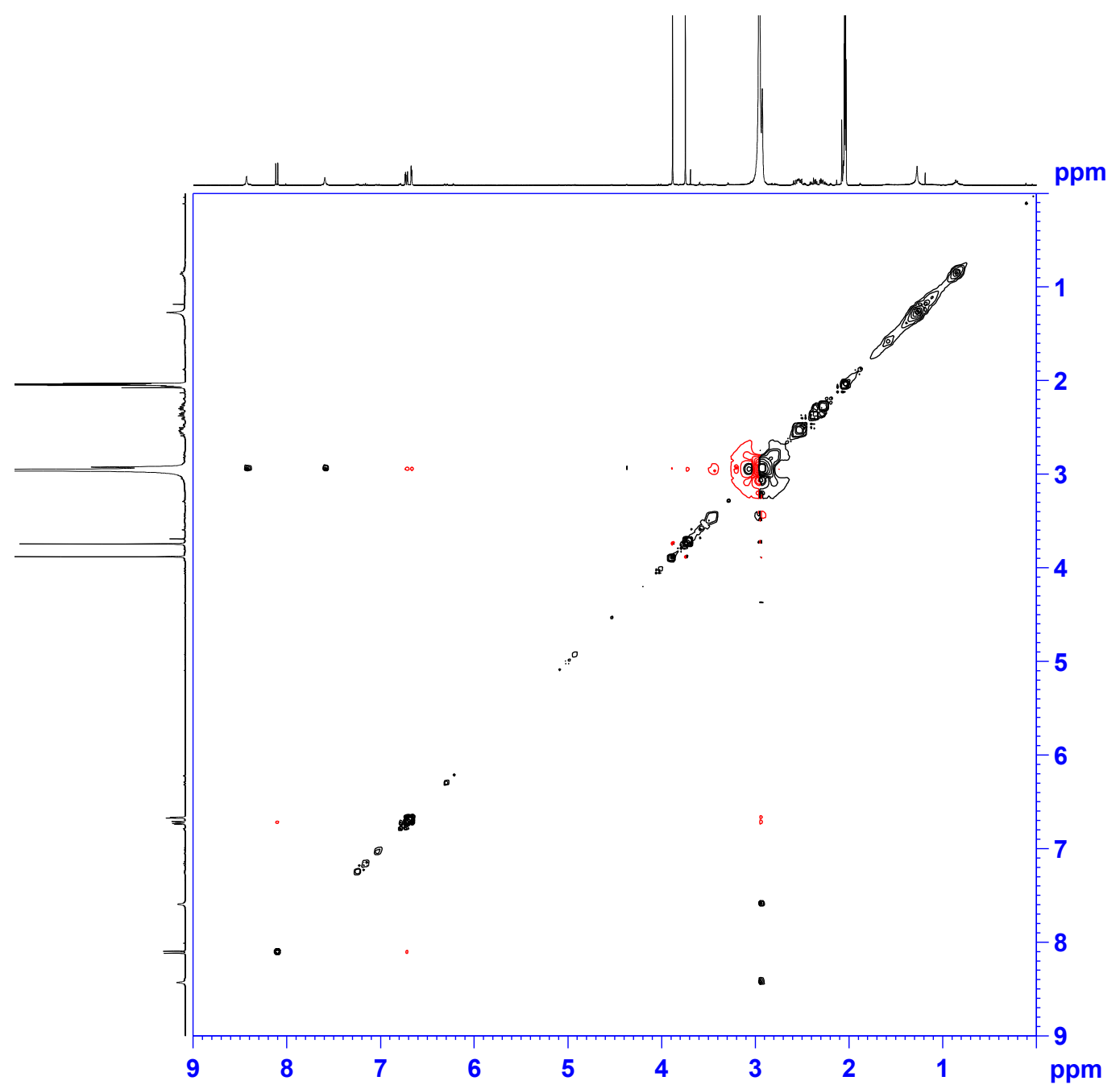


S 73 HSQC spectrum of the new compound $\mathbf{8}$

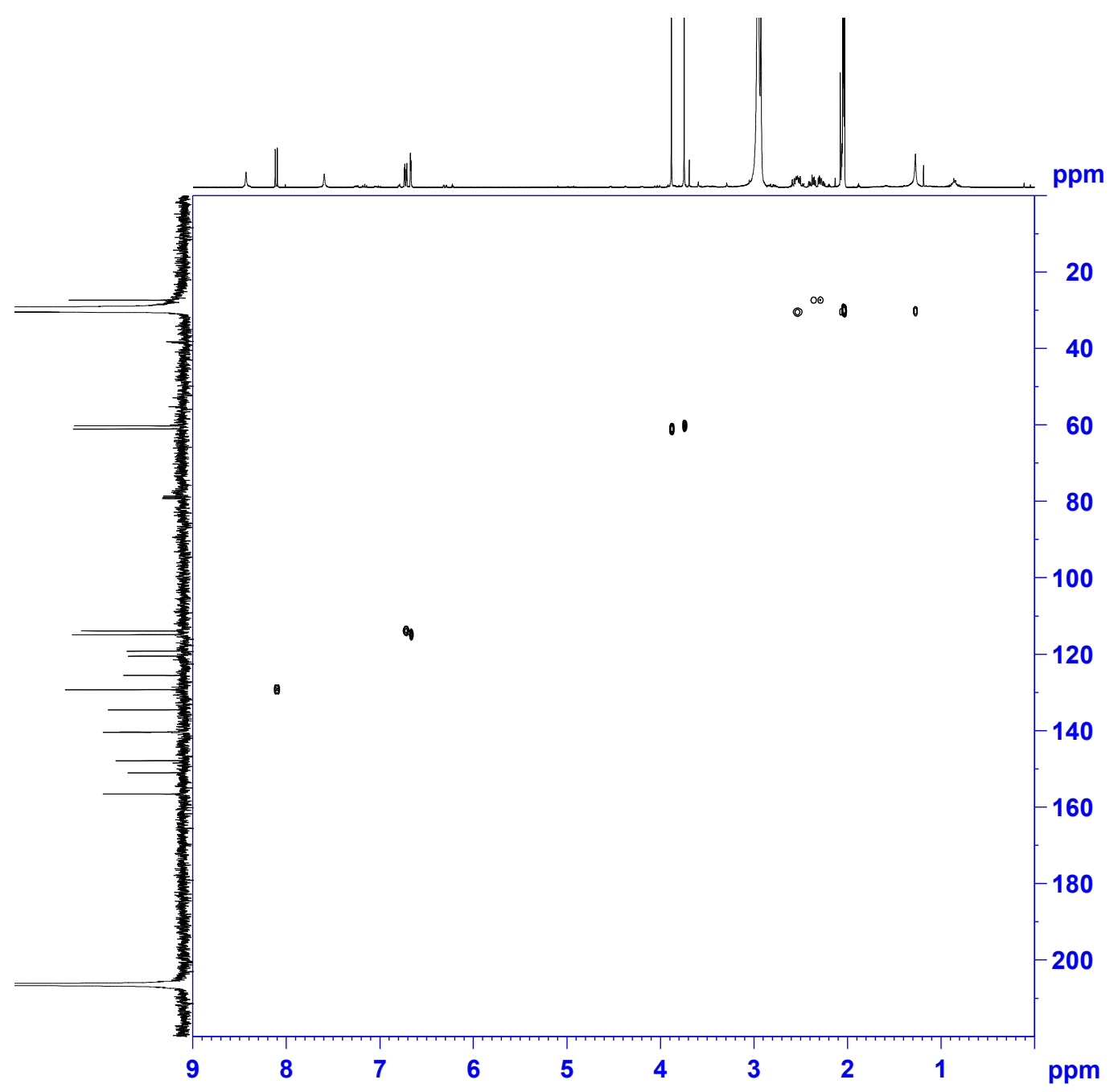


S 74 HMBC spectrum of the new compound 8

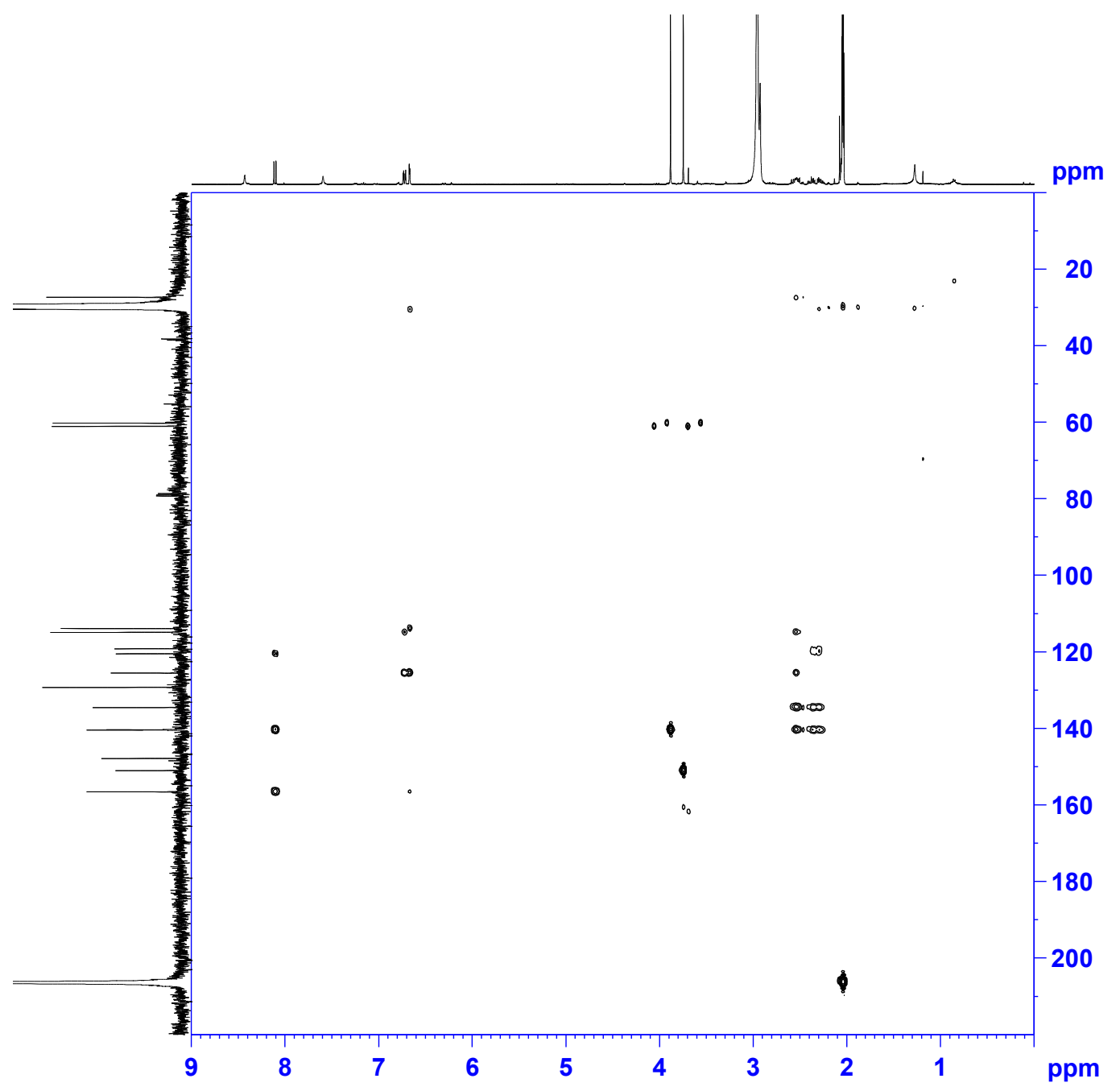




\section{S 75 UV spectrum of the new compound 8}

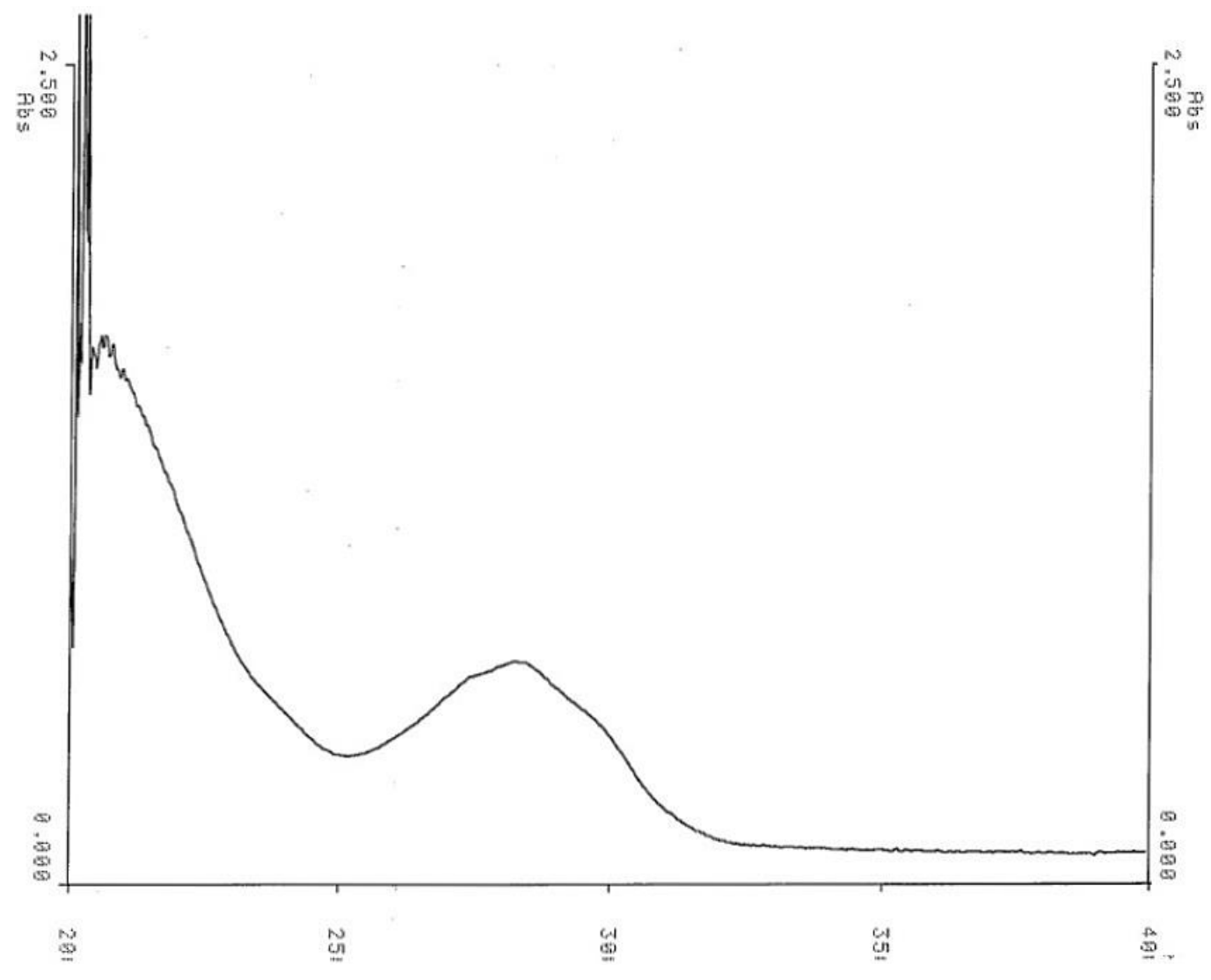




\section{S 76 IR spectrum of the new compound 8}

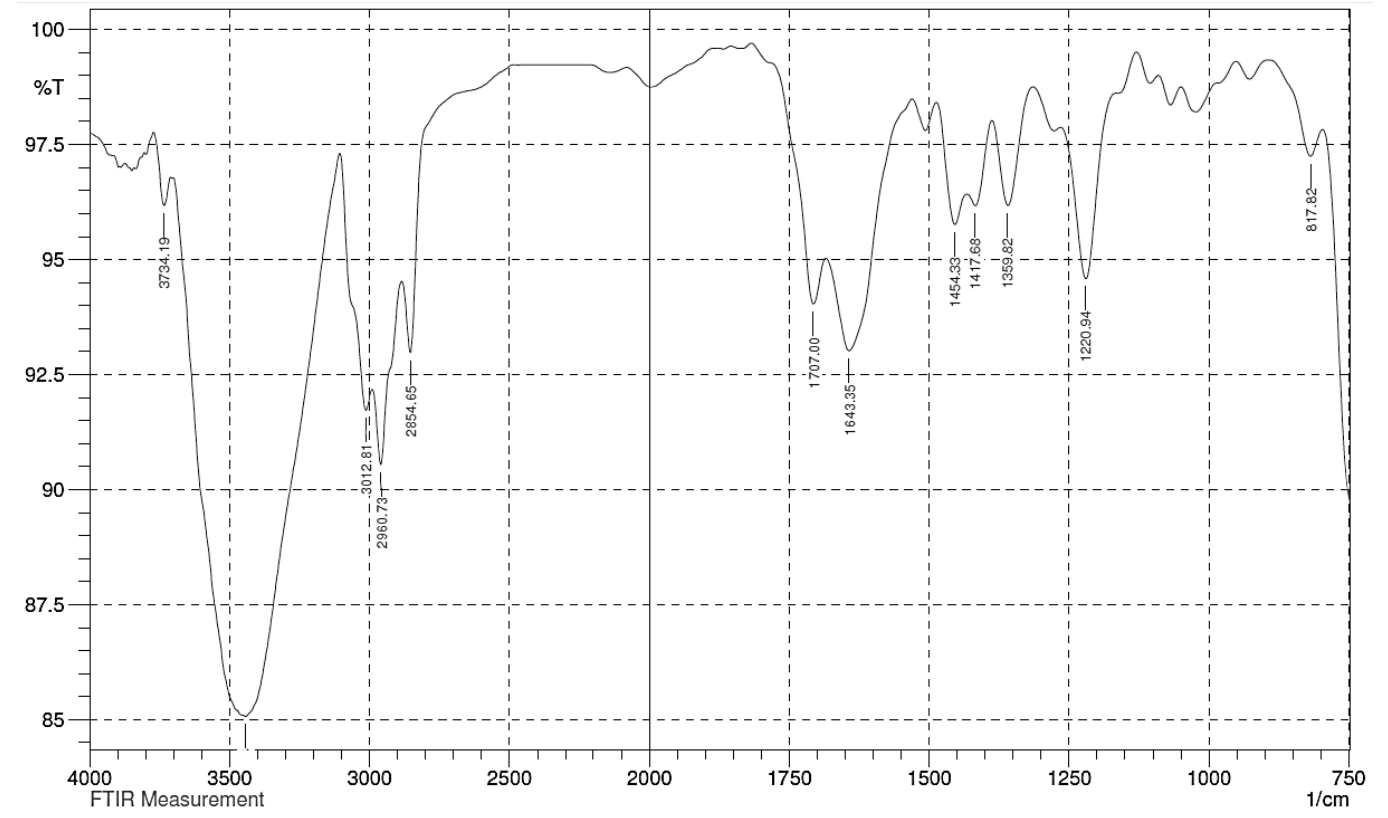


S 77 HRESIMS spectrum of the new compound $\mathbf{8}$

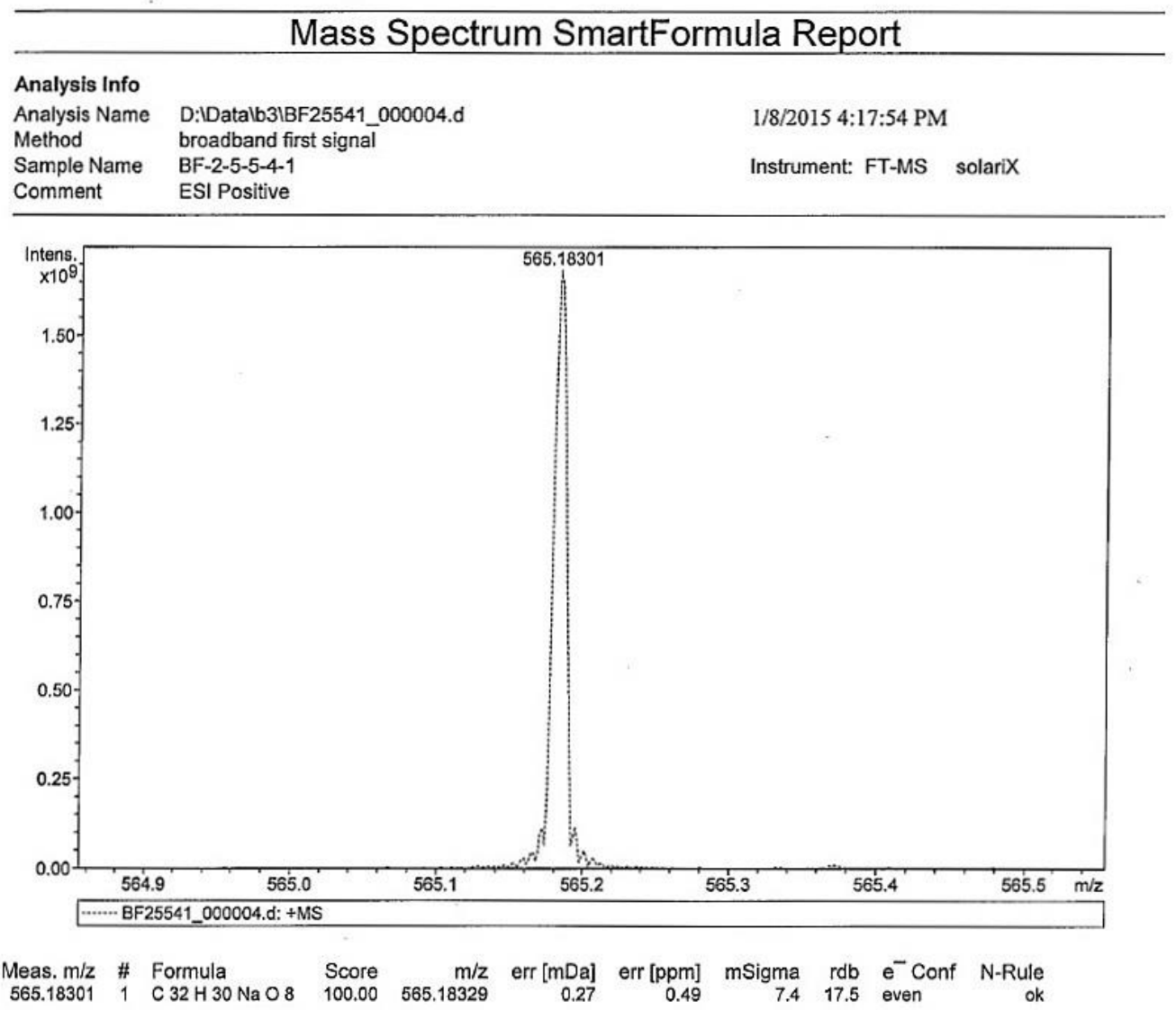


S 78 ECD spectrum of the new compound 8

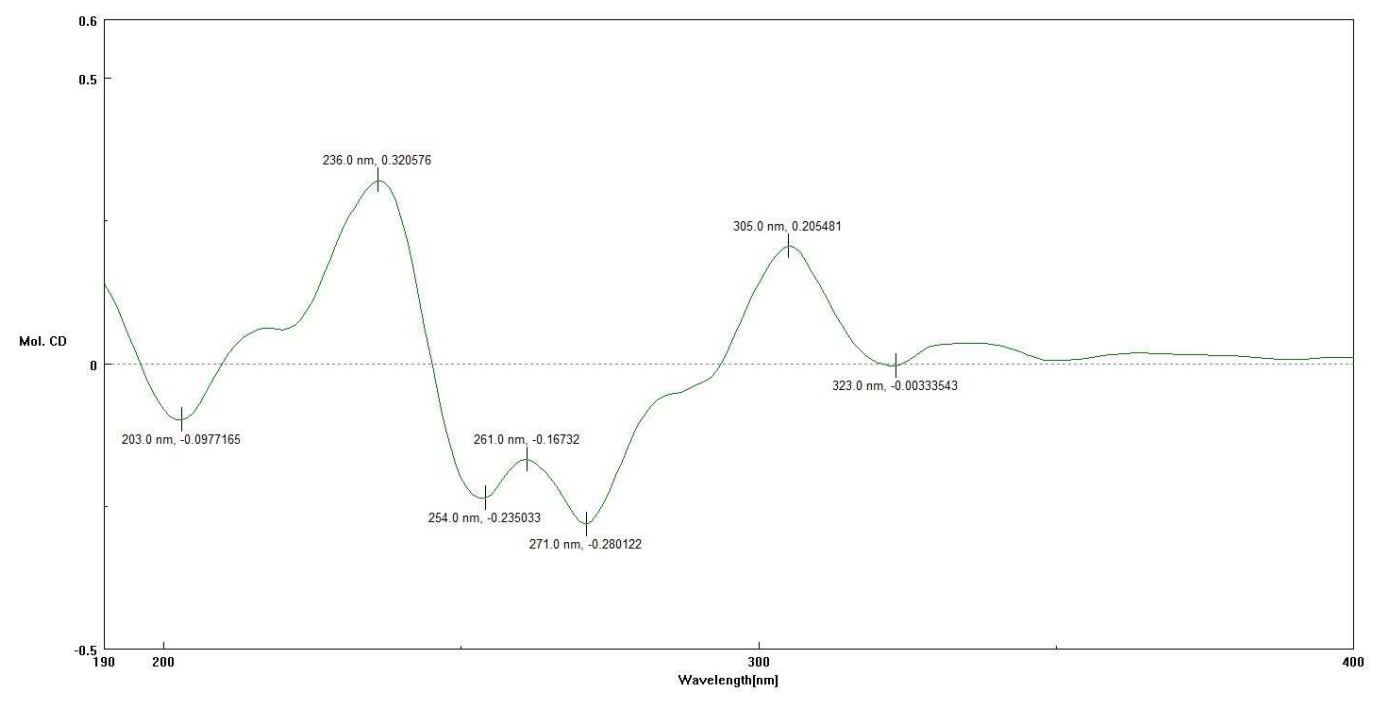


S $79{ }^{1} \mathrm{H}$ NMR (400 MHz, Acetone- $d_{6}$ ) spectrum of the new compound 9

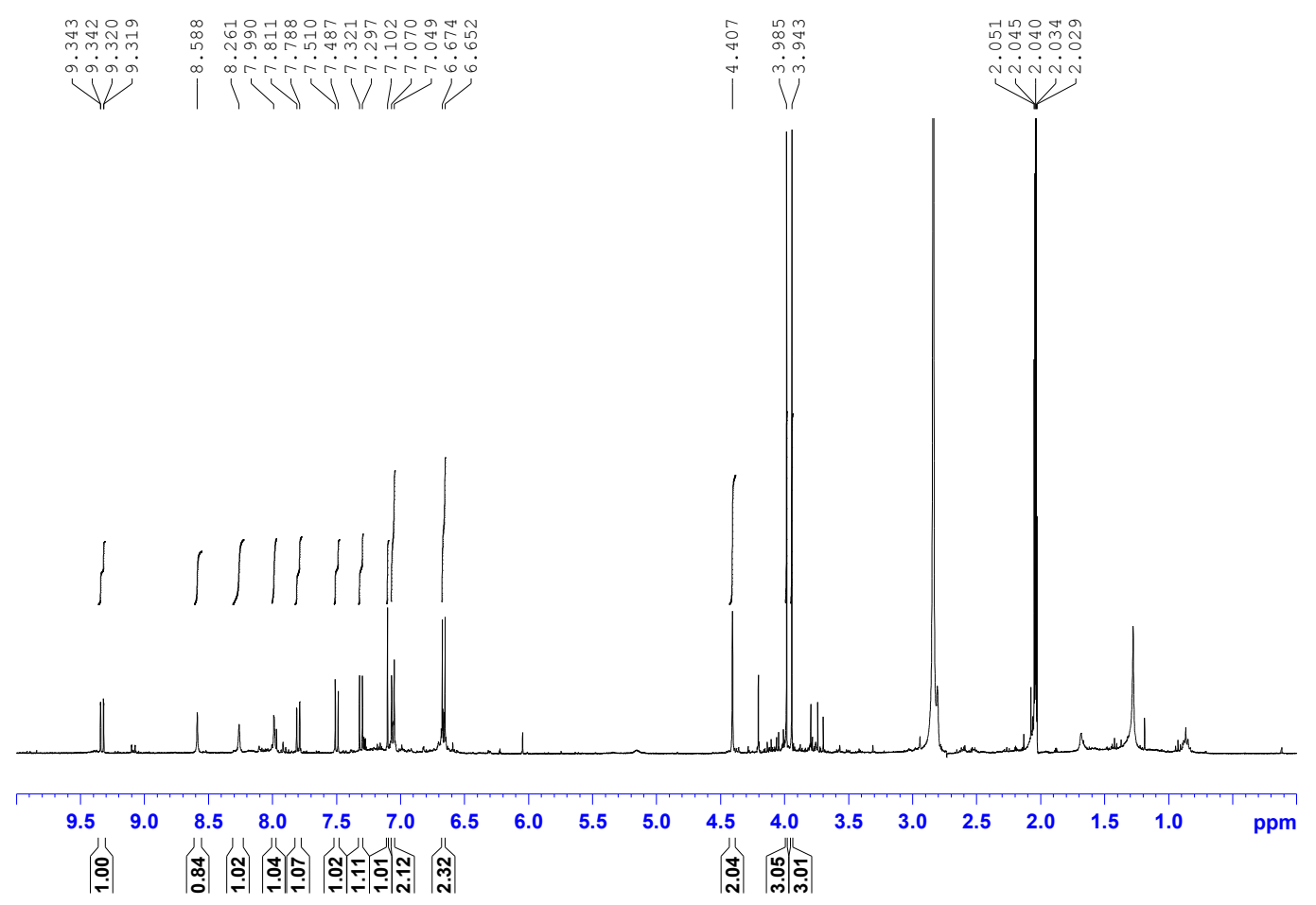


S $80{ }^{13} \mathrm{C}$ NMR (100 MHz, Acetone- $d_{6}$ ) spectrum of the new compound 9

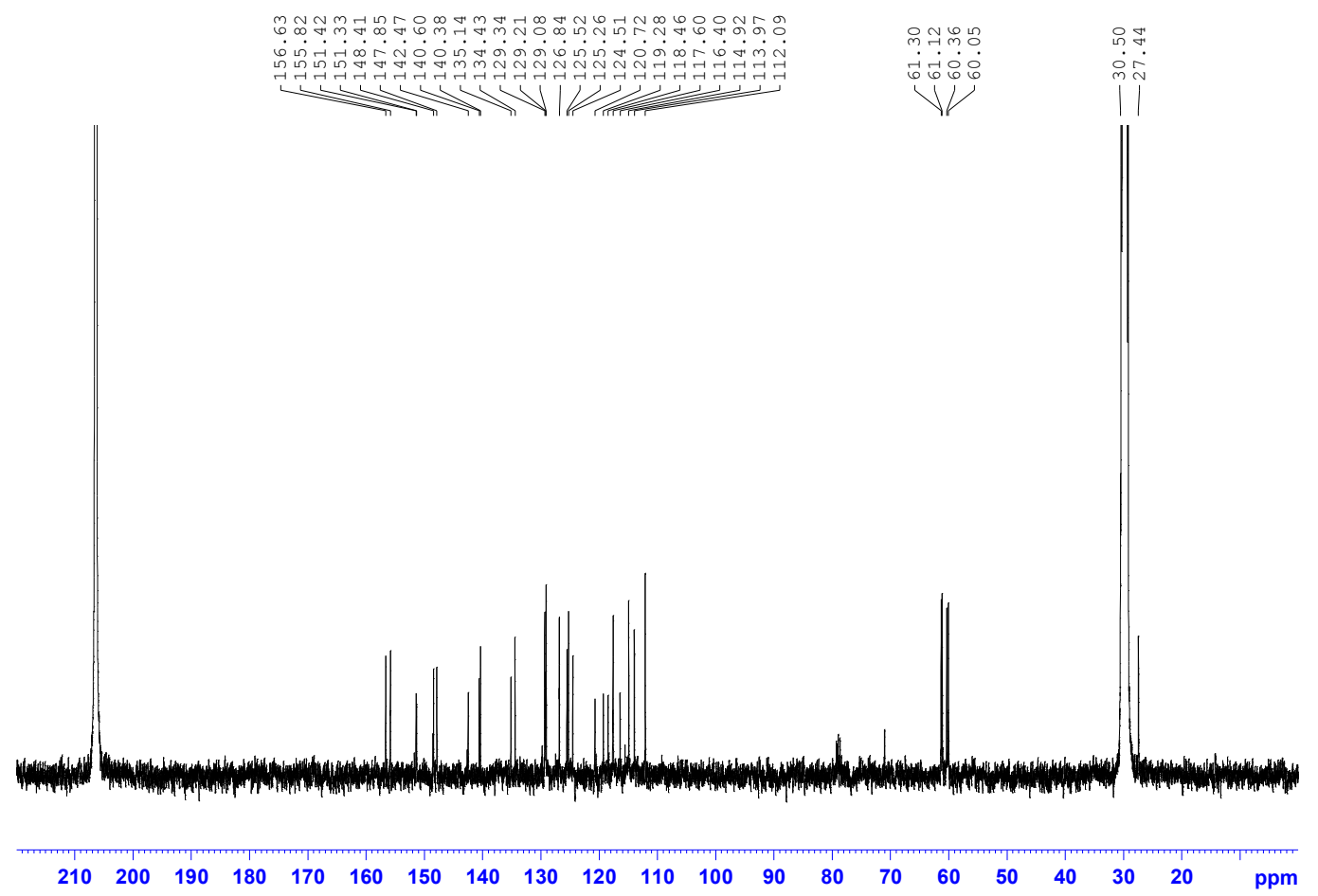


S 7 COSY spectrum of the new compound 9

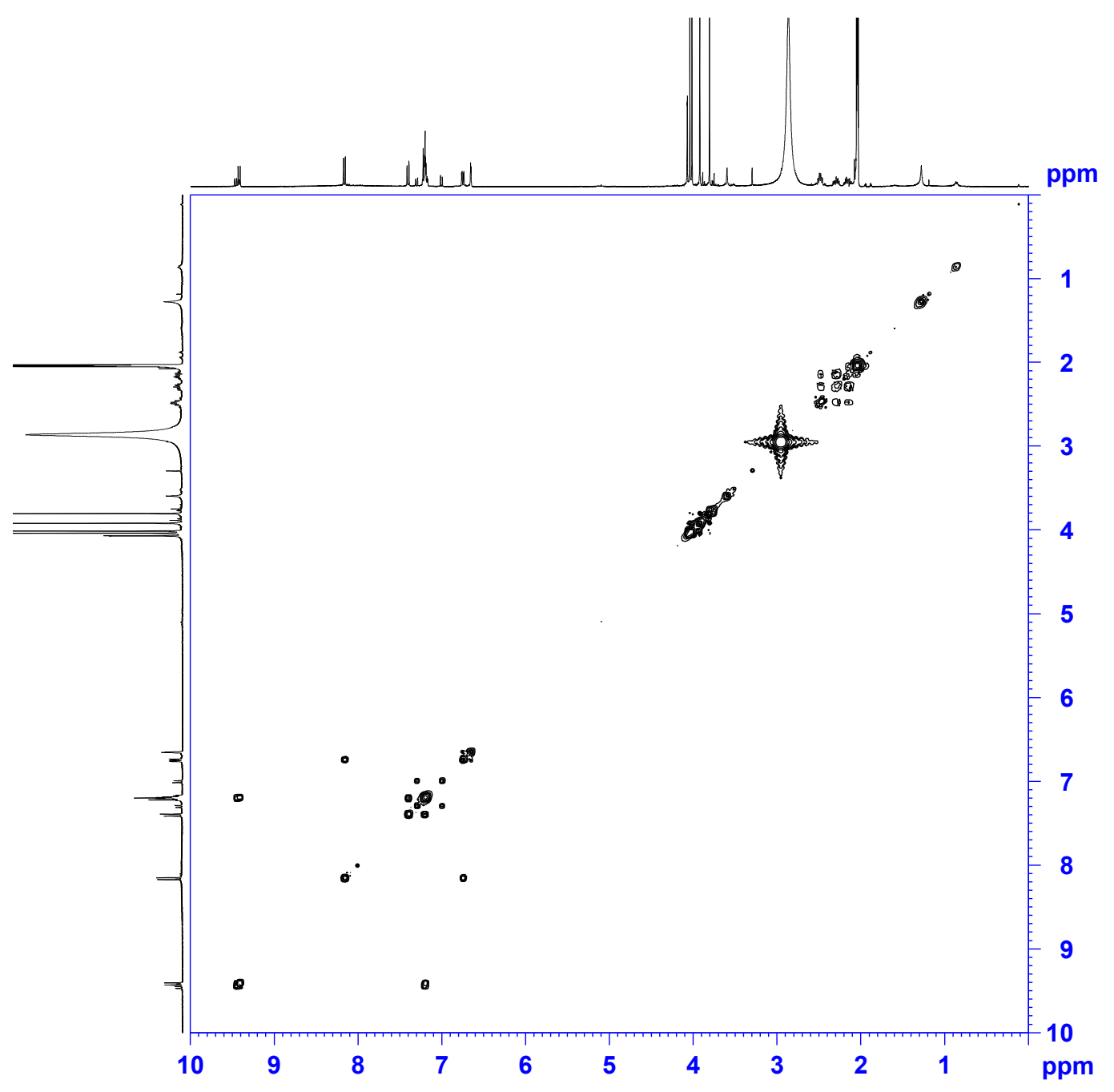


S 82 NOESY spectrum of the new compound 9

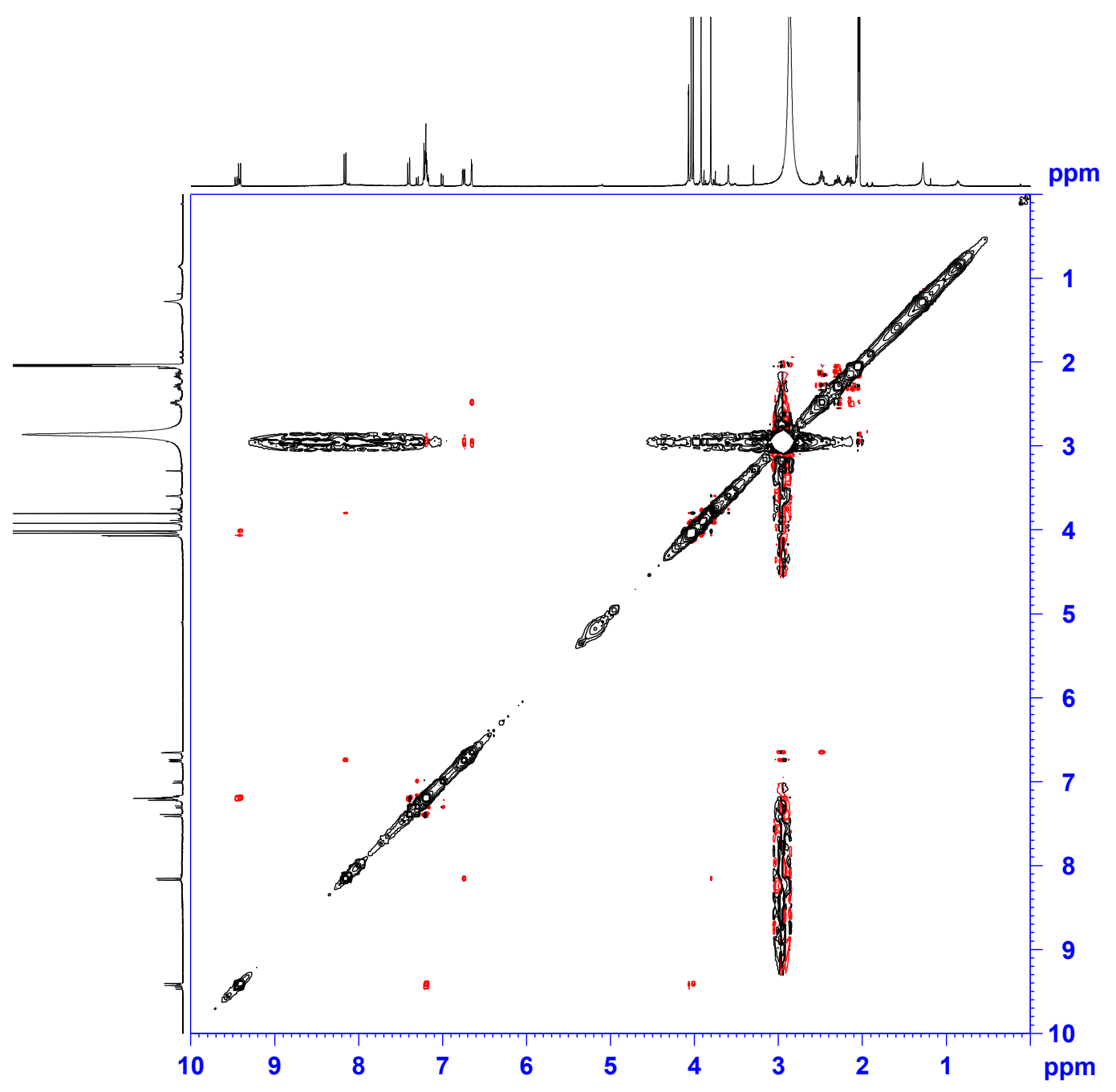


S 83 HSQC spectrum of the new compound 9

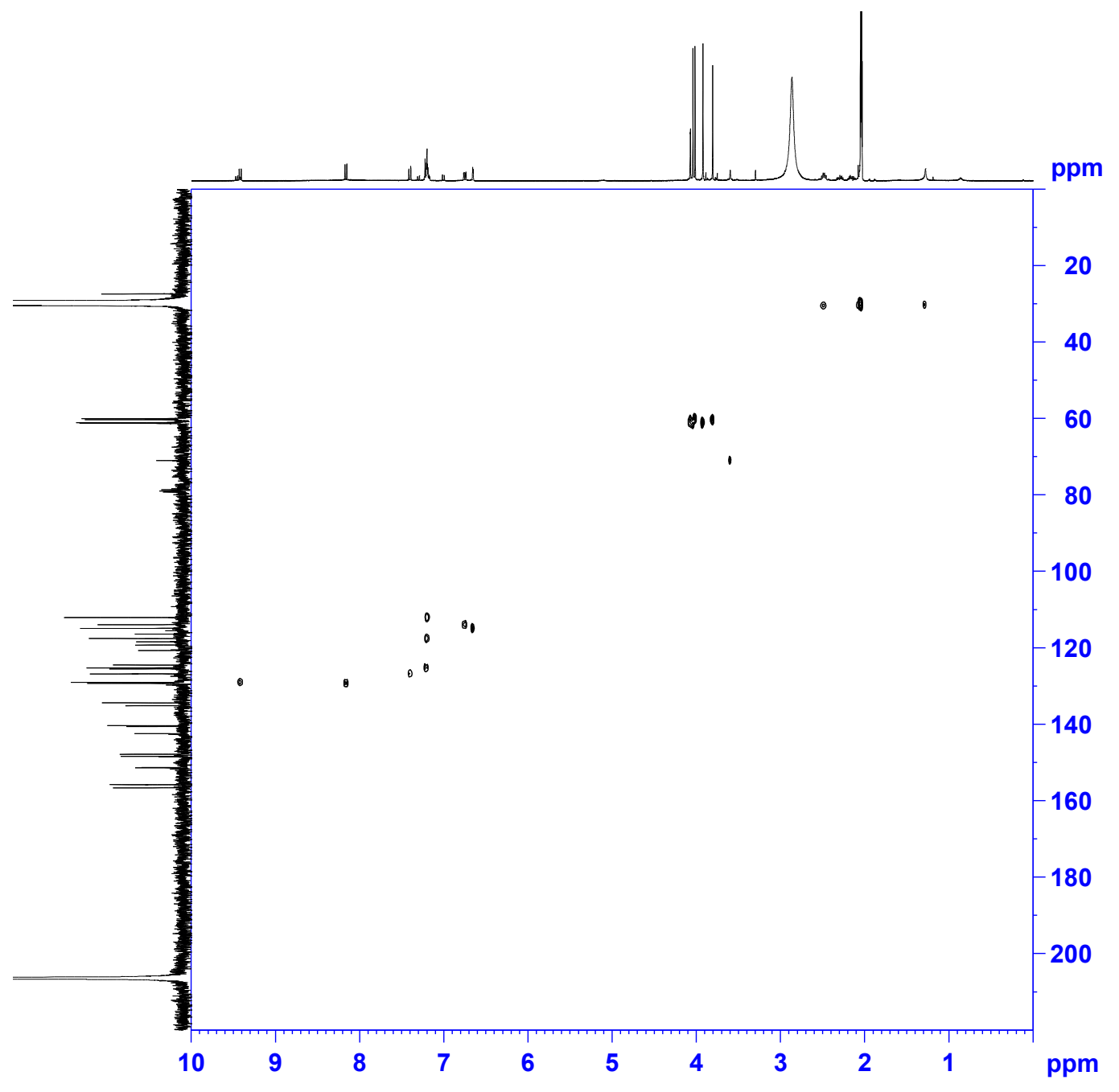


S 84 HMBC spectrum of the new compound 9

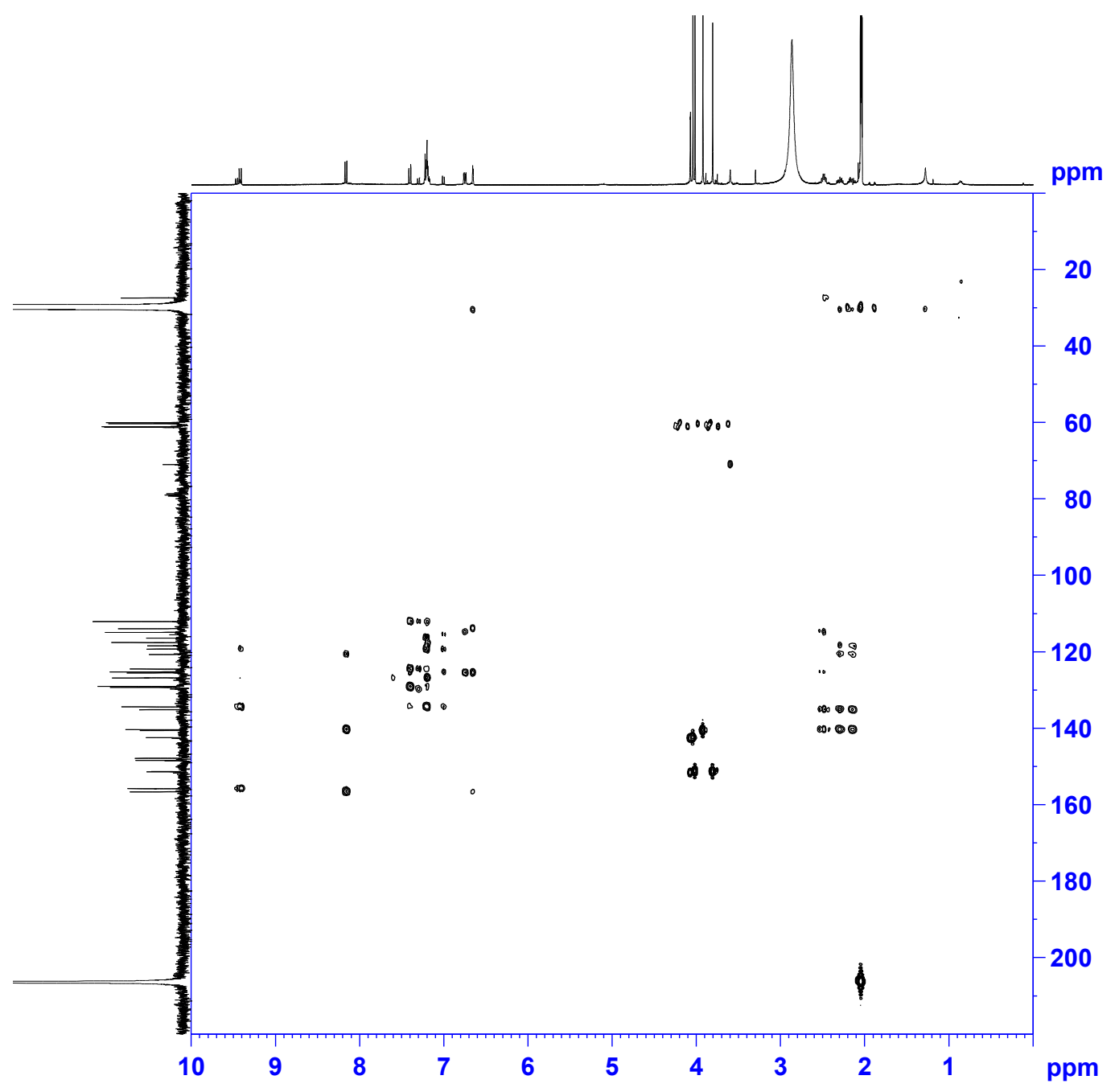


S 85 UV spectrum of the new compound 9

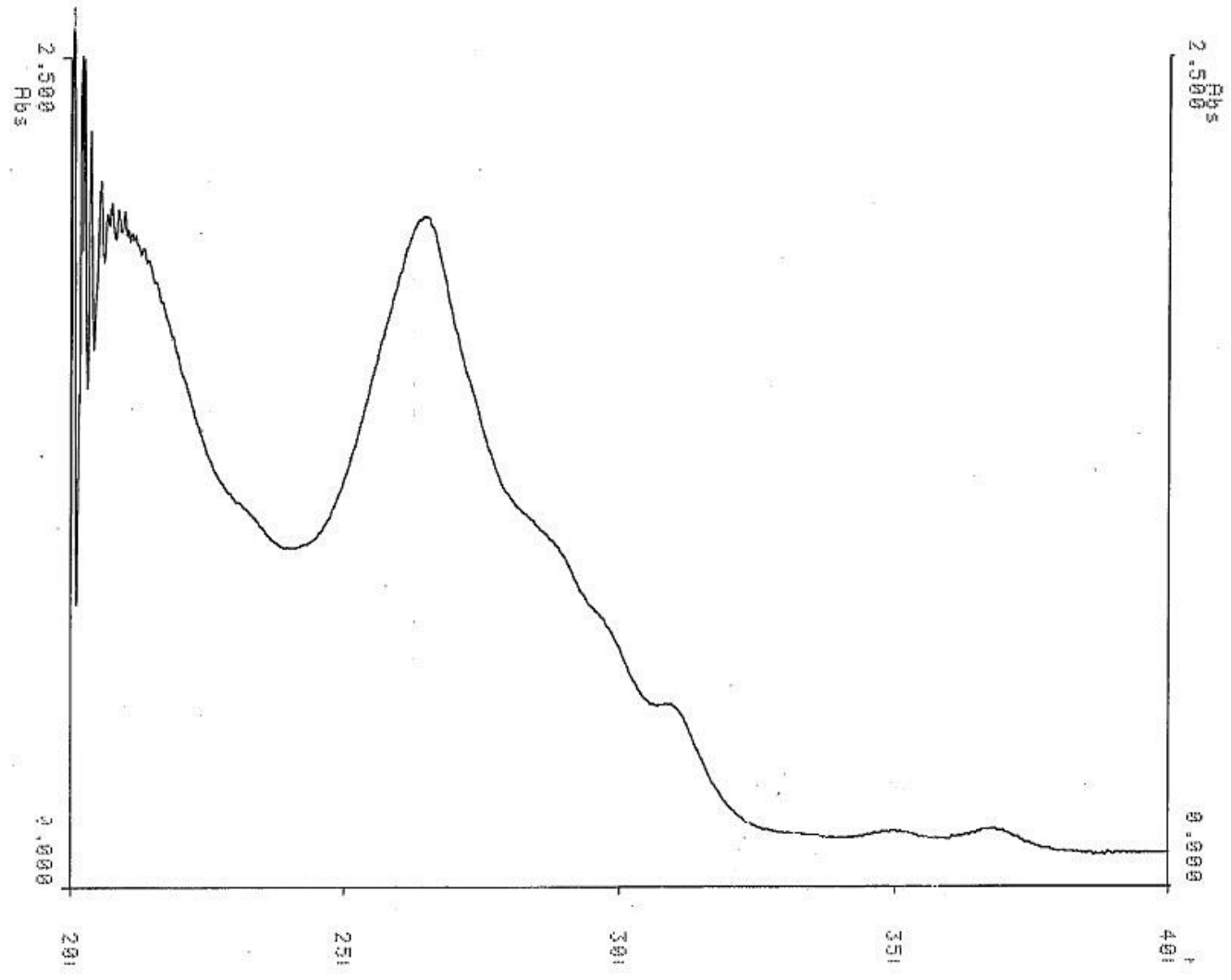




\section{S 86 IR spectrum of the new compound 9}

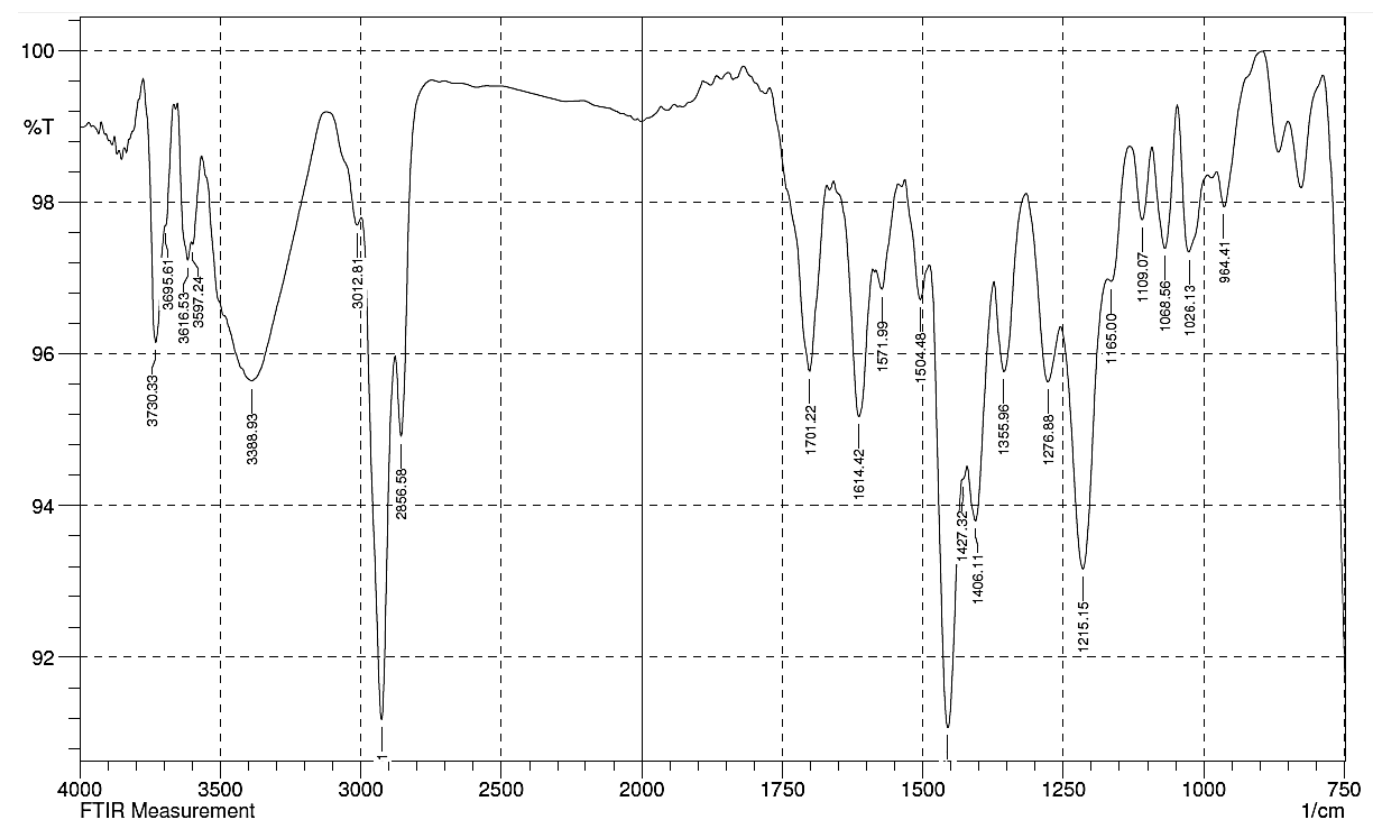


S 87 HRESIMS spectrum of the new compound 9

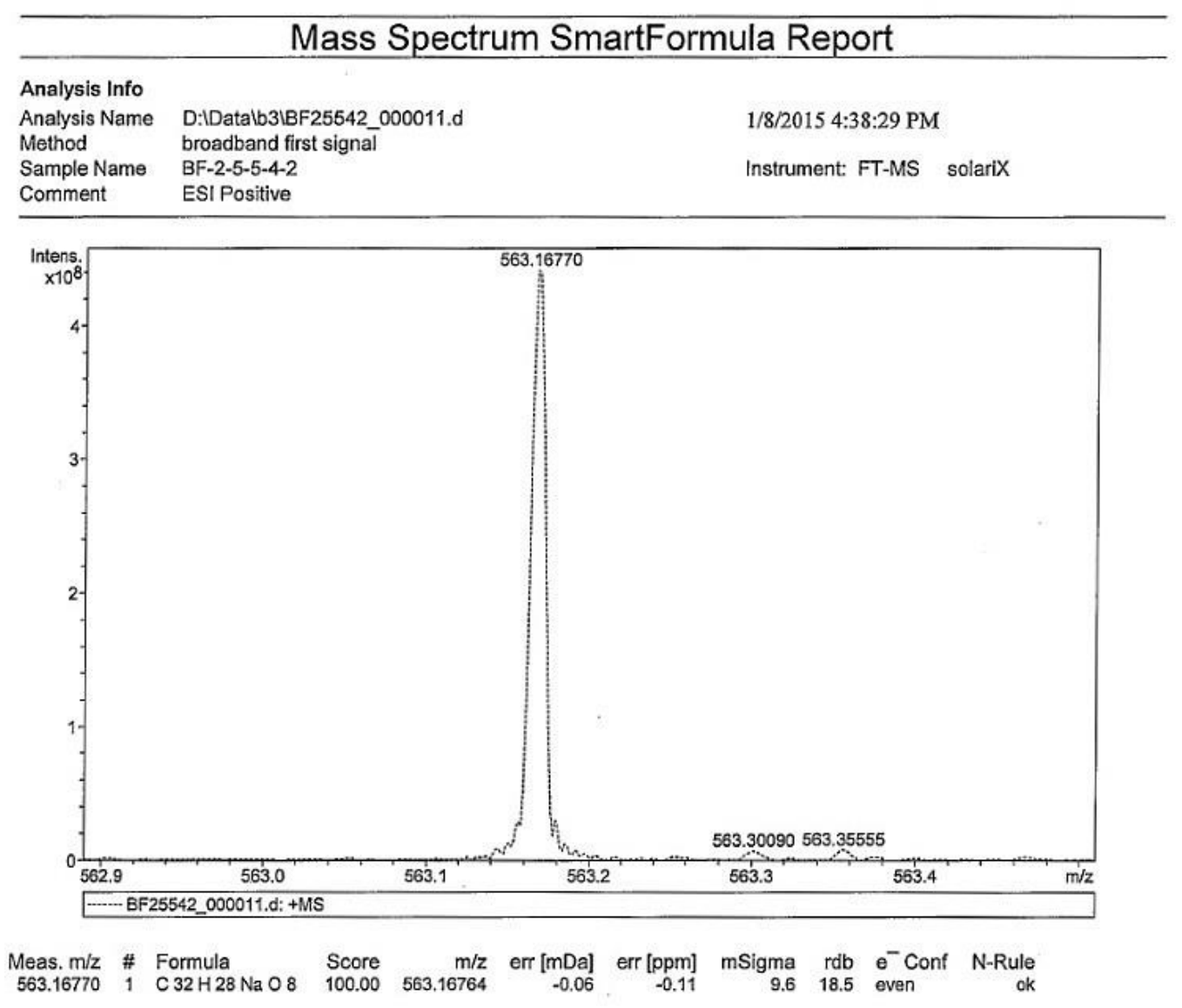


S 88 ECD spectrum of the new compound 9

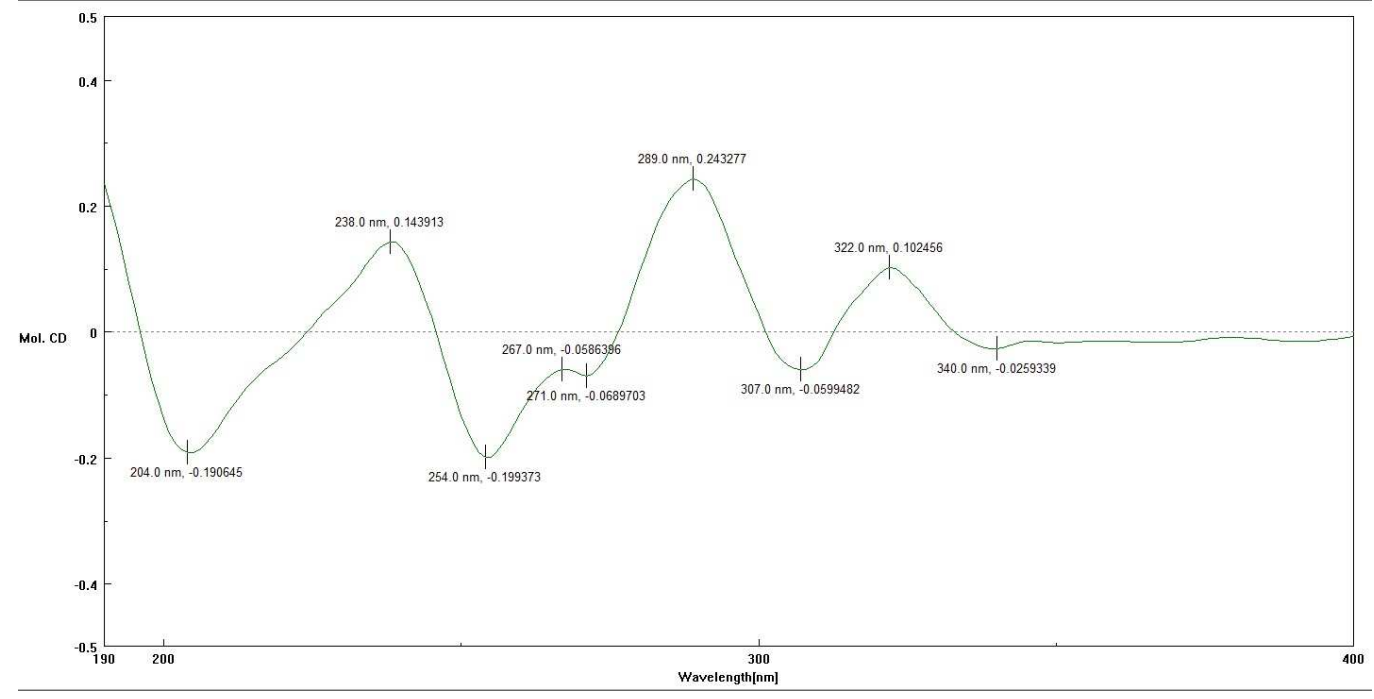


S $89{ }^{1} \mathrm{H}$ NMR (400 MHz, $\mathrm{CD}_{3} \mathrm{OD}$ ) spectrum of the new compound 10

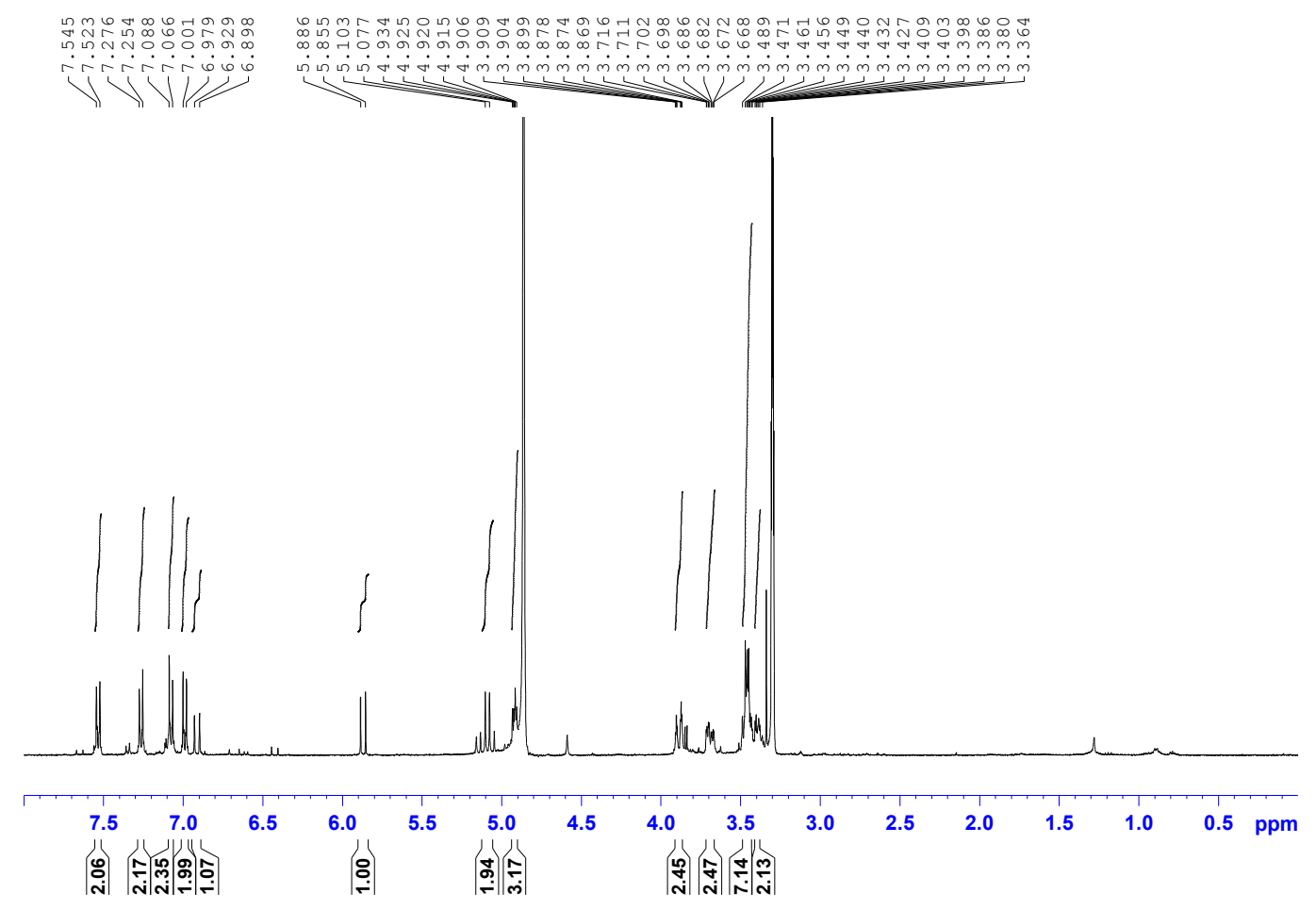


$\mathrm{S} 90{ }^{13} \mathrm{C} \mathrm{NMR}\left(400 \mathrm{MHz}, \mathrm{CD}_{3} \mathrm{OD}\right)$ spectrum of the new compound $\mathbf{1 0}$

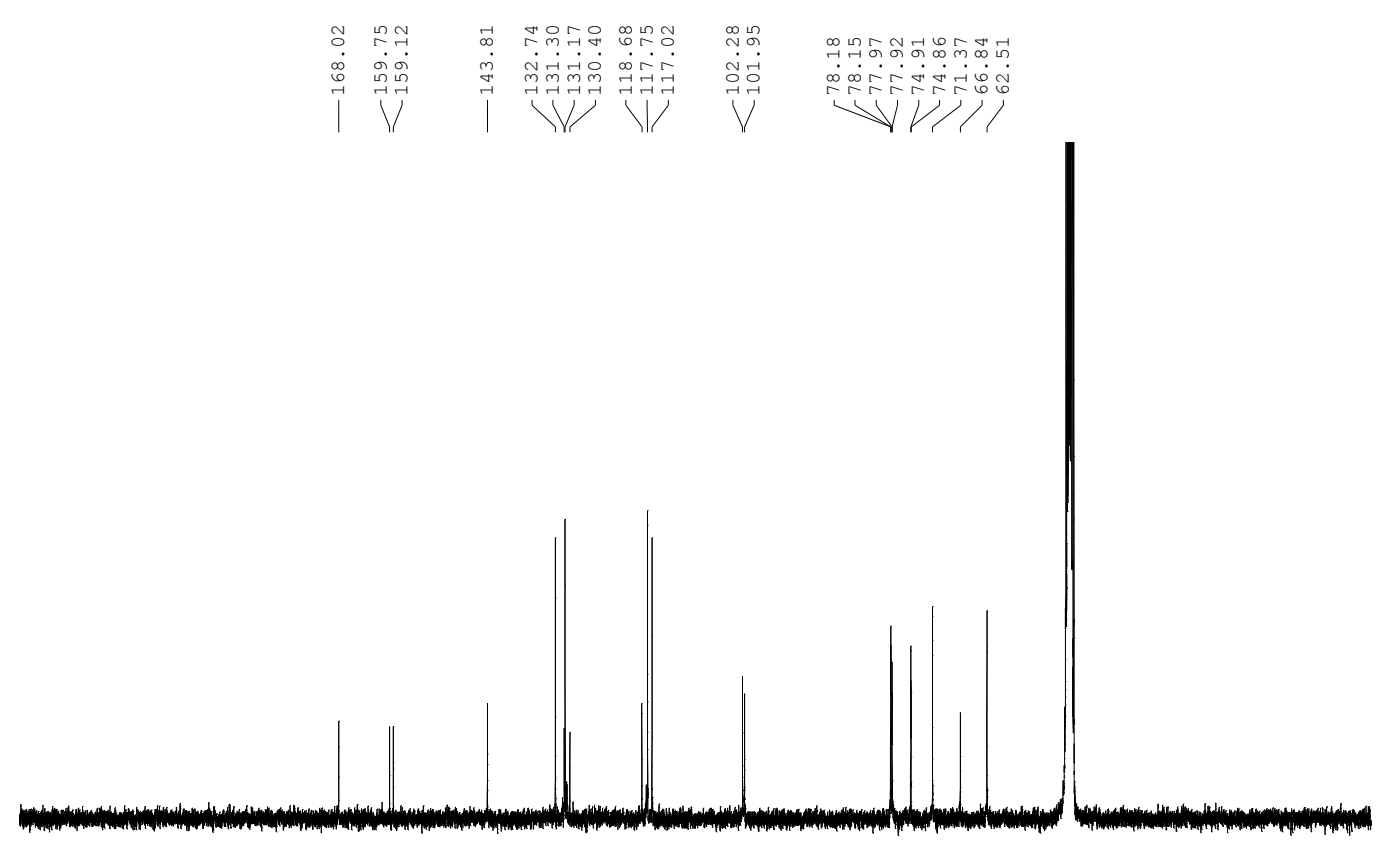

$\begin{array}{llllllllllllllllllllllll}210 & 200 & 190 & 180 & 170 & 160 & 150 & 140 & 130 & 120 & 110 & 100 & 90 & 80 & 70 & 60 & 50 & 40 & 30 & 20 & \mathrm{ppm}\end{array}$ 
S 91 COSY spectrum of the new compound $\mathbf{1 0}$

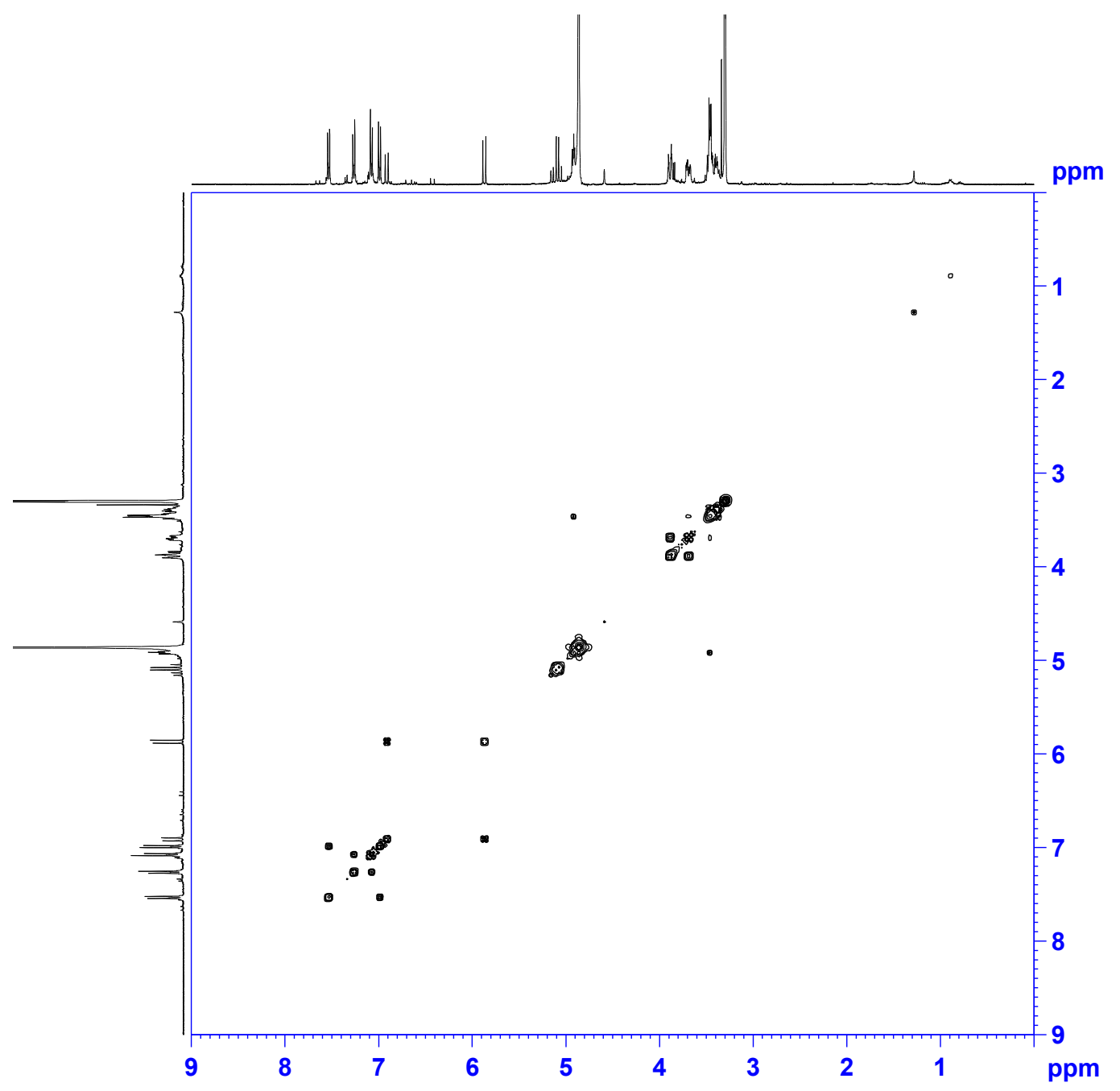


S 92 NOESY spectrum of the new compound $\mathbf{1 0}$

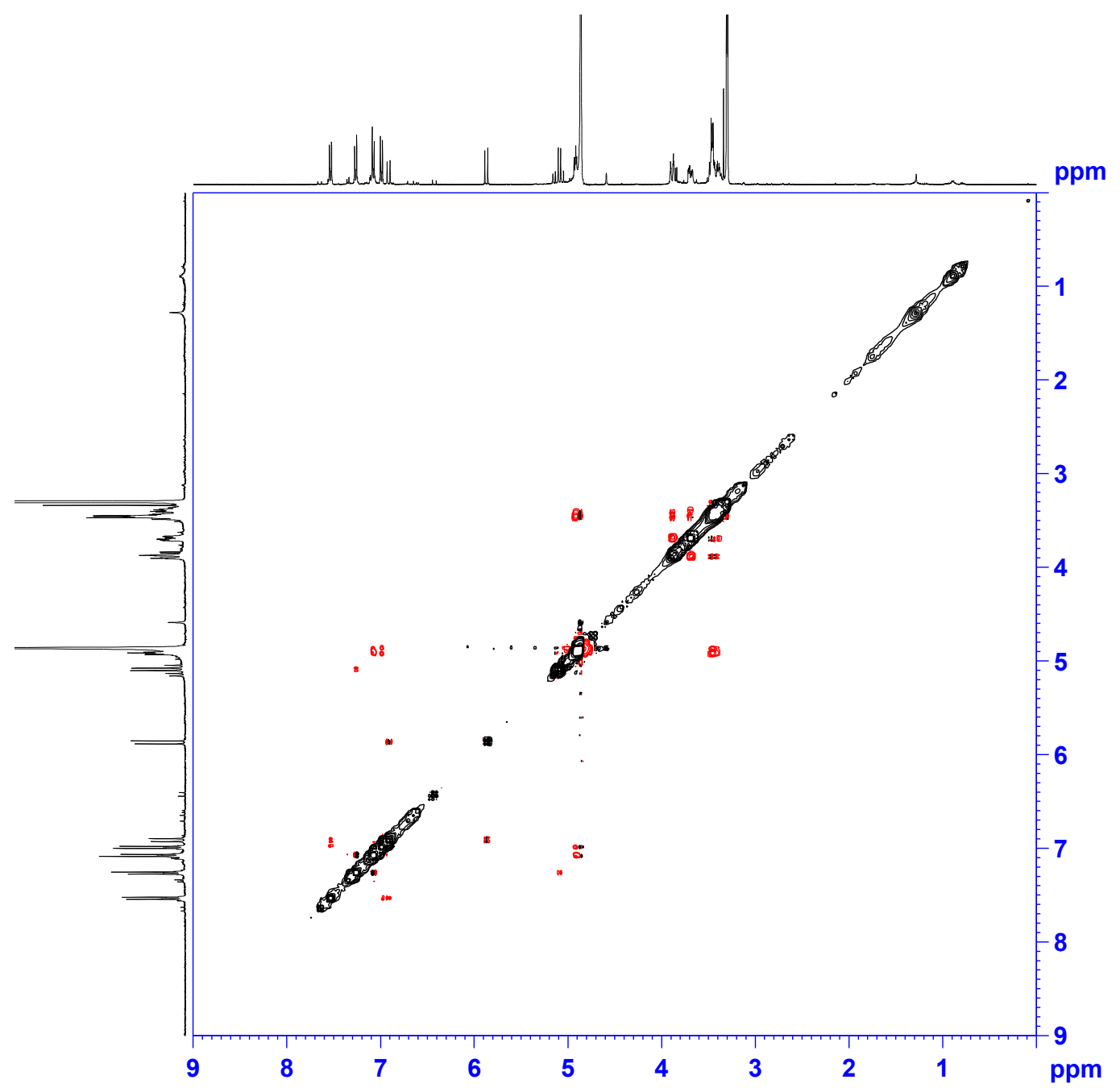


S 93 HSQC spectrum of the new compound $\mathbf{1 0}$

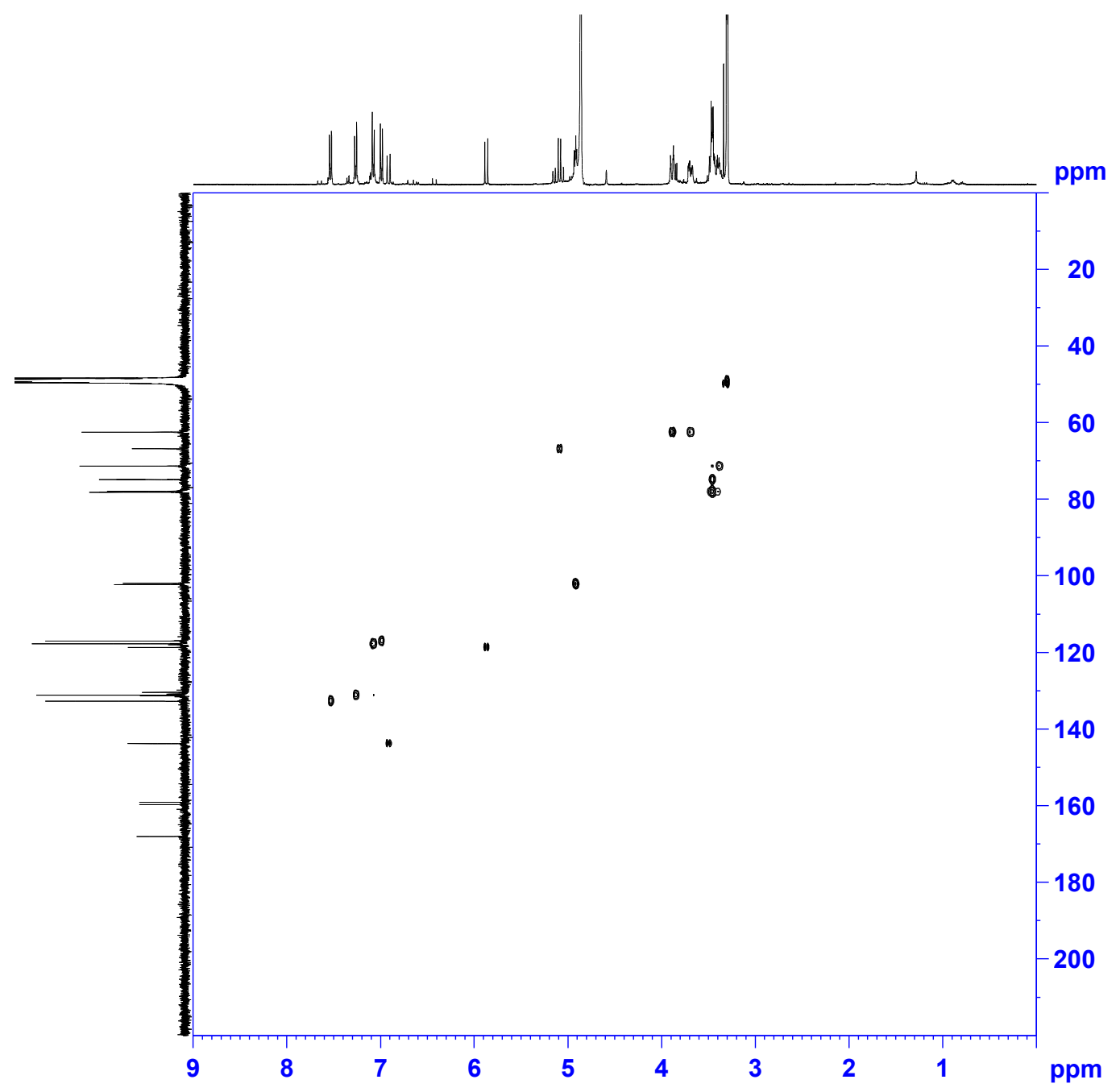


S 94 HMBC spectrum of the new compound $\mathbf{1 0}$

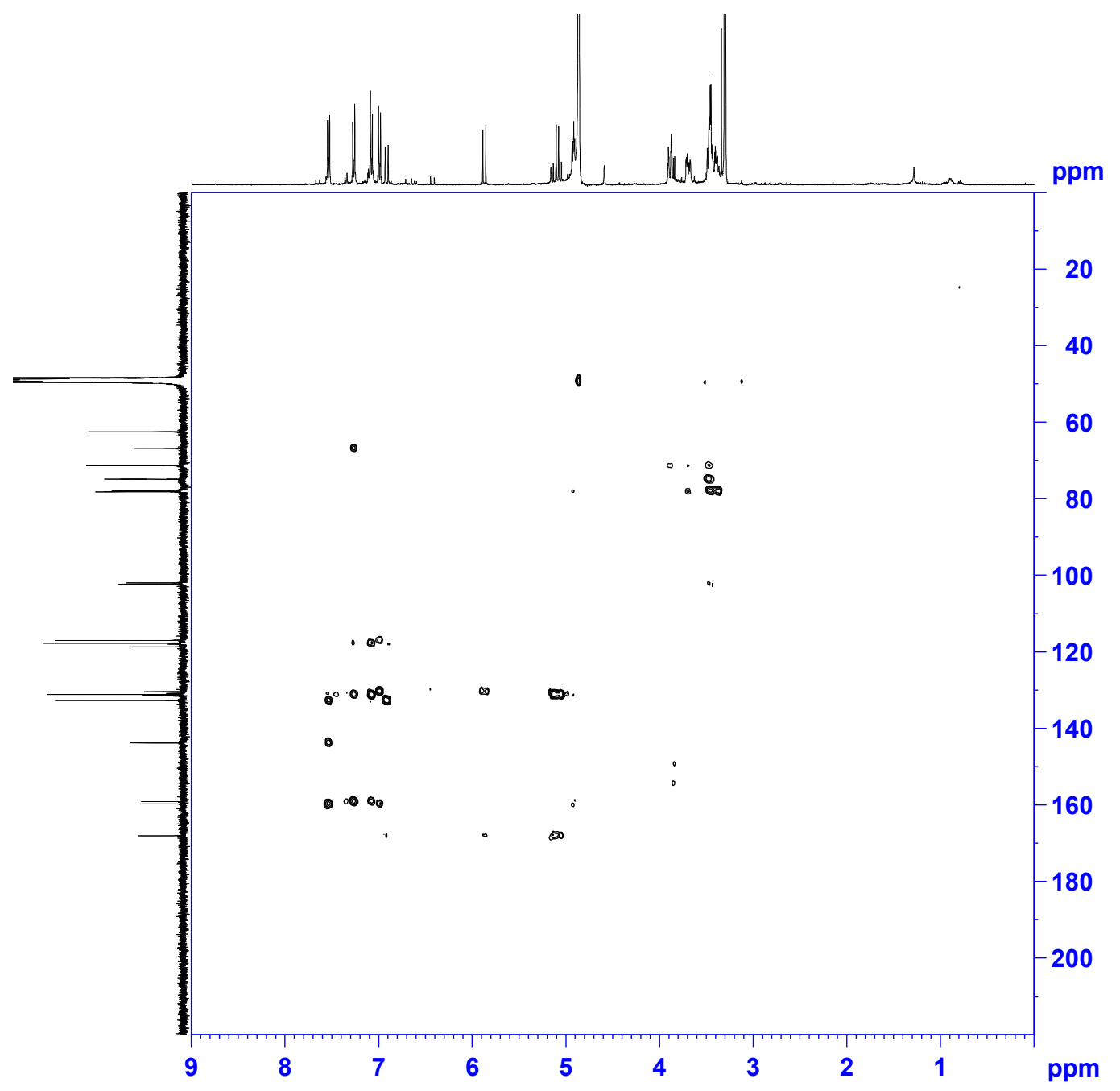


S 95 UV spectrum of the new compound $\mathbf{1 0}$

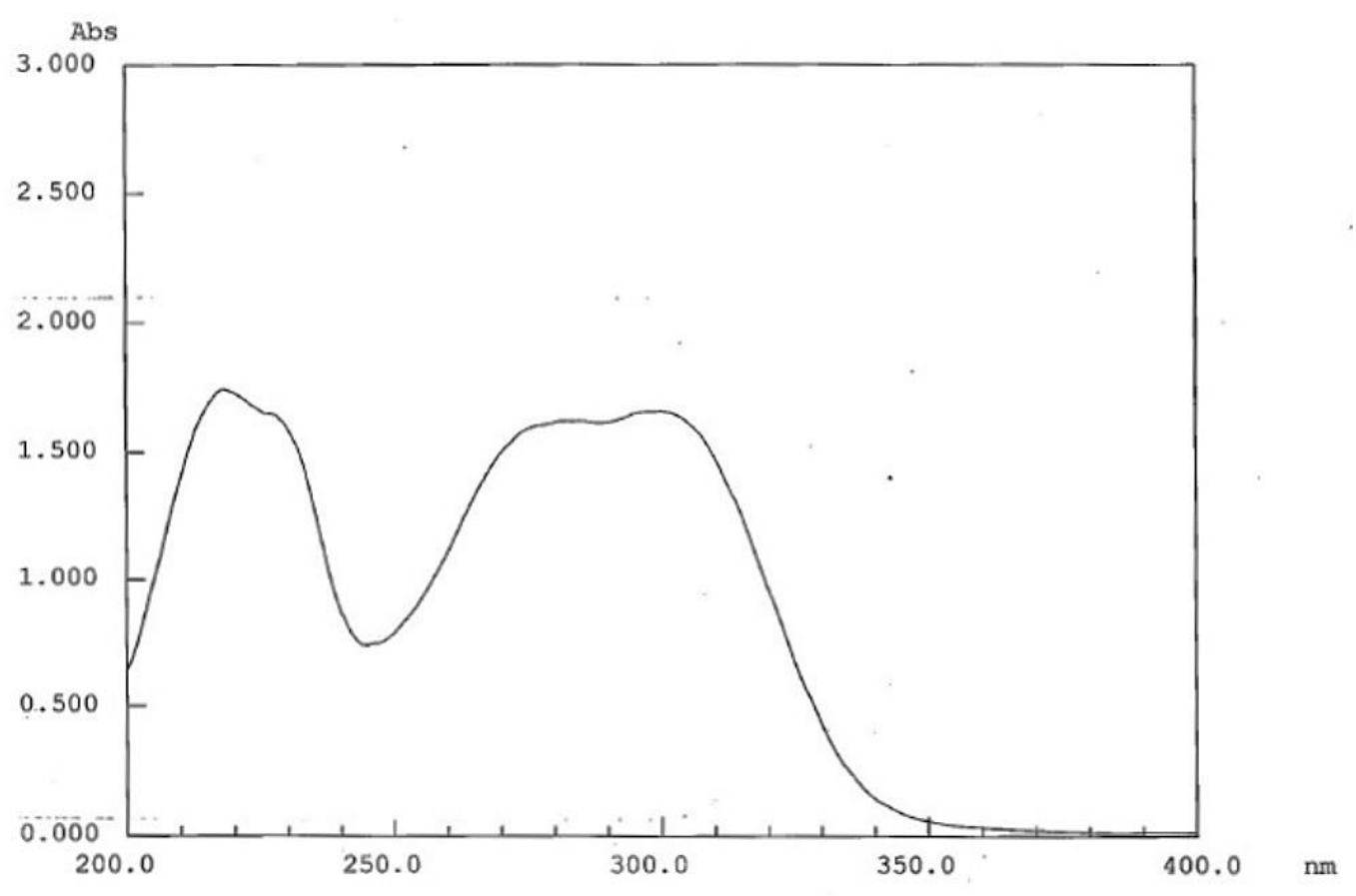


S 96 IR spectrum of the new compound $\mathbf{1 0}$

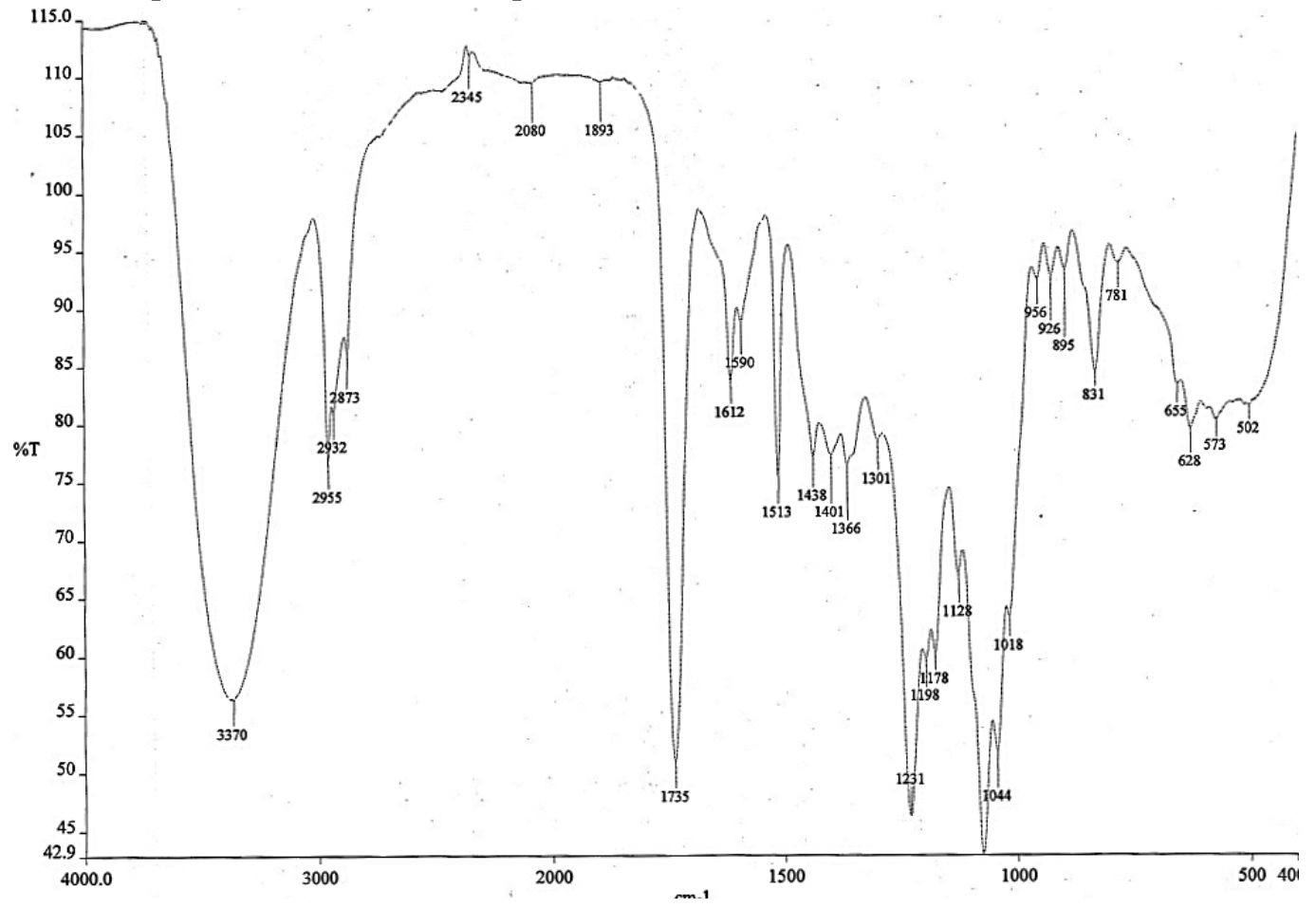


S 97 HRESIMS spectrum of the new compound $\mathbf{1 0}$

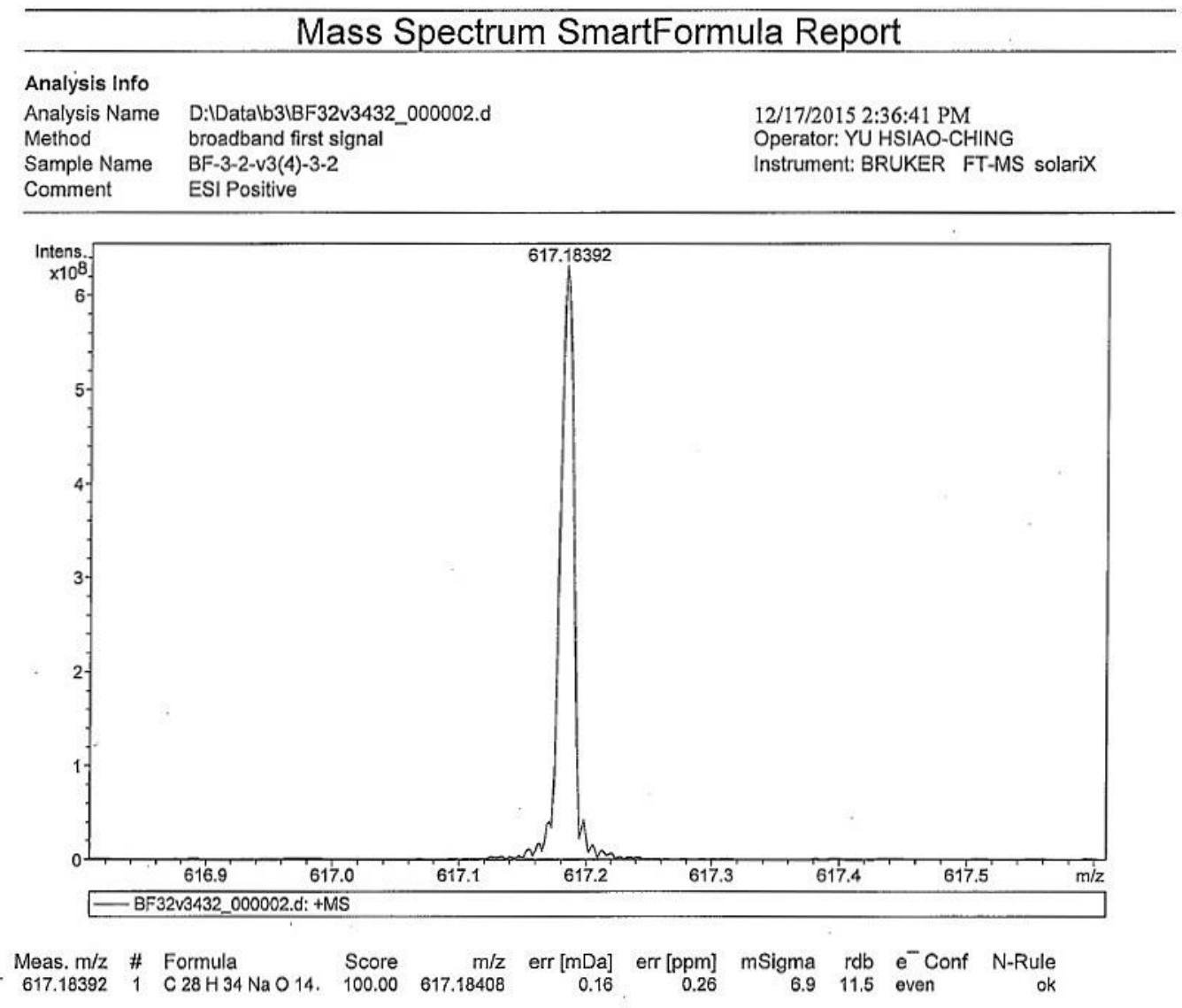


S 98 Optical rotation data of the new compound 3-9

\begin{tabular}{|l|l|}
\hline name & optical rotation \\
\hline Bleformin C (3) & {$[\alpha]_{\mathrm{D}}^{25}-0.896(c 0.03, \mathrm{MeOH})$} \\
\hline Bleformin D (4) & {$[\alpha]_{\mathrm{D}}^{25}-1.000(c 0.09, \mathrm{MeOH})$} \\
\hline Bleformin E (5) & {$[\alpha]_{\mathrm{D}}^{25}+0.389(c 0.04, \mathrm{MeOH})$} \\
\hline Bleformin F (6) & {$[\alpha]_{\mathrm{D}}^{25}-0.414(c 0.03, \mathrm{MeOH})$} \\
\hline Bleformin G (7) & {$[\alpha]_{\mathrm{D}}^{25}+0.778(c 0.05, \mathrm{MeOH})$} \\
\hline Bleformin $\mathrm{H}(\mathbf{8})$ & {$[\alpha]_{\mathrm{D}}^{25}+0.400(c 0.05, \mathrm{MeOH})$} \\
\hline Bleformin I (9) & {$[\alpha]_{\mathrm{D}}^{25}+0.000(c 0.05, \mathrm{MeOH})$} \\
\hline
\end{tabular}


S 99 HPLC of D-glucose $o$-toylthiocarbamate derivative

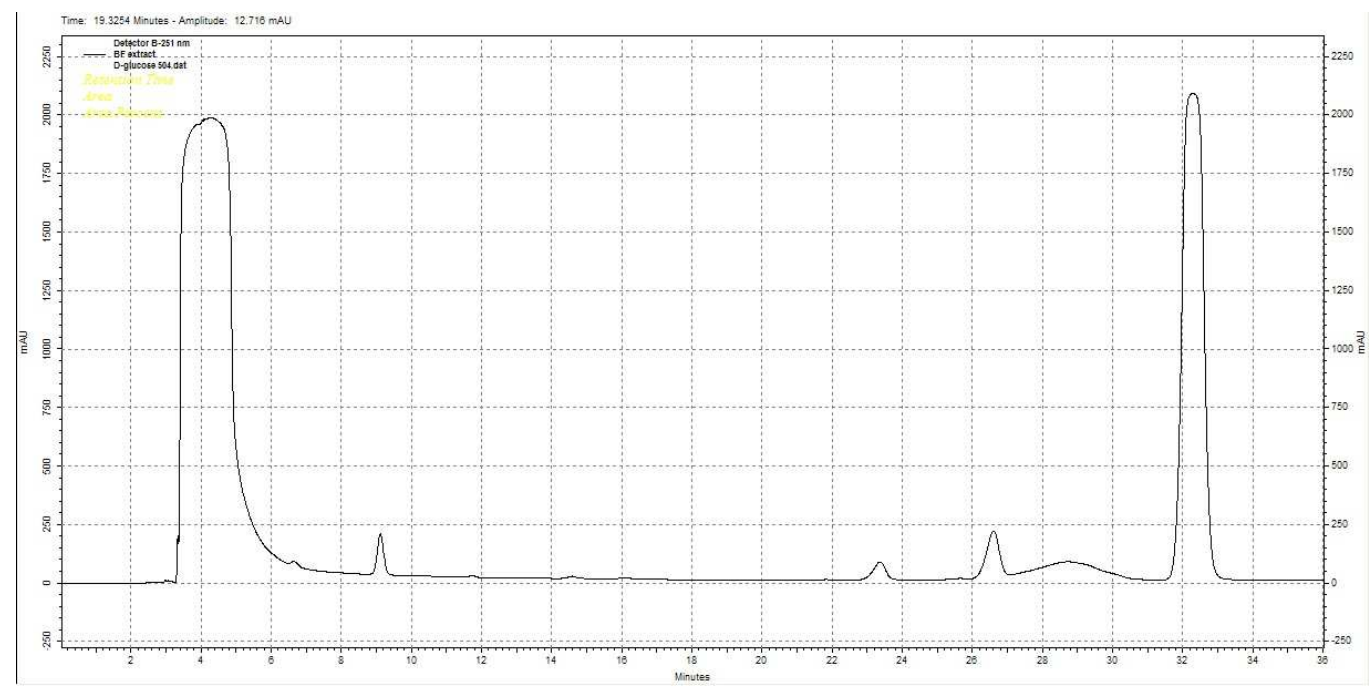

Gradient: Mobile phase A (0.05 M, pH 5.0 $\mathrm{CH}_{3} \mathrm{COOH} / \mathrm{CH}_{3} \mathrm{COONa}$ buffer). Mobile phase B (acetonitrile). A two-step gradient for 0 to $20 \mathrm{~min}$ (phase A from 85 to $80 \%$ ) and 20-50 min (phase A from 80 to $70 \%$ ).

Purospher STAR RP-8e column $(250 \times 4.6 \mathrm{~mm}$; i.d. $5 \mu \mathrm{m})$

Set Wavelength: $250 \mathrm{~nm}$

Flow rate: $0.8 \mathrm{~mL} / \mathrm{min}$

D-glucose $o$-toylthiocarbamate derivative $\left(t_{R}=32.2 \mathrm{~min}\right)$ 
S 100 HPLC of L-glucose $o$-toylthiocarbamate derivative

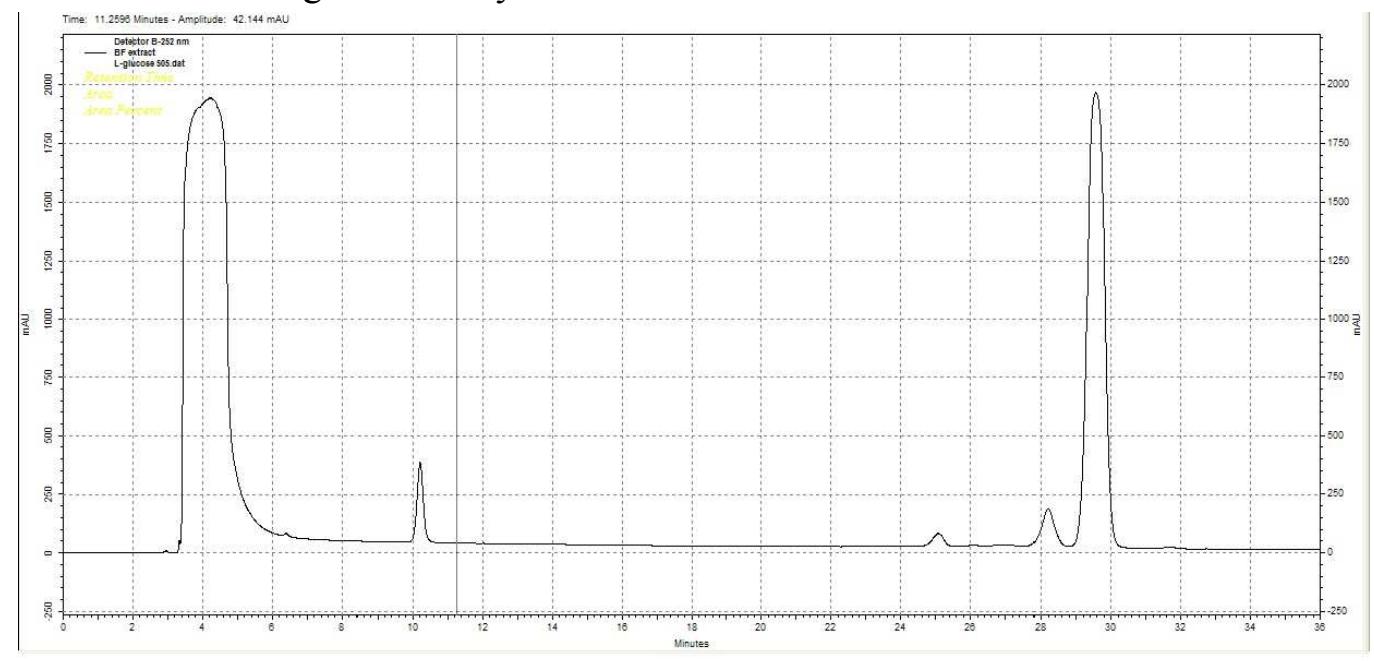

L-glucose $o$-toylthiocarbamate derivative $\left(\mathrm{t}_{\mathrm{R}}=29.6 \mathrm{~min}\right)$ 
S 101 HPLC of glycoside (10) $o$-toylthiocarbamate derivative

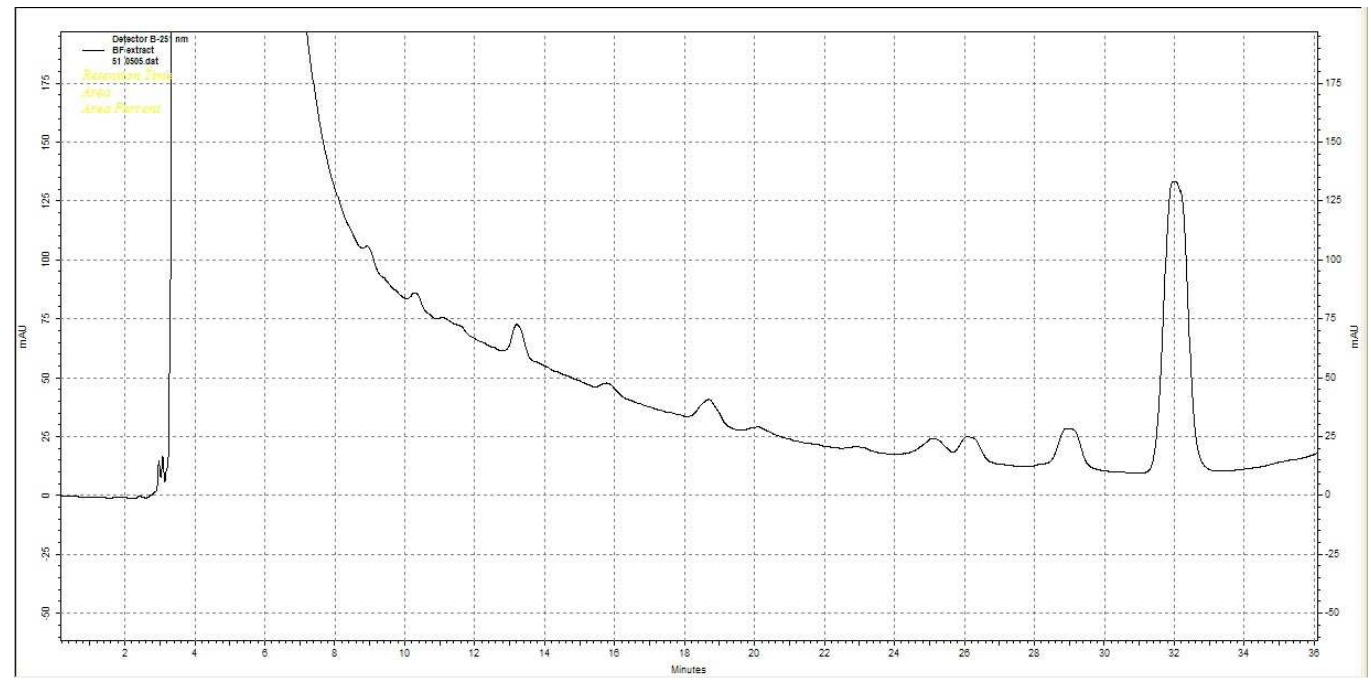

glycoside (10) $o$-toylthiocarbamate derivative $\left(t_{\mathrm{R}}=29.6 \mathrm{~min}\right)$ 